Check for updates

Cite this: Sustainable Energy Fuels, $2018,2,724$

Received 5th December 2017 Accepted 31st January 2018

DOI: $10.1039 / \mathrm{c} 7 \mathrm{se} 00582 \mathrm{~b}$

rsc.li/sustainable-energy

\section{From protein engineering to artificial enzymes - biological and biomimetic approaches towards sustainable hydrogen production}

\begin{abstract}
C. Esmieu, P. Raleiras (iD and G. Berggren (D)*
Hydrogen gas is used extensively in industry today and is often put forward as a suitable energy carrier due its high energy density. Currently, the main source of molecular hydrogen is fossil fuels via steam reforming. Consequently, novel production methods are required to improve the sustainability of hydrogen gas for industrial processes, as well as paving the way for its implementation as a future solar fuel. Nature has already developed an elaborate hydrogen economy, where the production and consumption of hydrogen gas is catalysed by hydrogenase enzymes. In this review we summarize efforts on engineering and optimizing these enzymes for biological hydrogen gas production, with an emphasis on their inorganic cofactors. Moreover, we will describe how our understanding of these enzymes has been applied for the preparation of bio-inspired/-mimetic systems for efficient and sustainable hydrogen production.
\end{abstract}

\section{Introduction}

Hydrogen gas is an important base chemical employed in e.g. the Haber-Bosch process and oil refining, and $>30$ million tonnes of $\mathrm{H}_{2}$ is produced every year, primarily via steam reforming. ${ }^{1-3}$ Moreover, the high energy content of the $\mathrm{H}-\mathrm{H}$ bond makes $\mathrm{H}_{2}$ highly promising as a future energy carrier. Indeed, the energy density of $\mathrm{H}_{2}$ is orders of magnitude higher than those of batteries. ${ }^{4}$ As such there would be large environmental benefits in developing more sustainable methods for $\mathrm{H}_{2}$ production, both in order to cover industrial needs as well as furthering the implementation of renewable energy in e.g. our transportation sector. The idea of light-driven proton reduction providing $\mathrm{H}_{2}$ as a solar fuel, utilizing either photosynthetic organisms or molecular catalysts in combination with a suitable photosensitizer, is particularly appealing in this context.

In light of a future hydrogen society it should be stressed that evolution has already developed a hydrogen economy, where the interconversion between protons and molecular hydrogen is catalysed with remarkable efficiencies by ancient gas processing enzymes called hydrogenases. ${ }^{5}$ The exceptional catalytic capacity of the hydrogenases makes them highly relevant for biological hydrogen production and in device applications as an alternative to Pt-based catalysts in e.g. (photo-)electrolysers and fuel cells, as well as serving as inspiration for the development of synthetic catalysts. $^{6-11}$ The interest in hydrogenases and related molecular models is underscored by the number of recent excellent reviews on these different topics (see e.g. ref. 11-20).

Department of Chemistry, Angström Laboratory, Uppsala University, Box 523, SE-75120 Uppsala, Sweden. E-mail: Gustav.berggren@kemi.uu.se
Herein we will cover both biochemical and biomimetic approaches of relevance to $\mathrm{H}^{+} / \mathrm{H}_{2}$ interconversion. Considering the activity of the field and the number of relatively recent reviews on hydrogenase related chemistry, we will not strive to cover the entire field. Instead, we will provide a short overview of the hydrogenases and then primarily focus our attention on efforts made at the molecular level aimed at engineering and optimizing these enzymes, with an emphasis on their inorganic cofactors. Moreover, we will showcase how our understanding of hydrogenases can be applied in the design of novel biomimetic/-inspired catalysts and the preparation of semi-synthetic hydrogenases.

\section{Hydrogenases}

The first report of organisms displaying hydrogenase activity was published in the 1930s. ${ }^{21}$ Since then these enzymes have been found in all domains of life and, despite the apparent simplicity of this reaction, Nature has designed different highly elaborate metal cofactors to perform this chemistry. Thus, hydrogenases are divided into different classes depending on the metal content of the catalytic cofactor, i.e. [NiFe], [FeFe] and [Fe] hydrogenases (Fig. 1). ${ }^{22,23}$ These main classes can in turn be further divided into different subclasses. It should be noted that, despite striking similarities in the cofactor structure and function, these three different classes of hydrogenases are not phylogenetically related. In the following section, we will briefly summarize the current knowledge of these highly efficient catalysts and their biologically unique, organometallic cofactors. 


\section{1 [NiFe] hydrogenases}

[NiFe] hydrogenases form multimeric protein structures, consisting of at least two subunits denoted the large subunit (harbouring the active site) and the small subunit (harbouring a number of iron-sulfur ([FeS]) clusters). These enzymes arguably represent the most studied class of hydrogenases and are often subdivided into different groups based on their molecular phylogeny, but other classification systems are also employed. ${ }^{17,22,23}$ The reactivity and function of these groups differ quite substantially. Still, they share a dependency on a heterodimeric [NiFe] cofactor, in which the Ni ion is generally coordinated by four cysteine derived thiol ligands. The octahedral Fe ion is bound to the $\mathrm{Ni}$ ion by two bridging thiol ligands and further decorated by a $\mathrm{CO}$ and two $\mathrm{CN}^{-}$ligands (Fig. 1). The one exception to this reported so far are the so-called [NiFeSe] hydrogenases that form a subgroup within group 1 [NiFe]
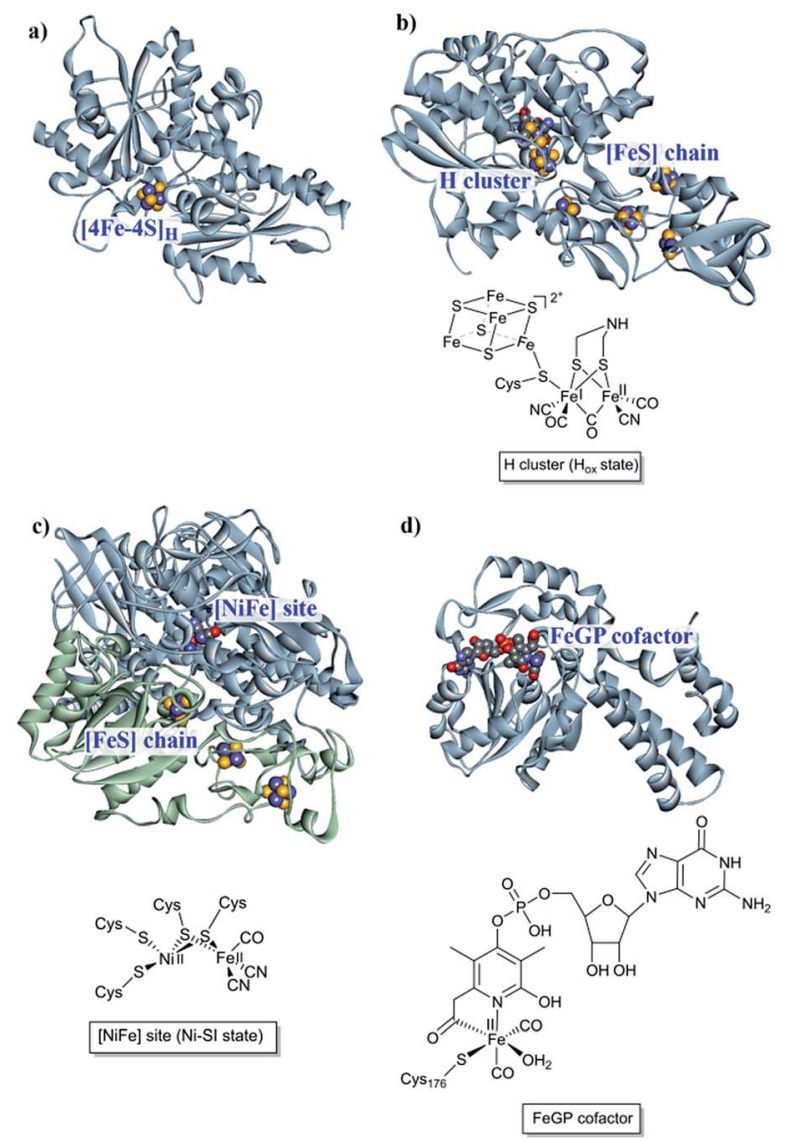

Fig. 1 [NiFe], [FeFe] and [Fe] hydrogenases. (a) The "apo" form of Chlamydomonas reinhardtii HydA1 ([FeFe] hydrogenase; PDB: 3LX4); 24 (b) Clostridium pasteurianum CpI ([FeFe hydrogenase]; PDB: 4XDC); ${ }^{25}$ (c) Allochromatium vinosum [NiFe] hydrogenase (PDB: 3MYR): ${ }^{26}$ (d) Methanocaldococcus jannaschii [Fe] hydrogenase (PDB: 3DAG). ${ }^{27}$ Protein backbones are shown as solid ribbons and coloured by chain, and metal cofactors are shown as space-filling models and coloured by element (structures drawn using BIOVIA Discovery Studio Visualizer). A schematic representation of the active site of the different subclasses is shown below the respective enzyme structure. Heteroatom colour coding: S: yellow; Fe: indigo; Ni: dark blue; O: red; N: blue; P: orange. hydrogenases, in which one of the bridging cysteines is replaced by a selenocysteine residue. ${ }^{13,28,29}$

Most mechanistic studies have been performed on group 1, represented by e.g. Escherichia coli hydrogenase 1 (Hyd-1). The other groups appear to use similar mechanisms, but the specific details may differ between different [NiFe] hydrogenases. ${ }^{30} \mathrm{X}$-ray crystallography and spectroscopy (primarily FTIR and EPR) in combination with electrochemical methods and DFT calculations have elucidated a number of states of relevance to the catalytic cycle (Fig. 2). ${ }^{\mathbf{1 2 , 3 0 - 3 2}}$ In short, purified [NiFe] hydrogenases generally exhibit a mix of oxidised states denoted as the $\mathrm{Ni}_{\mathrm{A}}$ (or un-ready) and $\mathrm{Ni}_{\mathrm{B}}$ (ready) states. Both states feature $\mathrm{a}\left[\mathrm{Ni}^{\mathrm{III}} \mathrm{Fe}^{\mathrm{II}}\right]$ dimer but differ in the nature of the bridging ligand, and both of these states can enter the catalytic cycle upon reduction..$^{33}$ During catalysis, $\mathrm{H}_{2}$ is heterolytically cleaved upon binding to the $\left[\mathrm{Ni}^{\mathrm{II}} \mathrm{Fe}^{\mathrm{II}}\right]$ cofactor, resulting in the release of a proton to a nearby proton acceptor and the formation of the diamagnetic $\mathrm{Ni}_{\mathrm{R}}$-state featuring a bridging hydride. ${ }^{32,34}$ Oneelectron oxidation of $\mathrm{Ni}_{\mathrm{R}}$ results in the paramagnetic $\mathrm{Ni}_{\mathrm{C}}$-state $\left[\mathrm{Ni}^{\mathrm{III}} \mathrm{Fe}^{\mathrm{II}}\right]$ retaining the $\mu$-hydride ligand. ${ }^{35,36}$ A further one-electron oxidation results in the release of the hydride ligand as a proton and formation of the $\mathrm{Ni}_{\mathrm{SI}}$-state, a $\left[\mathrm{Ni}^{\mathrm{II}} \mathrm{Fe}^{\mathrm{II}}\right]$ species lacking a bridging ligand. Thus, the Fe ion is believed to remain as $\mathrm{Fe}^{\mathrm{II}}$ throughout the reaction while the $\mathrm{Ni}$ ion cycles between $\mathrm{Ni}^{\mathrm{II}}$ and $\mathrm{Ni}^{\mathrm{III}}$. Additionally, a $\left[\mathrm{Ni}^{\mathrm{I}} \mathrm{Fe}^{\mathrm{II}}\right]$ state denoted as $\mathrm{Ni}_{\mathrm{L}}$ has previously been shown to form upon irradiation of the $\mathrm{Ni}_{\mathrm{C}^{-}}$ state, ${ }^{37,38}$ and recent spectroscopic studies support the direct involvement of this latter state in the catalytic cycle as an intermediate during the transition between the $\mathrm{Ni}_{\mathrm{C}}$ and the $\mathrm{Ni}_{\mathrm{SI}}$ states. $^{39,40}$

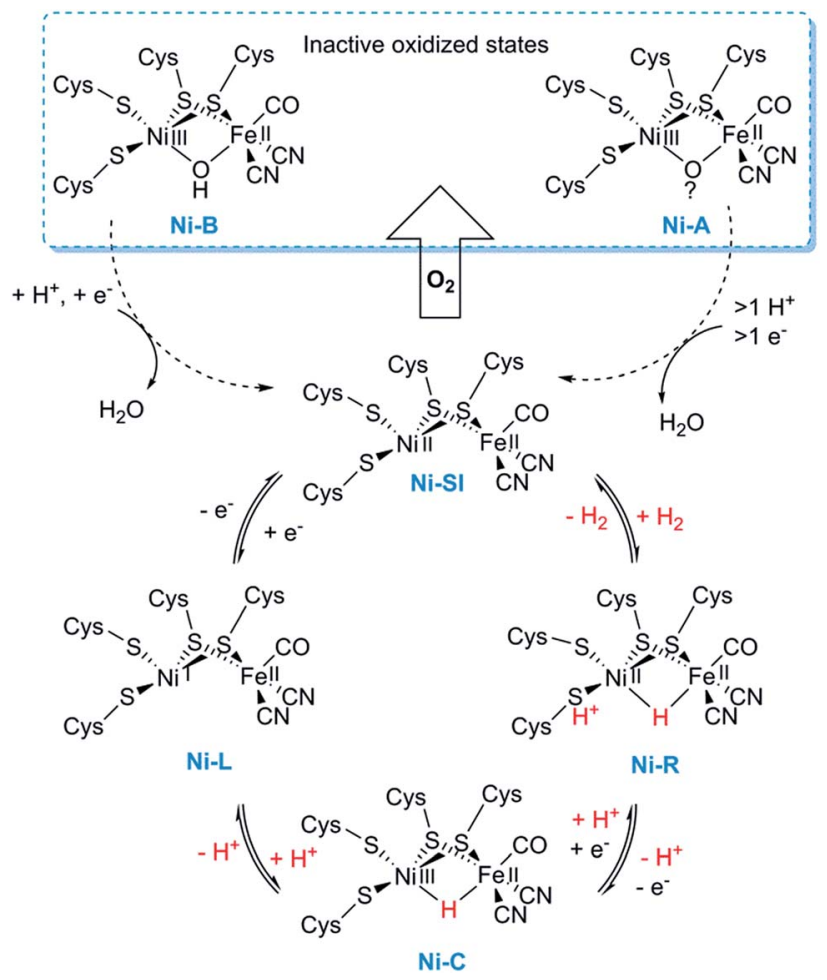

Fig. 2 Skeletal representation of the catalytic cycle of the [NiFe] hydrogenase including the $\mathrm{Ni}_{\mathrm{L}}$-state. 


\section{2 [FeFe] hydrogenases}

In the case of [FeFe] hydrogenases, the reaction is catalysed by a hexanuclear Fe complex, the H-cluster, which is buried in the so-called H-domain. Detailed structural information about [FeFe] hydrogenases is available from X-ray crystallography studies of hydrogenases from Clostridium (C.) pasteurianum (CpI), Desulfovibrio (D.) desulfuricans and Chlamydomonas (Ch.) reinhardtii..$^{\mathbf{2 4 1 - 4 3}}$ In contrast to [NiFe] hydrogenases, the [FeFe] hydrogenases are often monomeric. However, $[\mathrm{FeFe}]$ hydrogenases of bacterial origin generally feature additional domains of varying complexity harbouring a series of [FeS] clusters..$^{23,44}$ The smallest [FeFe] hydrogenases known are the eukaryotic [FeFe] hydrogenases found in green algae that consist of only the $\mathrm{H}$ domain, which features the H-cluster as its only metal site, as exemplified by e.g. HydA1 from Ch. reinhardtii. Still, there are also forms of [FeFe] hydrogenases that feature additional subunits (see for example ref. 44), as exemplified by e.g. the [FeFe] hydrogenases from $D$. desulfuricans and Thermotoga maritima. $^{\mathbf{4 3 , 4 5 - 5 1}}$

The H-cluster consists of a canonical cysteine-coordinated $[4 \mathrm{Fe}-4 \mathrm{~S}]$ cluster $\left([4 \mathrm{Fe}-4 \mathrm{~S}]_{\mathrm{H}}\right)$ coupled to a dinuclear iron complex called the $[2 \mathrm{Fe}]$ subsite. The [2Fe] subsite features a bridging azadithiolato ligand (adt $={ }^{-} \mathrm{SCH}_{2} \mathrm{NHCH}_{2}{ }^{-}$ $\left.\left.\mathrm{S}^{-}\right]^{2-}\right),{ }^{42,53,54}$ as well as three $\mathrm{CO}$ and two $\mathrm{CN}^{-}$ligands, and is connected to the $[4 \mathrm{Fe}-4 \mathrm{~S}]_{\mathrm{H}^{-}}$-cluster via a bridging cysteine thiol ligand (Fig. 1). The latter represents the only protein derived ligand to the $[2 \mathrm{Fe}]$ subsite; nevertheless, the proteinous surroundings have a dramatic effect on the reactivity of the cofactor. ${ }^{53,55-59}$ Many of the details related to the catalytic mechanism are still not fully resolved, but a skeletal mechanism including the recently observed "hydride-state $\left(\mathrm{H}_{\mathrm{Hyd}}\right)^{\text {"57,60 }}$ is summarized in Fig. 3. It should be noted the mechanism is still intensively studied and alternative protonation behaviour has recently been suggested, including the presence of bridging hydrides in $\mathrm{H}_{\text {red }}$ and $\mathrm{H}_{\text {sred }}$, which would argue against their direct involvement in the catalytic cycle. ${ }^{61-63}$ The paramagnetic $\mathrm{H}_{\mathrm{ox}}$-state contains an oxidised cluster and $[2 \mathrm{Fe}]$ subsite $\left([4 \mathrm{Fe}-4 \mathrm{~S}]_{\mathrm{H}}{ }^{2+}-\left[\mathrm{Fe}^{\mathrm{I}} \mathrm{Fe}^{\mathrm{II}}\right]\right)$ with an open coordination site or readily exchangeable ligand on the distal iron. Heterolytic cleavage of $\mathrm{H}_{2}$, facilitated by a bridgehead amine, results in the formation of another paramagnetic species, the $\mathrm{H}_{\mathrm{Hyd}^{-}}$-state, featuring a terminal hydride ligand on the distal $\mathrm{Fe}\left([4 \mathrm{Fe}-4 \mathrm{~S}]_{\mathrm{H}}{ }^{+}-\left[\mathrm{Fe}^{\mathrm{II}} \mathrm{Fe}^{\mathrm{II}}-\mathrm{H}\right]\right)$. Release of the hydride ligand as a proton with concomitant reduction of the H-cluster generates the $\mathrm{H}_{\text {sred }}$-state $\left([4 \mathrm{Fe}-4 \mathrm{~S}]_{\mathrm{H}}{ }^{+}-\left[\mathrm{Fe}^{\mathrm{I}} \mathrm{Fe}^{\mathrm{I}}\right]\right)$. Oxidation of the $[4 \mathrm{Fe}-4 \mathrm{~S}]_{\mathrm{H}}$-cluster generates the diamagnetic $\mathrm{H}_{\text {red }}$-state $([4 \mathrm{Fe}-$ $4 \mathrm{~S}]_{\mathrm{H}}{ }^{2+}-\left[\mathrm{Fe}^{\mathrm{I}} \mathrm{Fe}^{\mathrm{I}}\right]$ ), which is further oxidised back to the $\mathrm{H}_{\mathrm{Ox}}$-state to close the catalytic cycle. ${ }^{17,57,60}$

\section{$2.3[\mathrm{Fe}]$ hydrogenases}

The third class of hydrogenases, the $\mathrm{H}_{2}$-forming methylenetetrahydromethanopterin dehydrogenase (Hmd), or $[\mathrm{Fe}]$ hydrogenase, is found in methanogenic archaea and was first reported by Thauer and co-workers in $1990 .{ }^{64,65}$ In comparison to $[\mathrm{NiFe}]$ and $[\mathrm{FeFe}]$ hydrogenases, the reactivity of $\mathrm{Hmd}$ is noticeably different: the enzyme is involved in the reduction of

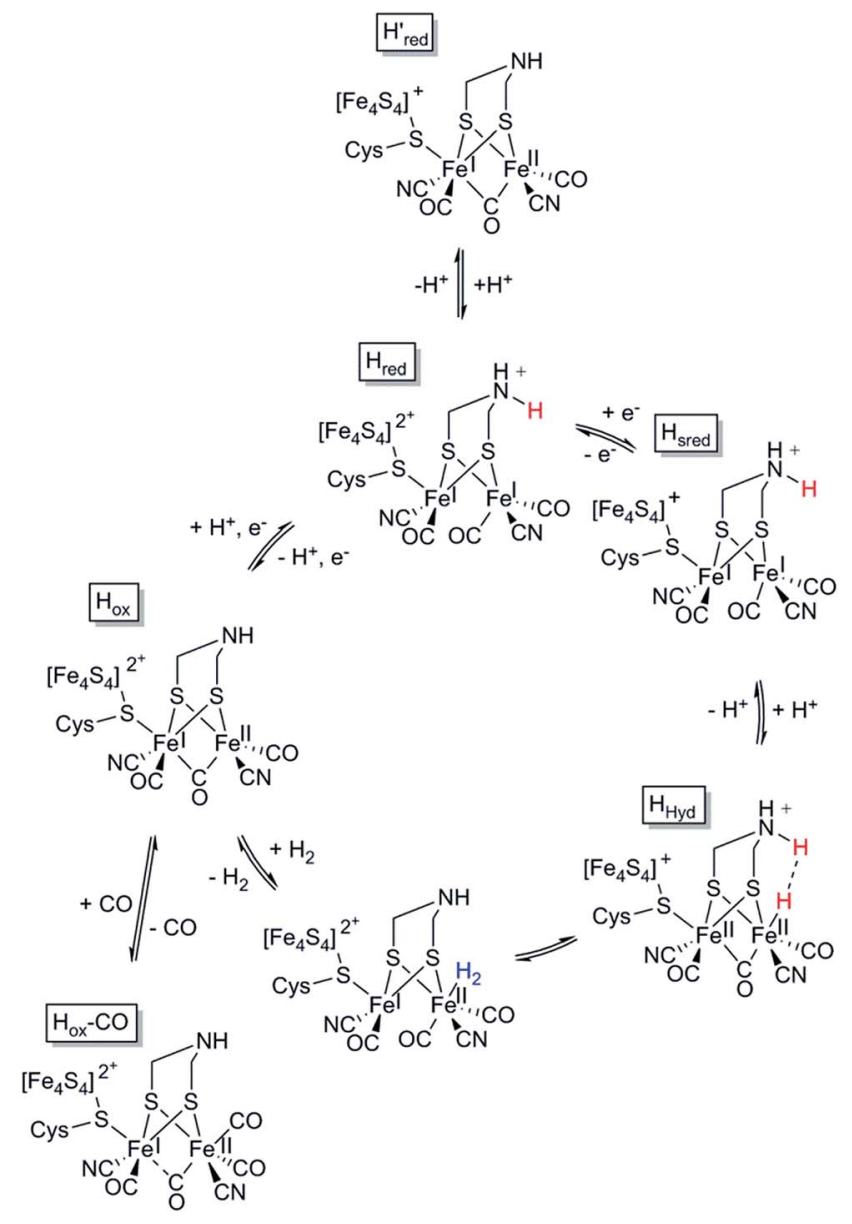

Fig. 3 Skeletal representation of the catalytic cycle of the [FeFe] hydrogenase, adapted from Sommer et al. ${ }^{52}$

$\mathrm{CO}_{2}$ to $\mathrm{CH}_{4}$. Instead of direct $\mathrm{H}^{+} / \mathrm{H}_{2}$ interconversion, Hmd utilizes $\mathrm{H}_{2}$ to catalyse the reversible reduction of $N^{5}, N^{10}$ methenyl-tetrahydromethanophterin $\left(\mathrm{MPT}^{+}\right)$to $N^{5}, N^{10}$-methylene-tetrahydromethanophterin (HMPT) (Fig. 4). ${ }^{66}$ The reaction is catalysed by a mononuclear Fe-guanylylpyridinol cofactor (Fe-GP), in which the low-spin Fe ion is further coordinated by two CO ligands and a cysteine-derived thiol ligand (Fig. 1). ${ }^{27,67,68}$ The Fe ion does not change the oxidation state during catalysis. In the presence of $\mathrm{MPT}^{+}$, the $\mathrm{Fe}^{\mathrm{II}}$ ion instead acts as a Lewis base, enabling the heterolytic cleavage of $\mathrm{H}_{2}$. The substrate acts as a hydride acceptor, while the proton is initially transferred to either the cysteine thiol or the oxygen atom of the pyridinol before it is rapidly exchanged with bulk water. ${ }^{69-71}$

\section{Designing robust hydrogenases through protein engineering}

Insight into molecular mechanisms of proton activation, gas transfer and electron transfer in hydrogenases has opened the doors to designing robust enzymes for optimal hydrogen production through protein engineering. Two main challenges in engineering hydrogenases are (a) shifting catalytic bias 


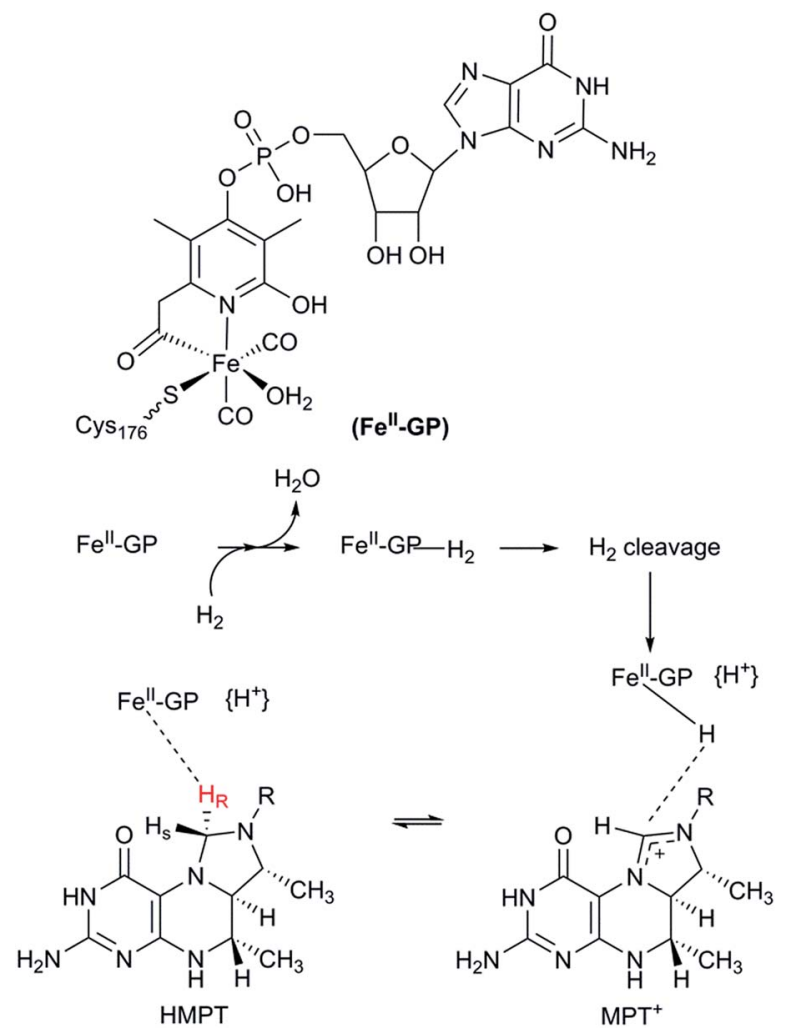

Fig. 4 Schematic representation of the catalytic cycle of the [Fe] hydrogenase.

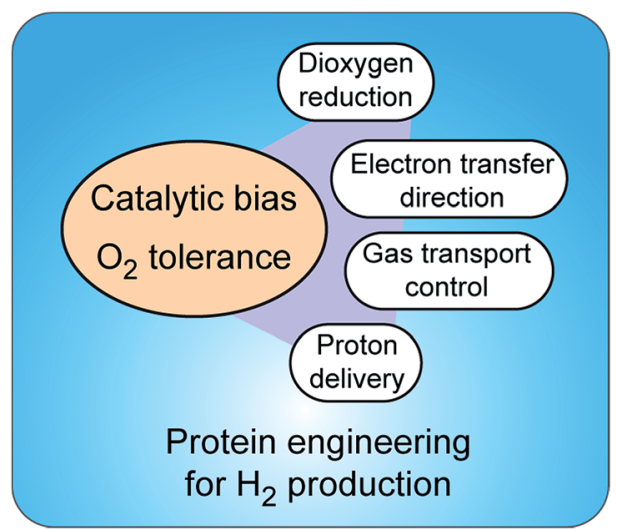

Fig. 5 Strategies to control catalytic bias and improve tolerance to $\mathrm{O}_{2}$ in hydrogenases. Protein engineering allows tuning proton and electron delivery and controlling the access of $\mathrm{O}_{2}$ to the active site.

towards hydrogen production and (b) producing enzymes tolerant to dioxygen $\dagger$ (Fig. 5). Other important aspects to consider, but that are outside of the scope of this review, are metabolic engineering to redirect the intracellular electron flow to native hydrogenases and the (over)expression of unmodified hydrogenases for increased hydrogen production.

$\uparrow$ The terms " $\mathrm{O}_{2}$ tolerance" and " $\mathrm{O}_{2}$ resistance" are used interchangeably in the current literature.

\subsection{What is catalytic bias?}

Hydrogenases can theoretically perform both $\mathrm{H}_{2}$ oxidation and $\mathrm{H}_{2}$ evolution, but usually one activity predominates significantly over the other, in vivo or in vitro. A straightforward definition of catalytic bias is the ratio between reaction rates for $\mathrm{H}_{2}$ oxidation and $\mathrm{H}_{2}$ production. As pointed out by Abou Hamdan et al., catalytic bias in a given enzyme is classically characterised by parameters related to the equilibrium constant; however, with oxidoreductases, catalytic bias is more often described in terms of the relative redox potentials of the active sites as compared to the potentials of substrate/product pairs. ${ }^{72}$ Armstrong et al. defined bias in hydrogenases as the ratio between rate constants for the anodic and the cathodic processes, where these constants include both intramolecular electron transfer (ET) and catalytic turnover. ${ }^{12}$ It is important to point out that this model interprets the behaviour of enzymes containing ET chains immobilized on electrode surfaces under non-limiting substrate conditions and relies on the redox potential of the distal cluster as the determinant factor in ET between the hydrogenase and an electron transfer partner. It should be noted that the direction of the reaction in vivo will be affected by external factors such as cell culture conditions and the availability of intracellular ET partner proteins.

In the context of developing $\mathrm{H}_{2}$-producing systems, it is paramount to elucidate the factors modulating catalytic bias to shift it towards $\mathrm{H}_{2}$ production. The [NiFe] hydrogenase from Desulfovibrio fructosovorans is one of the most studied enzymes in the context of understanding catalytic bias. The rate limiting step for $\mathrm{H}_{2}$ production in this hydrogenase was found to be proton transfer and the subsequent release of $\mathrm{H}_{2}$ from the active site, while $\mathrm{H}_{2}$ oxidation is primarily affected by electron transfer (ET) to and from the active site via the three [FeS] cluster relay in the small subunit. ${ }^{72,74}$

These findings prompt the question: can we change the catalytic bias in a hydrogenase by altering proton and/or electron transport through the enzyme? ${ }^{72}$ Some answers have recently started to appear in the literature as we gain understanding about proton pathways, gas transport and electron transfer in different types of hydrogenases.

\subsection{Tuning electron transfer for the control of catalytic bias}

The ET chains in hydrogenases, composed of [FeS] clusters, are a key target for protein engineering to control catalysis. In particular, the effects of non-cysteinyl coordination and the binding pocket properties on the redox and structural properties of [FeS] clusters remain largely unexplored. ${ }^{75,76} \mathrm{It}$ is however not always an easy feat to perform site-directed mutagenesis on residues binding, or in the near vicinity of [FeS] clusters, as mutated proteins may not incorporate iron or be expressed at all. $^{77}$

$\ddagger$ The correct specific epithet for this bacterium is fructosivorans. ${ }^{73}$ (A. S. Ouattara, B. K. C. Patel, J.-L. Cayol, N. Cuzin, A. S. Traore and J.-L. Garcia, Int. J. Syst. Evol. Microbiol., 1999, 49, 639-643). The epithet fructosovorans is nevertheless more common in the literature, and we use it here for the sake of clarity. 
The ET can presumably be tuned in clostridial [FeFe] hydrogenases by engineering of [FeS] clusters in the ET subunit, using rationales similar to those employed for [NiFe] hydrogenases (see below). For green algal hydrogenases (which do not possess an ET chain), it is the interaction between the catalytic unit and an ET partner protein that becomes more interesting. An example of the latter is Ch. reinhardtii HydA1. Sybirna et al. mutated Arg171, a highly conserved residue involved in the recognition of ferredoxin as an ET partner, to Asp or Trp (Table 1). ${ }^{78}$ The change in electrostatic charge disrupted the interaction with ferredoxin, as predicted, resulting in lower activity when using this protein as an electron donor. However, when using a methyl viologen assay for $\mathrm{H}_{2}$ evolution, the Arg171Asp mutant presented six times higher $V_{\max }$, attributed to an increase in affinity to methyl viologen upon introduction of a positive charge. This study showed that ET was rate-limiting in Ch. reinhardtii HydA1 and suggests that the protein can be engineered to increase the active site accessibility to electron donors.

Several [NiFe] hydrogenases have been targeted in recent years for the enhancement of ET to/from the active site through protein engineering. A number of crystal structures exist to aid in the design of specific mutations, even if limited to a few groups of hydrogenases. An alternative is found in performing random mutagenesis and screening for enhanced activity. Maeda et al. applied error-prone PCR and saturation mutagenesis on the catalytic subunit, HycE, from hydrogenase-3 in $E$. coli. $^{79}$ Seven mutants were found to have up to nine times enhanced $\mathrm{H}_{2}$ evolution, possibly due to strengthening proteinprotein interaction between the large and the small subunits of hydrogenase-3, thereby enhancing ET between the [FeS] cluster chain and the catalytic site.

[NiFe] hydrogenases present a highly conserved histidine residue as one of the four ligands of the distal cluster (i.e. the cluster farthest from the active site), a fact that has raised questions on its role in intra- and inter-molecular ET. ${ }^{80}$ DFT calculations by Petrenko \& Stein identified two amino acids as crucial for intermolecular ET, the aforementioned ligand His184 and Ser196, in the D. fructosovorans enzyme. ${ }^{81}$ Introducing the His184Cys mutation does not significantly change the reorganization energy between the mutant and wild-type enzyme, in contrast to what was suggested by Dementin et al. ${ }^{\mathbf{8 0}}$ Rather, the all-cysteine coordination affected the electronic coupling to the electrode surface, decreasing the ET rate by several orders of magnitude. ${ }^{81}$ Thus it seems that the distal cluster in [NiFe] hydrogenases has a crucial role as an entry/exit point for intramolecular ET and in the recognition of an ET partner for intermolecular ET. An interesting exception to the histidine ligation is the cyanobacterial uptake (HupSL) hydrogenases, where a strictly conserved glutamine is found instead of the histidine. Despite this difference, a [4Fe-4S] cluster is assembled in the distal position. ${ }^{82}$ If this glutamine residue binds the cluster, it might significantly reduce the rate of ET to its electron acceptor. ${ }^{83}$

In parallel to the work on the distal cluster, efforts have also been invested in the medial and proximal clusters. Almost two decades ago, Rousset et al. reported the conversion of the medial $[3 \mathrm{Fe}-4 \mathrm{~S}]$ cluster to a $[4 \mathrm{Fe}-4 \mathrm{~S}]$ metal centre in the $[\mathrm{NiFe}]$ hydrogenase from D. fructosovorans. ${ }^{84}$ This was achieved through a Pro238Cys mutation that inserted a fourth thiolate ligand in a similar position to that found in [NiFeSe] hydrogenases, where a medial [4Fe-4S] cluster occurs naturally. Functionally, the mutant enzyme became a slightly worse $\mathrm{H}_{2}$ oxidiser, whereas the $\mathrm{H}_{2}$ evolution activity increased; intramolecular ET was not deemed to be rate limiting in either wildtype or Pro238Cys hydrogenases. While the enzyme was still a net $\mathrm{H}_{2}$ oxidiser, this work showcased how catalytic bias could be shifted by perturbing the ET chain.

The presence of functional enzymes in photosynthetic organisms would be an important factor for efficient photobiological $\mathrm{H}_{2}$ gas production. In order to address this challenge, it is critical to introduce engineered hydrogenases into such organisms and evaluate their true activity in vivo. An important step was taken by Yonemoto et al. through the heterologous expression of the [NiFe] hydrogenase HynSL from the marine bacterium Alteromonas macleodii in both $E$. coli and the cyanobacterium Synechococcus elongatus. ${ }^{85}$ Furthermore, the authors engineered the small subunit HynS through the mutations Pro285Cys (which converts the medial $[3 \mathrm{Fe}-4 \mathrm{~S}]$ cluster to a $[4 \mathrm{Fe}-4 \mathrm{~S}]$ ) and His230Cys

Table 1 Mutations introduced in hydrogenases resulting in positive effects on hydrogen production or tolerance to dioxygen (see the text for details)

\begin{tabular}{|c|c|c|c|}
\hline Enzyme, organism & Mutation & Main effect & Ref. \\
\hline HoxG (MBH), [NiFe] R. eutropha & $\begin{array}{l}\text { C81A, C81V, C81S, C81T } \\
\text { (catalytic subunit) }\end{array}$ & Higher (variable) $\mathrm{O}_{2}$ tolerance & 98 \\
\hline Periplasmic, [NiFe] D. fructosovorans & $\begin{array}{l}\text { V74M, V74C, V74S, V74N } \\
\text { (catalytic subunit) }\end{array}$ & Increased $\mathrm{O}_{2}$ tolerance, decreased $\mathrm{H}_{2}$ oxidation & $33,99,100$ \\
\hline HycG (hydrogenase- 3 ), [NiFe] K. oxytoca & $\begin{array}{l}\text { G47C, G50C, G113C, G120C, } \\
\text { G50C/G120C (ET subunit) }\end{array}$ & Increased $\mathrm{O}_{2}$ tolerance, unaltered in vivo activity & 107 \\
\hline HydA1, $[\mathrm{FeFe}]$ Ch. reinhardtii & R171D (catalytic unit) & Decreased $\mathrm{H}_{2}$ evolution but increased $V_{\max }$ & 78 \\
\hline HycE (hydrogenase-3), [NiFe] E. coli & Various, random (catalytic unit) & Increased $\mathrm{H}_{2}$ production & 79 \\
\hline Periplasmic, $[\mathrm{NiFe}]$ D. fructosovorans & P238C (ET subunit) & Shift in catalytic bias towards $\mathrm{H}_{2}$ production & 84 \\
\hline HynS, [NiFe] A. macleodii & P285C/H230C (ET subunit) & Shift in catalytic bias towards $\mathrm{H}_{2}$ production & 85 \\
\hline HupS, uptake, $[\mathrm{NiFe}] N$. punctiforme & C12P (ET subunit) & Shift in catalytic bias towards $\mathrm{H}_{2}$ production in vivo & 87 \\
\hline HyaA (MBH/hydrogenase-1), & E73Q (ET subunit) & Shift in catalytic bias towards $\mathrm{H}_{2}$ production & 88 \\
\hline
\end{tabular}

[NiFe] E. coli 
(which alters the coordination sphere of the distal cluster to a full cysteinyl one). It was found that HynSL carrying both mutations showed an effective change in the catalytic bias as measured in lysates of $E$. coli, observable by an increase in the production of $\mathrm{H}_{2}$. The enzyme was still an overall $\mathrm{H}_{2}$ oxidiser, as uptake activity remained virtually unchanged at levels slightly higher than the production rate. Nevertheless, this modified hydrogenase served as a starting point for further engineering of the electron transfer chain of Hyns, through replacement of all twelve coordinating amino acids by [FeS] cluster ligands found in other hydrogenases (Asp, His, Asn and Gln). ${ }^{86}$ Albeit none of the tested mutants presented a net $\mathrm{H}_{2}$ in vivo production, this work further showcased how tweaking the properties of the ET chain may affect the catalytic activity.

Recently, Raleiras et al. demonstrated the in vivo production of $\mathrm{H}_{2}$ in the filamentous cyanobacterium Nostoc (N.) punctiforme ATCC 29133 following engineering of the uptake hydrogenase HupSL. ${ }^{87}$ The single point mutation Cys12Pro was inserted in the proximal $[\mathrm{FeS}]$ cluster, causing its conversion from a $[4 \mathrm{Fe}-$ $4 \mathrm{~S}]$ to a $[3 \mathrm{Fe}-4 \mathrm{~S}]$ species; $N$. punctiforme carrying this modified HupSL presented a net production of $\mathrm{H}_{2}$ (Fig. 6). The authors proposed that particular metabolic conditions, when the reducing power provided by photosynthesis needs an outlet, combined with the structural change in the proximal cluster, facilitate a reverse direction of electron transfer towards the active site, with the concomitant production of $\mathrm{H}_{2}$. Petrenko \& Stein have recently suggested that a glutaminate coordination to the distal cluster is probably associated with the possibility to reverse the electron flow in this hydrogenase. ${ }^{83}$ There is an interesting parallel with the $\mathrm{O}_{2}$ detoxification mechanism of membrane-bound hydrogenases (MBHs), where a reverse electron flow is likely facilitated by the ET chain containing [FeS] clusters with relatively positive redox potentials.

The latest effort in a rational tuning of catalytic bias is the attempt to modulate the redox potential of the proximal cluster in the $\mathrm{O}_{2}$-tolerant $E$. coli hydrogenase- 1 by Flanagan et al., through changes in the second coordination sphere. ${ }^{88}$ In
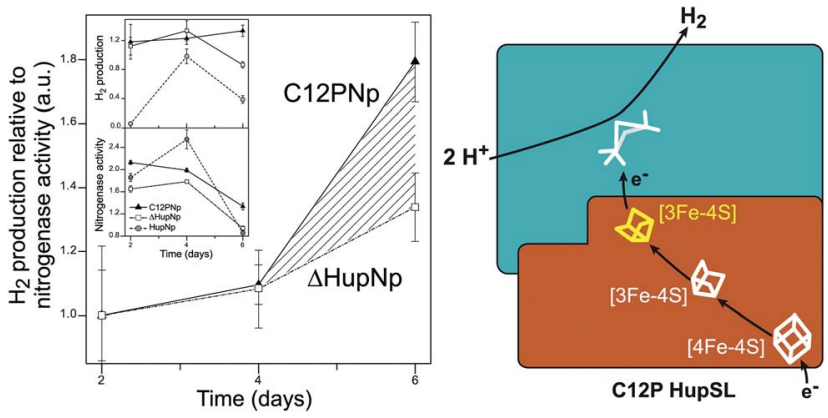

Fig. 6 Engineering of the uptake hydrogenase HupSL in Nostoc punctiforme for hydrogen production. Left: N. punctiforme expressing C12P HupS (C12PNp strain) produces $\mathrm{H}_{2}$ in addition to the background production from nitrogenase activity ( $\Delta$ HupNp strain). Right: the C12P mutation induces a [4Fe-4S] $\rightarrow[3 \mathrm{Fe}-4 \mathrm{~S}]$ cluster conversion in the proximal position in HupS, facilitating reverse electron flow towards the active site. The figure was adapted from Raleiras et al. ${ }^{87}$ with permission from the Royal Society of Chemistry. particular, Glu73 was identified as a conserved amino acid in $\mathrm{O}_{2}$-tolerant hydrogenases, in contrast to a glutamine residue present in the homologous position in $\mathrm{O}_{2}$-sensitive enzymes. Introducing the Glu73Gln mutation into hydrogenase-1 did not affect its $\mathrm{O}_{2}$ tolerance but impacted the catalytic bias markedly by doubling the $\mathrm{H}_{2}$ production. The exact cause of this shift in the catalytic bias is so far not fully understood, as there was no significant change in the redox potential of the proximal cluster in the mutant as compared to the wild-type enzyme.

In summary, a number of recent reports support the notion that shifting the relative potentials of the clusters in the ET chain can affect catalytic bias towards $\mathrm{H}_{2}$ production. Further in vivo studies of these modified enzymes in combination with metabolic engineering will be critical to establish the technical feasibility of this approach to biological $\mathrm{H}_{2}$ production.

\subsection{The $\mathrm{O}_{2}$ problem: gas channels and $\mathrm{O}_{2}$ reduction}

The conversion of sunlight to chemical energy stored as hydrogen through photosynthesis requires conditions where hydrogenases are protected from or tolerant to the presence of $\mathrm{O}_{2} \cdot{ }^{15}$ Fortunately, functional hydrogenases have been found in organisms where exposure to $\mathrm{O}_{2}$ cannot be avoided, which has awakened research into the factors that make a hydrogenase $\mathrm{O}_{2}$ tolerant. [FeFe] hydrogenases have long been considered very sensitive to $\mathrm{O}_{2}$, although a few exceptions exist. ${ }^{\mathbf{8 9}, 90} \mathrm{Gas}$ transfer has been studied in [FeFe] hydrogenases, and potential $\mathrm{O}_{2}$ access routes have been identified. ${ }^{91}$ However, attempts to engineer $\mathrm{O}_{2}$-tolerance in the $[\mathrm{FeFe}]$ hydrogenase $\mathrm{CpI}$ resulted in a drastic decrease in activity. ${ }^{92}$ In contrast, [NiFe] hydrogenases are able to reverse $\mathrm{O}_{2}$-mediated inactivation through reduction of the active site, and some [ $\mathrm{NiFe}$ ] hydrogenases actively detoxify $\mathrm{O}_{2}$ during catalysis. For this reason, most efforts have been focused on understanding and improving $\mathrm{O}_{2}$ tolerance in [NiFe] hydrogenases.

An early hypothesis concerning the sensitivity to $\mathrm{O}_{2}$ was the selectivity in the access of $\mathrm{O}_{2}$ and $\mathrm{H}_{2}$ to the active site. Gas transport pathways have been identified by structural analysis in several hydrogenases. These pathways are channels within the protein structure, typically lined with hydrophobic amino acids, that connect the active site to the protein surface. ${ }^{93}$

Compariso $n$ of primary sequences reveals small differences in the immediate vicinity of the active site between $\mathrm{O}_{2}$-sensitive and $\mathrm{O}_{2}$-tolerant [NiFe] hydrogenases. Both $\mathrm{H}_{2}$ and $\mathrm{O}_{2}$ can be transported along the same hydrophobic channels found within the catalytic subunit, as suggested by X-ray crystal structures and molecular dynamics simulations. ${ }^{\mathbf{9 4}, 95}$ Manipulating these channels so that only $\mathrm{H}_{2}$ could selectively move within the protein has been suggested as a way to increase $\mathrm{O}_{2}$ tolerance in [NiFe] hydrogenases. In the $\mathrm{O}_{2}$-tolerant, $\mathrm{H}_{2}$-sensitive [NiFe] hydrogenases from Ralstonia (R.) eutropha§ $\mathrm{H} 16$ and Rhodobacter (Rh.) capsulatus, substitution of two particular, bulky amino acid residues (Ile65 and Phe113, Rh. capsulatus

$\S$ Now renamed to Cupriavidus necator; the name Ralstonia eutropha is nevertheless still common in the literature, and we use it here for the sake of clarity. 
numbering) increased sensitivity to $\mathrm{O}_{2}$ by allowing the larger gas molecule to reach the [NiFe] active site.96,97 Ludwig et al. identified Gly80 and Cys81 in the $\mathrm{O}_{2}$-tolerant $\mathrm{MBH}$ from $R$. eutropha $\mathrm{H} 16$ as potentially important for the tolerance mechanism. ${ }^{98}$ The authors noticed, however, that $\mathrm{O}_{2}$ tolerance was likely not due simply to selective gas access to the active site, given that the wild-type enzymes reacted rapidly with $\mathrm{O}_{2}$ without becoming completely inhibited.

Molecular dynamics simulations on the [NiFe] hydrogenase from $D$. gigas demonstrated that $\mathrm{H}_{2}$ is able to quickly penetrate the catalytic subunit through a number of different channels, but uses preferentially one to reach the active site, possibly using Glu18 and Val67 in a gating mechanism near the active site. ${ }^{93}$ Dementin et al. and Liebgott et al. mutated the corresponding valine residue in the $D$. fructosovorans hydrogenase, valine-74 (Fig. 7; Table 1), and found that the mutant enzymes could still competently oxidise $\mathrm{H}_{2}$ in the presence of small concentrations of $\mathrm{O}_{2}$, while the wild-type enzyme is completely inactivated. ${ }^{99,100}$ The effect seems to be mostly kinetic due to a partial obstruction of $\mathrm{O}_{2}$ access to the active site in the mutated enzyme. An attempt to understand the molecular basis for this higher tolerance to $\mathrm{O}_{2}$ using a larger collection of valine74 mutants led to the observation that replacing valine with a more hydrophilic amino acid increased the rate of reactivation after $\mathrm{O}_{2}$ exposure. ${ }^{33}$

An alternative mechanism for $\mathrm{O}_{2}$ tolerance was identified in MBHs from several organisms, which perform $\mathrm{H}_{2}$ oxidation in the presence of low tensions of $\mathrm{O}_{2}$. Enzymes in the oxidised, $\mathrm{Ni}_{\mathrm{A}}$ state typically need long reduction periods to recover to an active state; it follows that if exposure to $\mathrm{O}_{2}$ cannot be avoided, then the enzyme must use part of an available electron pool to reduce $\mathrm{O}_{2}$ to $\mathrm{H}_{2} \mathrm{O}$. The proximal [FeS] cluster in MBHs is an unusual [4Fe-

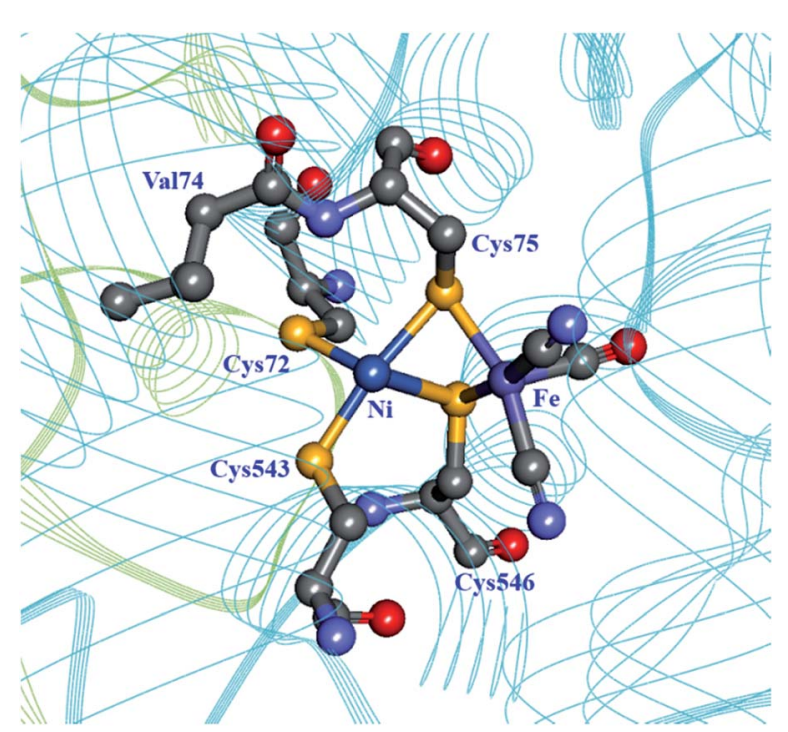

Fig. 7 The coordination sphere of the [NiFe] site in the $D$. fructosovorans hydrogenase (PDB: 1YRQ). ${ }^{101}$ Through site-directed mutagenesis, valine-74 has been shown to have a role in the gas accessibility to the active site, possibly through a gating action. Blue ribbon: large subunit; green ribbon: small subunit; heteroatom colour coding as in Fig. 1.
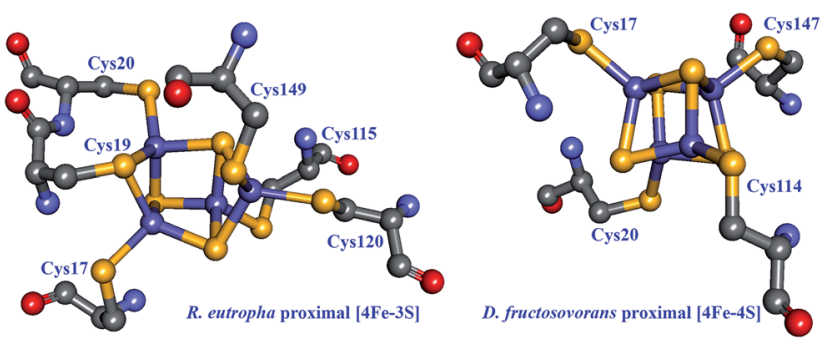

Fig. 8 Structural comparison between proximal [FeS] clusters in $\mathrm{O}_{2}-$ tolerant and $\mathrm{O}_{2}$-sensitive [NiFe] hydrogenases. Left: the proximal [4Fe-3S] cluster in the $R$. eutropha $\mathrm{MBH}$ (PDB: 3RGW), ${ }^{103}$ involved in the direct detoxification of $\mathrm{O}_{2}$. Right: the proximal [4Fe-4S] cluster in the $D$. fructosovorans hydrogenase (PDB: 1YRQ). ${ }^{108}$ Cysteine residues directly coordinating the clusters are shown. Heteroatom colour coding as in Fig. 1.

3S] cluster ligated by not four (the most common ligation pattern in [FeS] clusters) but rather six cysteines in the small subunit (Fig. 8), ${ }^{102-104}$ and this cluster has been shown to play an active role in reducing $\mathrm{O}_{2}$ to water as a means to protect the active site from oxidative deactivation. ${ }^{105}$ While four of the ligating cysteines are homologous to those found in other [NiFe] hydrogenases, the two supernumerary cysteine residues (Cys19 and Cys120 in R. eutropha) were unequivocally shown to be essential for $\mathrm{O}_{2}$ tolerance: replacing these cysteines in the R. eutropha MBH restores the $\mathrm{Ni}_{\mathrm{A}}$ state and abolishes $\mathrm{O}_{2}$ tolerance. ${ }^{103}$ Lukey et al. pinpointed Cys19 in hydrogenase-1 from E. coli as having the critical role in $\mathrm{O}_{2}$ tolerance as seen by a dramatic decrease in $\mathrm{H}_{2}$ oxidation in the Cys19Gly and Cys19Gly/Cys120Gly mutants. ${ }^{106}$ All enzyme variants (wild type and Cys19Gly, Cys120Gly, and Cys19Gly/Cys120Gly mutants) present some degree of the $\mathrm{Ni}_{\mathrm{A}}$ state in EPR spectroscopy, but reduction of the [NiFe] site to an active species varies markedly, with the Cys19 mutants requiring much longer reactivation times.

Critically, the $[4 \mathrm{Fe}-3 \mathrm{~S}]$ proximal cluster undergoes two redox transitions at relatively mild redox potentials $(-60 \mathrm{mV}$ and +160 $\mathrm{mV} v$ s. SHE in the $R$. eutropha enzyme) ${ }^{109}$ necessary for the direct reduction of $\mathrm{O}_{2}$ to $\mathrm{H}_{2} \mathrm{O} \cdot{ }^{105}$ Additionally, the other [FeS] clusters in the ET chain also present less reducing than usual redox potentials. This in combination with a structural arrangement allowing fast ET between the distal clusters of two enzymes has been argued to facilitate an efficient electron flow to afford the necessary four electrons for the complete reduction of $\mathrm{O}_{2}$ in a kinetically competent fashion. ${ }^{\mathbf{1 0 3 , 1 0 5 , 1 0 9}}$

So far, there are no reports of a successful introduction of $\mathrm{O}_{2}$ tolerance into an $\mathrm{O}_{2}$-sensitive [NiFe] hydrogenase by introducing supernumerary cysteines in homologous positions. Nevertheless, an improvement of pre-existing $\mathrm{O}_{2}$ tolerance of the hydrogenase from Klebsiella oxytoca HP1 was recently reported by Huang et al., upon replacement of several glycine residues by cysteines, including those homologous to Cys19 and Cys120 in the $R$. eutropha MBH. ${ }^{107}$ Since no structural or spectroscopic studies have been conducted on these mutants, it is currently not known whether a successful cluster conversion has taken place.

[NiFeSe] hydrogenases are biased towards $\mathrm{H}_{2}$ production and present some degree of tolerance to $\mathrm{O}_{2} \cdot{ }^{13}$ These enzymes do 
not present the characteristic $\mathrm{Ni}_{\mathrm{A}}$ and $\mathrm{Ni}_{\mathrm{B}}$ inactive states found in $\mathrm{O}_{2}$-exposed [NiFe] hydrogenases. Marques et al. reported recently that substituting the Ni-coordinating selenocysteine in the D. vulgaris Hildenborough [NiFeSe] hydrogenase for cysteine (Sec489Cys) abolished the enzyme's tolerance to $\mathrm{O}_{2}$, effectively turning it into a "regular" [NiFe] hydrogenase. ${ }^{\mathbf{1 1 0}}$ The mutation also had a negative effect on the enzyme's ability to incorporate nickel and to produce $\mathrm{H}_{2}$.

So far, attempts to engineer $\mathrm{O}_{2}$-tolerance, primarily via manipulations of gas channels, result invariably in decreased $\mathrm{H}_{2}$ production, but do not affect significantly $\mathrm{H}_{2}$ oxidation. As such, these modified enzymes appear more suitable for exploration in fuel cell applications rather than $\mathrm{H}_{2}$ gas production.

\subsection{Proton transport pathways}

Proton transport pathways in proteins use either water molecules or amino acid side chains, likely through a Grotthuss mechanism. Understanding how protons move within hydrogenases and how this movement couples with electron transfer is a key step to control reactivity.

Three main proton transport pathways have been proposed for [FeFe] hydrogenases, based on computational and structural studies on the enzymes from $C$. pasteurianum and D. desulfuricans Hildenborough. ${ }^{\mathbf{4 1 1 1 1 - 1 1 3}}$ One pathway seems to dominate, involving proton transport through a tight hydrogen bond network formed by Glu279, Glu282, Cys299, Ser319 (C. pasteurianum numbering) and a water molecule, rather than through a water molecule wire (Fig. 9). ${ }^{111}$ Interestingly, the hydrogen bond occupancy in this network differs depending on whether the enzyme is producing or oxidising $\mathrm{H}_{2},{ }^{111}$ which could indicate different preferential pathways depending on the direction of the reaction. The highly conserved Cys299 and its homologue in Ch. reinhardtii HydA1 (Cys169) and C. acetobutylicum HydA (Cys298) cannot be replaced without severely impairing the enzyme activity; the H-cluster is structurally retained in these mutants but mostly locked in an inactive state. ${ }^{56,59,112,114}$

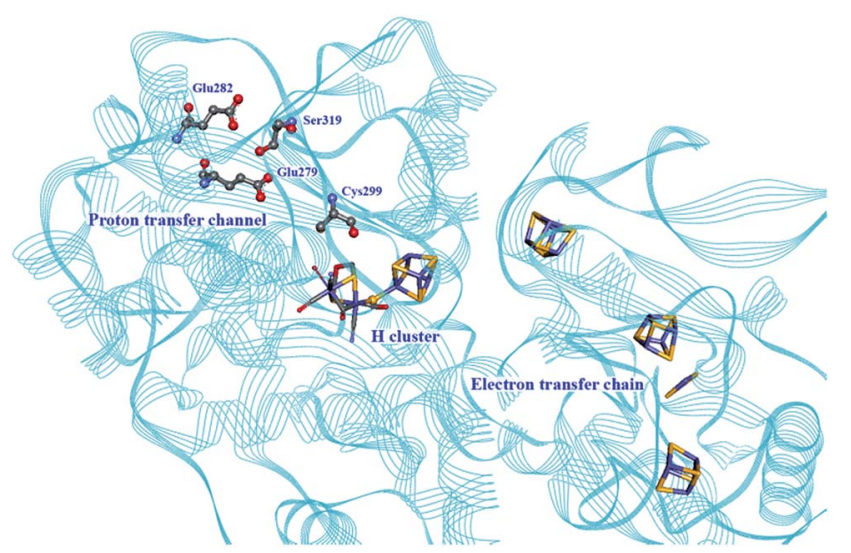

Fig. 9 Proton and electron transfer chains in the $C$. pasteurianum [FeFe] hydrogenase (PDB: 3C8Y). ${ }^{115}$ Highlighted residues have been identified as part of a hydrogen bond network transporting protons between the protein surface and the active site ( $\mathrm{H}$-cluster). Heteroatom colour coding as in Fig. 1.
Mulder et al. found recently that the Cys169Ser mutant slows down catalysis significantly ( $\approx 1 \%$ residual activity), and this disruption of the $\mathrm{H}$-bonding network allows for accumulation of a terminal hydride on the distal iron of the [2Fe] subsite in the $C h$. reinhardtii enzyme. ${ }^{57}$ A similar species has also been identified by Reijerse et al. after the [2Fe] subsite was replaced with an ether variant ( $c f$. Section 5, semi-synthetic hydrogenases). ${ }^{60}$

The earliest proposals of proton transport pathways in [NiFe] hydrogenases involved a combined amino acid side chain/ structural water molecule wire leading from the active site to a $\mathrm{Mg}^{2+}$-bound water molecule close to the protein surface. ${ }^{101}$ Alternative pathways were later analysed by Teixeira et al. through Poisson-Boltzmann/Monte Carlo simulations of protonation steps in the enzyme from D. gigas; in particular, a pathway comprising mostly histidine and glutamate residues was found as the most likely one. ${ }^{116}$ Interestingly, and in contrast to earlier proposals, this pathway includes not only amino acids from the large, catalytic subunit, but also residues from the small subunit in close proximity to the proximal [FeS] cluster. It is still not known if there is proton-coupled electron transfer involving residues around this particular cluster. A parallel study by Fdez. Galván et al. using quantum mechanics/ molecular mechanics (QM/MM) on the D. fructosovorans enzyme supported the findings on D. gigas. ${ }^{117}$ Interestingly, it was found that different pathways have different energy barriers depending on the direction of proton transfer, suggesting that a pathway that is not preferential for one direction may be in use for the reverse reaction. More recently, ultra-high resolution XRD studies of the D. vulgaris Miyazaki F enzyme provided experimental support for the participation of His36 (D. vulgaris numbering) in a well conserved proton transfer network, including residues from both the large and the small subunit. ${ }^{32}$

No modification has been performed to date to proton channels in hydrogenases that would improve catalysis (in either direction). However, discerning pathways that work towards a particular catalytic bias may help us to design better hydrogenases. It is particularly interesting to notice that in the case of $[\mathrm{FeFe}]$ hydrogenases, artificial maturation using variants of the diiron subsite offers new possibilities for controlling proton transfer. ${ }^{16,53}$

\subsection{Summary and outlook}

Molecular characterization of diverse types of hydrogenases has provided a portfolio of different solutions used by nature to combine hydrogen production/oxidation and the presence of oxygen. Clearly, there are many starting points to be explored for the engineering of hydrogenases for in vivo and in vitro applications. Results from engineering [FeS] clusters in hydrogenases have been very promising, and it is entirely feasible to take this route for fine tuning intra- and intermolecular electron transfer and thus controlling catalysis without perturbing the structure of the active site. Further controlling the gas access to the active site may help us to develop more $\mathrm{O}_{2}$-tolerant hydrogenases. It remains to be fully assessed whether high rates of $\mathrm{H}_{2}$ production are compatible 
with oxygenic conditions, but the tools exist now within our grasp to explore this possibility.

\section{Synthetic catalysts: from biomolecules to artificial enzymes and bioinspired catalysts}

Studies on hydrogenases have repeatedly demonstrated the importance of the protein environment for the catalytic efficiency of their cofactors. This has inspired the biomimetic chemistry community towards the preparation of increasingly elaborate synthetic systems for efficient catalysis.

Whereas traditional transition-metal catalysts typically only take advantage of the first coordination sphere to modulate reactivity and selectivity, the preparation of artificial metalloenzymes allows much more elaborate control. This includes the possibility to provide specific microenvironments by controlling the local hydrophobicity/-philicity of the catalyst site, the generation of e.g. specific hydrogen bonding networks and the formation of entatic states via push-pull effects, as well as site isolation and substrate/product specificity, properties that are often referred to as second or outer coordination sphere effects (Fig. 10). Thus, the nature of the metal centres and the first coordination sphere can be modified using standard synthetic techniques. In parallel, the choice of the scaffold environment, ranging from proteins to the presence of a few amino acids or the use of a non-biological matrix, and the mode of ligation between the two partners offer a major opportunity to fine-tune the properties of the assembly. In combination, this provides the chemist with a significantly larger palette for the development of novel catalysts. The artificial enzyme field, born in the 1970 s with the pioneering work of Whitesides and coworkers, ${ }^{118}$ has been constantly growing in the last few decades, as illustrated by recent reviews on e.g. protein design to make

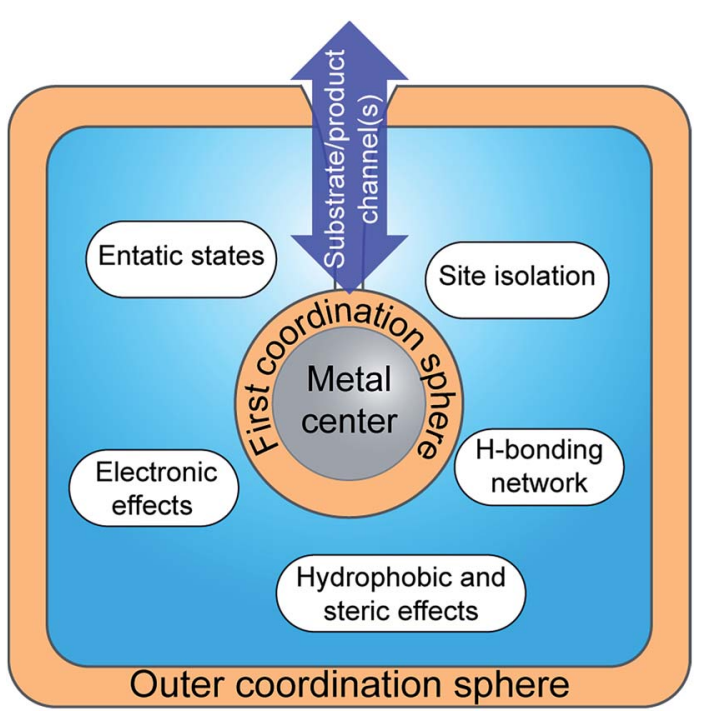

Fig. 10 Schematic representation of the insertion of a metallic cofactor in a scaffold highlighting the potential contributions of the outer coordination sphere. efficient artificial enzymes, ${ }^{119-121}$ and their application for oxygen activation, ${ }^{122}$ oxidation catalysis ${ }^{123}$ and asymmetric catalysis. ${ }^{124}$

In the context of $\mathrm{H}_{2}$ gas catalysis, the development of artificial hydrogenases is a relatively recent development, which holds great promise for the development of efficient, stable and sustainable catalysts. This section will cover work ranging from repurposing proteins (via metal substitution and metal cofactor replacement) to generate novel artificial enzymes showing hydrogenase activity to selecting purely synthetic systems mimicking specific aspects of enzyme catalysts.

\subsection{Re-purposed proteins}

The first steps towards the assembly of artificial $\mathrm{H}_{2}$-evolving enzymes relied mainly on the modification of well-known native metalloproteins in order to induce hydrogenase activity by metal centre substitution, co-factor exchange or self-assembly of protein matrices with an active synthetic catalyst. In 1988, Moura et al. described the preparation of nickel-substituted rubredoxins (NiRd), resulting in a mononuclear Ni site coordinated by four cysteine residues. ${ }^{125}$ This simple metal exchange allowed NiRd to evolve $\mathrm{H}_{2}$ in the presence of reduced methyl viologen, making it the first artificial hydrogenase ever reported. The NiRd (D. desulfuricans ATCC 27774) system has recently been re-investigated, and its electrocatalytic and photocatalytic performances for $\mathrm{H}_{2}$ evolution have been explored. ${ }^{126}$ Similar to the original study, photochemical or chemical reduction of NiRd allows catalytic $\mathrm{H}_{2}$ evolution in aqueous solution with a moderate turnover frequency (TOF) as compared to native hydrogenases. Protein film voltammetry demonstrated the existence of a proton-coupled electron transfer process within the $\mathrm{pH}$ range $3-5$. Under these conditions, the overpotential of the NiRd was estimated to be $\approx 540 \mathrm{mV}$, and the initial catalytic rate was $20-100 \mathrm{~s}^{-1}$.

Myoglobin and other heme-binding proteins have attracted more attention as potential protein scaffolds to assemble artificial hydrogenases, due to their natural ability to incorporate porphyrin-based cofactors in a well-defined environment; in particular in combination with various cobalt based catalysts. Ghirlanda et al. introduced cobaltous protoporphyrin IX (CoP, 1) into an apo-myoglobin, thus replacing the native iron protoporphyrin IX (Fig. 11a). ${ }^{127}$ Electrochemical investigations of the CoP-myoglobin system in aqueous medium showed significant catalytic waves associated with proton reduction. Interestingly, this catalytic behaviour did not appear to be strongly affected by $\mathrm{O}_{2}$. Conversely, at $\mathrm{pH}$ below 6, a loss of activity was observed, attributed to the release of the porphyrin from the heme-binding pocket due to protonation of the ligating His-93. Under photochemical conditions, the CoPmyoglobin was able to produce $\mathrm{H}_{2}$ with a turnover number (TON) ranging from 230 to 520 depending on the $\mathrm{pH}$, significantly superior to free $\mathrm{CoP}$ under the same conditions. The influence of the protein environment was probed by the preparation of different mutants, in which histidine residues in vicinity to the metal centre were replaced by alanine. The His97Ala mutant is of particular interest, as it showed 
a)

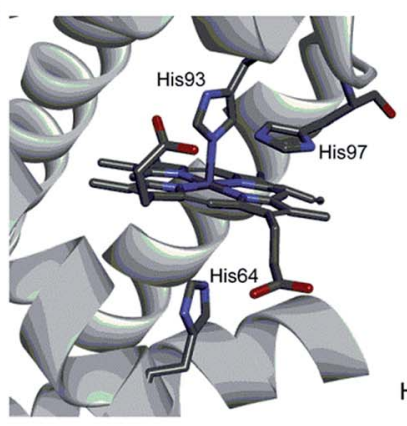

Myoglobin active site

b)

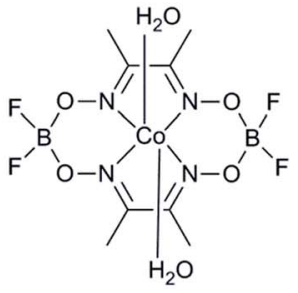

2

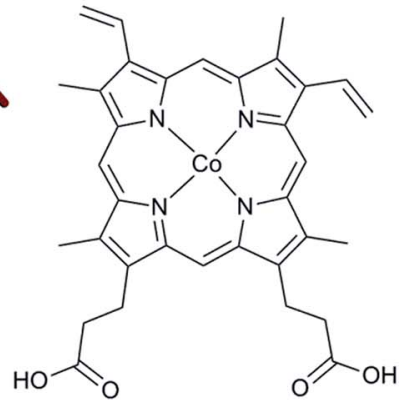

Co-protoporphyrin IX, CoP, 1

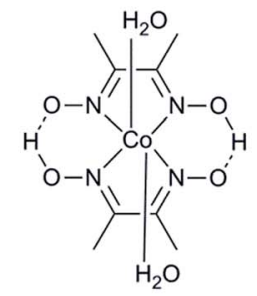

3 c)

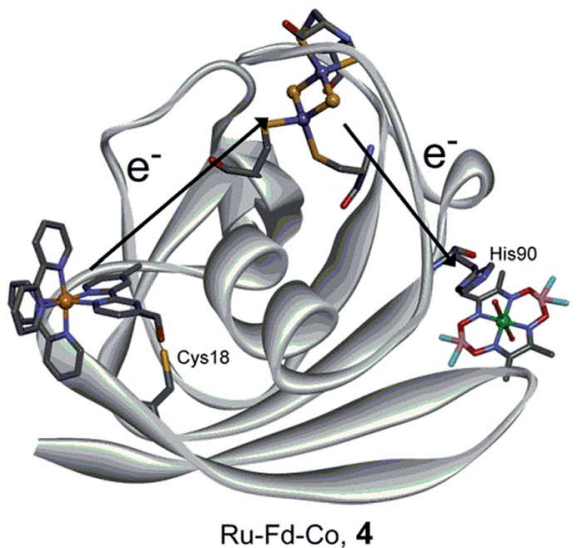

d)

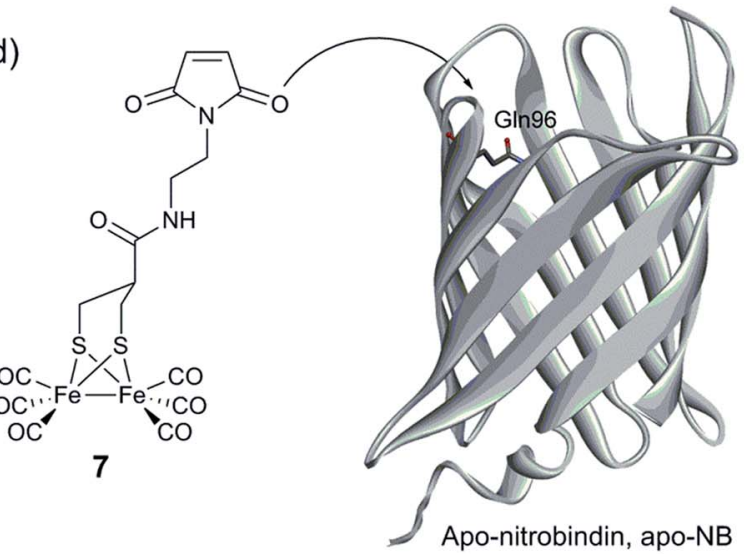

Fig. 11 (a) Structure of the active site of myoglobin (PDB ID: 1YOI)135 showing relevant histidine residues and structure of Co-protoporphyrin IX (COP, 1). (b) Cobalt catalysts (cobaloxime derivatives) inserted into a myoglobin matrix. (c) Scheme of the Ru-Fd-Co, 4 biohybrid, based on the structure of ferredoxin (PDB ID: 1A70) with a potential pathway for electron transfer from the PS to the catalyst. (d) Preparation of the artificial hydrogenase containing a $\left\{\mu-\left(\mathrm{SCH}_{2}\right)_{2} \mathrm{CHCOR}\right\}$ $\mathrm{Fe}_{2}(\mathrm{CO})_{6}$ (7) moiety within a Q96C apo-nitrobindin (apoNB) (PDB ID for NB: 2A13). ${ }^{136}$ a decreased TON of 120 at $\mathrm{pH}$ 6.5. This value is close to that observed for free CoP, suggesting decreased cofactor stability for this mutant. In a related approach, $\mathrm{CoP}$ was introduced into the well-characterised electron transfer protein cytochrome $b_{562}$ $\left(\right.$ Cyt $\left.b_{562}\right) \cdot{ }^{128}$ This cofactor substitution resulted in a modest catalyst for photo-induced proton reduction. However, mutating Met7, which potentially blocks the catalyst via axial coordination to the Co ion, resulted in a 2.5 fold increase in the TON. The activity of this new artificial enzyme is close to the activity determined for the CoP-myoglobin system assayed under the same conditions. Another cobalt-substituted cytochrome system was prepared by Bren and co-workers (vide infra, Ht c-552, Fig. 14). Under constant potential electrolysis the resulting artificial enzyme is capable of achieving a very high TON (>270 000) operating at an overpotential of $830 \mathrm{mV} .^{129}$

Sperm-whale myoglobin (SwMb) has also been utilized as a host for cobalt based proton reduction catalysts. Artero and co-workers reported on the incorporation of two cobaloxime derivatives, $\mathrm{Co}(\mathrm{dmgH})_{2}(2)$ and $\mathrm{Co}\left(\mathrm{dmgBF}_{2}\right)_{2}$ (3) $\left(\mathrm{dmgH}_{2}=\right.$ dimethyl-glyoxime; Fig. 11b), into the cavity of an apomyoglobin. ${ }^{130}$ In-depth spectroscopic investigations of these biohybrids clearly indicate cobaloxime insertion in the cavity, most probably through the coordination of His93 to the cobalt centre, as further supported by docking calculations. Cyclic voltammograms recorded at neutral $\mathrm{pH}$ have established that a low overpotential $(200 \mathrm{mV})$ is required to evolve $\mathrm{H}_{2}$. Chemical reduction (using $\mathrm{Eu}$ (II) complexes at $\mathrm{pH} 7$ ) $^{131,132}$ and photocatalytic assays ( $\mathrm{pH}$ 6) showed the ability of both bio-hybrids to reduce water to hydrogen $\left(\mathrm{TON}_{\mathrm{CR}}=0.3-3.2 / \mathrm{TON}_{\text {Рното }}=3-3.8\right)$, the catalytic performances being similar to the values reported for the free cobaloxime derivatives under similar conditions. The authors suggested that the $\mathrm{Co}(\mathrm{III})$-hydride generated during the course of the catalytic cycle is quickly deactivated through an intramolecular hydride transfer to the glyoximato ligand, thus leading to the loss of activity. ${ }^{133}$ In order to overcome this fast deactivation, two analogous heme-binding protein scaffolds providing a similar cavity, but with slightly different binding environments, have also been explored. ${ }^{134}$ Under optimal conditions, hydrogen evolution was enabled at neutral $\mathrm{pH}$ with a 3-fold increase of the TON compared to the isolated cobaloxime.

Cobaloxime catalysts have also been investigated in combination with electron transfer proteins, namely a ferredoxin and an apo-flavodoxin (Fig. 11b and c). ${ }^{137,138}$ These two proteins have previously been re-engineered to provide them with light-harvesting properties, through the covalent binding of a $\left[\mathrm{Ru}(\mathrm{bpy})_{3}\right]$ derivative $\left(\left[\mathrm{Ru}\left(4-\mathrm{CH}_{2} \mathrm{Br}-4^{\prime}-\mathrm{CH}_{3}-2,2^{\prime} \text {-bpy }\right)(\mathrm{bpy})_{2}\right]^{2+}\right)$. In both cases, self-assembly of the protein with a cobalt catalyst was achieved (Ru-Fd-Co, 4, Fig. 11c and Ru-apoFld-Co, 5 biohybrids), providing efficient photocatalytic assemblies for proton reduction in aqueous medium. The electron transfer from the photosensitizing unit to the catalytic moieties has been investigated by EPR and ultrafast spectroscopies. When the distance is short enough (10.2 $\AA$ ), as in the case of flavodoxin, direct ET from the reduced photosensitizer (PS) to the catalyst can occur. However, when the distance between the two partners is increasing (16 ̊), as in the case of ferredoxin, an 
intermediate $[2 \mathrm{Fe}-2 \mathrm{~S}]$ cofactor is needed to achieve efficient ET. ${ }^{138}$

A similar biohybrid based on a typical Dubois catalyst $\left[\mathrm{Ni}\left(\mathrm{P}_{2}{ }^{\mathrm{Ph}} \mathrm{N}_{2}{ }^{\mathrm{Ph}}\right)_{2}\right]\left(\mathrm{BF}_{4}\right)_{2}(6)^{139}$ and a previously described $\mathrm{Ru}-\mathrm{Fld}$ system has been prepared. ${ }^{140}$ Again, this assembly is able to perform photo-induced proton reduction over a wide $\mathrm{pH}$ range (from 3.5 to 12). Notably, a maximum TOF of $410 \mathrm{~h}^{-1}$, associated with a TON of 620 , can be reached at $\mathrm{pH}$ 6.2. A rather longlived separated charge state of $20 \mathrm{~ms}$ was identified, suggesting a crucial role played by the protein to support and protect relevant catalytic intermediates in an aqueous environment.

Photocatalytic $\mathrm{H}_{2}$ production using biomimetic synthetic diiron carbonyl moieties coupled to a non-hydrogenase protein matrix either by dative anchoring or by covalent linkage has also been investigated. The specific amino acid sequence -CXXC-, found in the pocket of apo-cytochrome c, has been used as an anchoring group for the diiron nonacarbonyl precursor $\left[\mathrm{Fe}_{2}(\mathrm{CO})_{9}\right]$, thus allowing the formation of a $\left[\left(\mu-\mathrm{S}_{2}\right) \mathrm{Fe}_{2}(\mathrm{CO})_{6}\right]$ motif mimicking the $[2 \mathrm{Fe}]$ subsite of $[\mathrm{FeFe}]$ hydrogenases. ${ }^{141}$ Under photocatalytic conditions in aqueous medium ( $\mathrm{pH} 4.7)$, $\mathrm{H}_{2}$ production was evidenced (up to $80 \mathrm{TON}$ ). In contrast, when a smaller heptapeptide having the same-CXXC- sequence was used, $\mathrm{H}_{2}$ production was found to decrease dramatically, providing an example of the importance of catalyst isolation for efficient (photo-)catalysis. Similarly, the photo-induced hydrogen generation of an engineered apo-nitrobindin (apo$\mathrm{NB})$ containing a $[2 \mathrm{Fe}]$ subsite model, $\left\{\mu-\left(\mathrm{SCH}_{2}\right)_{2} \mathrm{CHCOR}\right\}$ $\left.\mathrm{Fe}_{2}(\mathrm{CO})_{6}\right](7, \mathrm{R}=2$-(2,5-dioxo-2,5-dihydro-1 $\mathrm{H}$-pyrrol-1-yl)ethanammonium), covalently linked into its cavity has also been evaluated by Hayashi and co-workers. ${ }^{142}$ This protein presents a rigid $\beta$-barrel structure, where a cysteine residue was introduced (Gln96Cys mutant) into the large internal cavity to allow the coupling with the $[2 \mathrm{Fe}]$ subsite model via the maleimide moiety (Fig. 11d). Photochemical $\mathrm{H}_{2}$ production experiments employing 7-NB reached a maximum turnover of 130 at $\mathrm{pH}$ 4.0. The final TON did not appear to exceed those observed for the
[2Fe] mimic alone. However, 7-NB allowed catalysis in pure aqueous media and displayed a higher initial TOF.

The catalytic performance of the different systems described in this subsection is summarised in Table 2. In short, under photocatalytic and other comparable conditions, the activities reported for these re-purposed proteins are in the same range (TONs ranging from tens to hundreds). Thus, the efficiencies of these artificial systems are still far from the efficiencies of the native enzymes, and reports of artificial hydrogenases capable of performing $\mathrm{H}_{2}$ oxidation are still rare. Still, work during the last decade has firmly established the feasibility of preparing artificial enzymes displaying hydrogenase like-activities, i.e. they are capable of producing $\mathrm{H}_{2}$ in aqueous media under reducing conditions. This forms a solid foundation for further optimization and underscores the importance of optimizing both the catalyst and the binding pocket.

\subsection{Miniaturized enzymes}

As an alternative to the use of proteins, small synthetic peptides appear as a promising route towards affordable and efficient artificial hydrogenases, presenting a well-controlled microenvironment for the metallic active sites.

4.2.1 Biomimetic [FeFe] and [NiFe] models. The first report of a peptide-based model of the [FeFe] hydrogenase active site was published in 2007 by Jones et al. ${ }^{143}$ A diiron carbonyl moiety was coordinated to a -CXXC- motif within a 36 residue helical peptide by treating the peptide with $\left[\mathrm{Fe}_{3}(\mathrm{CO})_{12}\right]$, generating $\mathrm{a}\left[\left(\mu-\mathrm{S}_{2}\right) \mathrm{Fe}_{2}(\mathrm{CO})_{6}\right]$ entity. Although the catalytic properties of the resulting bio-assembly have not been reported, the peptide assembly provides the opportunity to construct water-soluble hydrogenase mimics and allows countless strategies for the design of more sophisticated systems. Using a similar approach, a macrocyclic octapeptide closed by a disulfide bridge between two cysteine residues was used as a scaffold to build a $[2 \mathrm{Fe}]$ subsite model, through reaction with $\left[\mathrm{Fe}_{3}(\mathrm{CO})_{12}\right]^{144}$ Cyclic voltammograms of the self-assembled

Table 2 Properties of catalysts based on re-purposed protein for catalytic production of $\mathrm{H}_{2}$ from aqueous solution ${ }^{a}$

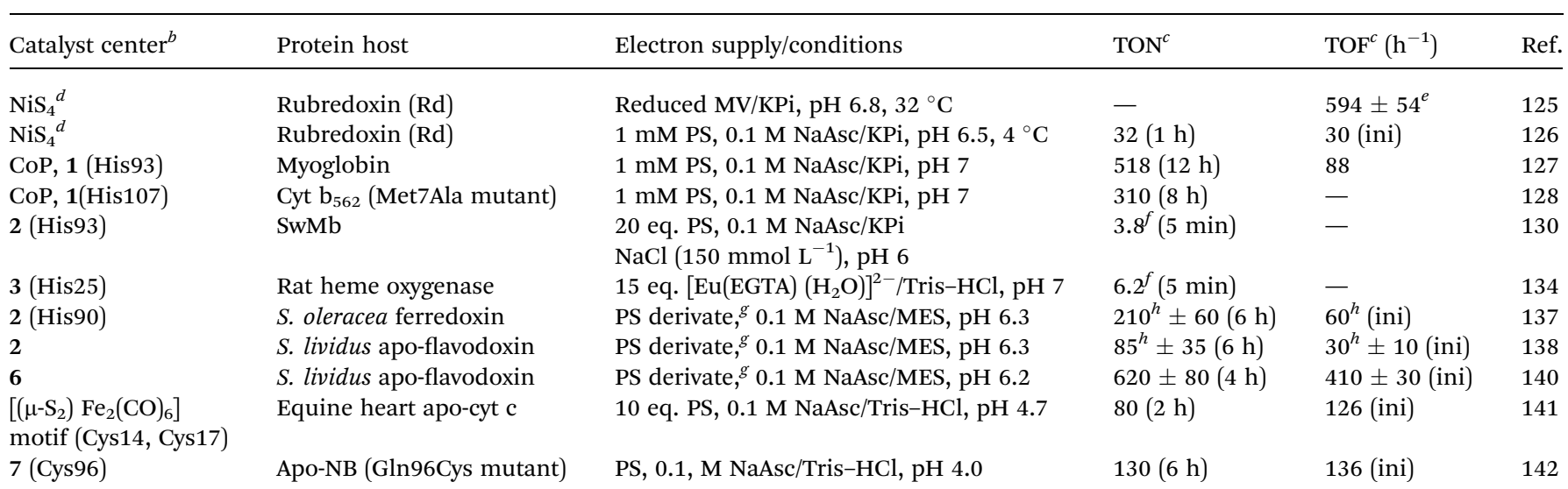

${ }^{a} \mathrm{MV}=$ methyl viologen, $\mathrm{PS}=\left[\mathrm{Ru}(\mathrm{bpy})_{3}\right]^{2+}$, and NaAsc $=$ sodium ascorbate. ${ }^{b}$ In parentheses are the amino acids from the protein host involved in the metal binding. ${ }^{c}$ In parentheses is the duration of the experiment used to determine the corresponding value. ${ }^{d}$ Direct coordination by four Cys from the protein. ${ }^{e}$ nmol per s${ }^{-1}$ per $\mathrm{mg} \mathrm{Rd} .{ }^{f}$ TON is calculated $v s$. the number of introduced cobalt centers. ${ }^{g}$ PS covalently bound to the protein. ${ }^{h}$ TONs and TOFs are calculated $v s$. the number of photosensitizers. 
model demonstrated the capacity of the system to reduce protons to $\mathrm{H}_{2}$ in acidic DMF solution. Analogously, Hayashi et al. used an octadecapeptide (YIGKACGNCHENFRDKEG) derived from cytochrome c-556 as a host associating a $\left[\left(\mu-\mathrm{S}_{2}\right)\right.$ $\left.\mathrm{Fe}_{2}(\mathrm{CO})_{6}\right]$ motif to a ruthenium-based photosensitizing unit (Fig. 12a, 8). ${ }^{\mathbf{1 4 5}}$ Photo-induced hydrogen evolution was achieved with a modest maximum TON of 9 after $2 \mathrm{~h}$ of irradiation. However, no catalytic activity with the analogous bimolecular

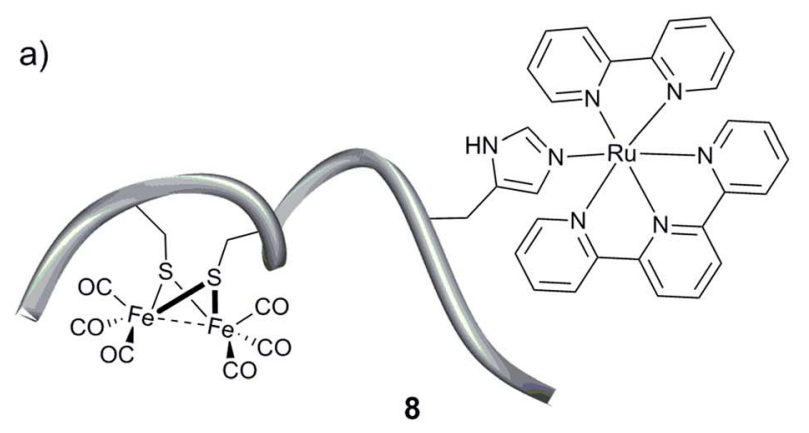

b)

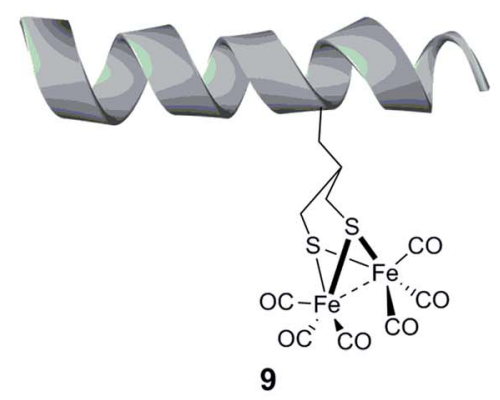

c)

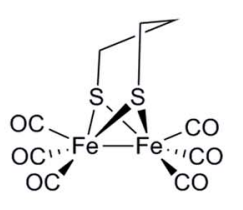

10

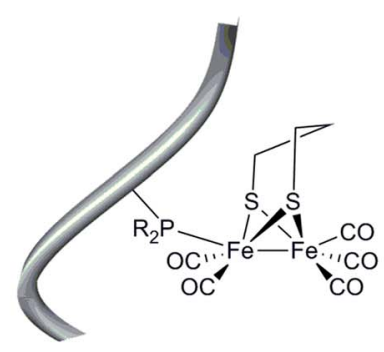

11 d)

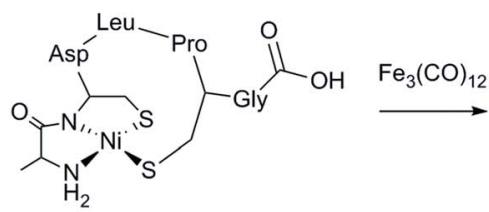

12

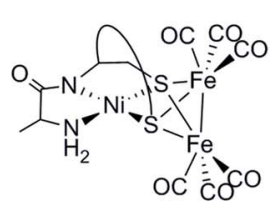

13
Fig. 12 Schematic representation of the (a) cytochrome c-556 fragment containing a $\left[\left(\mu-\mathrm{S}_{2}\right) \mathrm{Fe}_{2}(\mathrm{CO})_{6}\right]$ moiety and a ruthenium-based photosensitizing unit, (b) helical nonadecapeptide containing a $[(\mu-$ $\left.\left.\mathrm{S}\left(\mathrm{CH}_{2}\right)_{3} \mathrm{~S}\right) \mathrm{Fe}_{2}(\mathrm{CO})_{6}\right]$ motif, and (c) peptide containing an unnatural amino acid linked to a $\left[(\mu-p d t) \mathrm{Fe}_{2}(\mathrm{CO})_{6}\right](10)$ complex and (d) formation of a heterobimetallic cluster in a heptapeptide construct. system was observed; the authors attributed this to a more efficient electron transfer from the photo-excited $\mathrm{Ru}$ moiety to the diiron cluster within the peptide matrix.

A second synthetic route to create models even closer to the [FeFe] hydrogenase active site has been explored. Instead of employing cysteine residues present in the peptide sequence to link a diiron carbonyl complex, more engineered peptides relying on the incorporation of an artificial amino acid or postsynthetic modification have been prepared. ${ }^{146,147}$ To that end, a functionalized propanedithiolate ligand $\left(\mathrm{pdt}^{\prime}={ }^{-} \mathrm{S}-\mathrm{CH}_{2}-\right.$ $\mathrm{CHRCH}_{2}-\mathrm{S}^{-}$) was coupled to the amine group of a lysine residue of an octapeptide via amide linkage. Finally, the $\left[\mu-\left(\mathrm{S}-\mathrm{CH}_{2}-\right.\right.$ $\left.\left.\mathrm{CHRCH}_{2}-\mathrm{S}\right) \mathrm{Fe}_{2}(\mathrm{CO})_{6}\right]$ motif was generated by reaction of the $\left[\mathrm{Fe}_{3}(\mathrm{CO})_{12}\right]$ precursor with the pdt'-containing peptide. While the spectroscopic data indicate the incorporation of the $[2 \mathrm{Fe}]$ subsite into the peptide, the catalytic properties of the resulting bio-hybrid assembly have not been reported. ${ }^{\mathbf{1 4 6}}$ In a related approach, Ghirlanda et al. described the introduction of a nonnatural amino acid bearing a 1,3-dithiol moiety into a helical nonadecapeptide, followed by generation of the $\left[\mu-\left(\mathrm{S}-\mathrm{CH}_{2}-\right.\right.$ $\left.\left.\mathrm{CHRCH}_{2}-\mathrm{S}\right) \mathrm{Fe}_{2}(\mathrm{CO})_{6}\right]$ motif within the peptide (Fig. 12b, 9). ${ }^{\mathbf{1 4 7}}$ Both photocatalytic and electrocatalytic properties towards proton reduction in water for this miniaturized hydrogenase have been demonstrated.

Phosphines are well-known $\sigma$-donor and $\pi$-acceptor ligands and have been extensively used in the context of [FeFe] hydrogenase models. ${ }^{\mathbf{1 1 , 1 4 8}}$ Such a functionality has been introduced into small peptides through two different pathways. ${ }^{\mathbf{1 4 9}}$ The resulting phosphine-functionalized peptides were able to react with a $[(\mu-$ pdt) $\left.\mathrm{Fe}_{2}(\mathrm{CO})_{6}\right]$ complex (pdt $\left.={ }^{-} \mathrm{S}-\left(\mathrm{CH}_{2}\right)_{3}-\mathrm{S}^{-}\right)$(Fig. 12c, 10) via the substitution of a CO ligand (Fig. 12c, 11). This ligand exchange generates an electrocatalyst for $\mathrm{H}_{2}$ production, which however suffers from a large overpotential requirement ranging between 0.75 and $0.9 \mathrm{~V}$ in acid-containing acetonitrile.

Among the rare examples of [NiFe]-hydrogenase active site biomimics, Jones et al. investigated the use of a small heptapeptide as a scaffold to coordinate both nickel and iron ions. ${ }^{\mathbf{1 5 0}}$ The amino acid sequence used in this work is well known to bind a mononuclear Ni(II) in a square-planar $\mathrm{N}_{2} \mathrm{~S}_{2}$ environment. After incorporation of the nickel ion into the peptide, the Nicontaining peptide (Fig. 12d, 12) was exposed to a solution of $\left[\mathrm{Fe}_{3}(\mathrm{CO})_{12}\right]$. A polynuclear compound, containing two iron and one nickel ions, was then isolated, where the sulfur atoms are the anchoring sites of the iron, forming bridges between the $\mathrm{Ni}$ centre and the iron carbonyl fragments $\left[\left(\mu-\mathrm{S}_{2}\right) \mathrm{Fe}_{2}(\mathrm{CO})_{6}\right]$ (Fig. 12d, 13). The catalytic activity of this hetero-metallic compound has not been reported.

4.2.2 Bioinspired nickel and cobalt models. The possibility to improve the performance of molecular catalysts via manipulations of the second coordination sphere has been extensively studied by Shaw and co-workers. Their work has focused on modifications of a class of highly efficient bio-inspired catalysts with the general formula: $\left[\mathrm{Ni}\left(\mathrm{P}^{\mathrm{R}}{ }_{2} \mathrm{~N}^{\mathrm{R}^{\prime}}{ }_{2}\right)_{2}\right]$, often referred to as the Dubois catalyst. ${ }^{\mathbf{1 9}, 139,151-153}$ Key studies in the context of this review include the preparation of single amino acid derivatives, $\left[\mathrm{Ni}\left(\mathrm{P}_{2}^{\mathrm{Cy}} \mathrm{N}_{2}^{\text {amino-acid }}\right)_{2}\right]^{n+}$ (Fig. 13, 14, $n$ being dependent on the amino acid introduced), where the amino acid was directly 
incorporated into the diphosphine ligand framework through the pendant amine to generate a two-component proton channel. ${ }^{154-158}$ Notably, the complex containing arginine (Fig. 13, 15) showed the fastest $\mathrm{H}_{2}$ oxidation for a homogenous electrocatalyst reported to-date with a TOF of $1.1 \times 10^{6} \mathrm{~s}^{-1}$
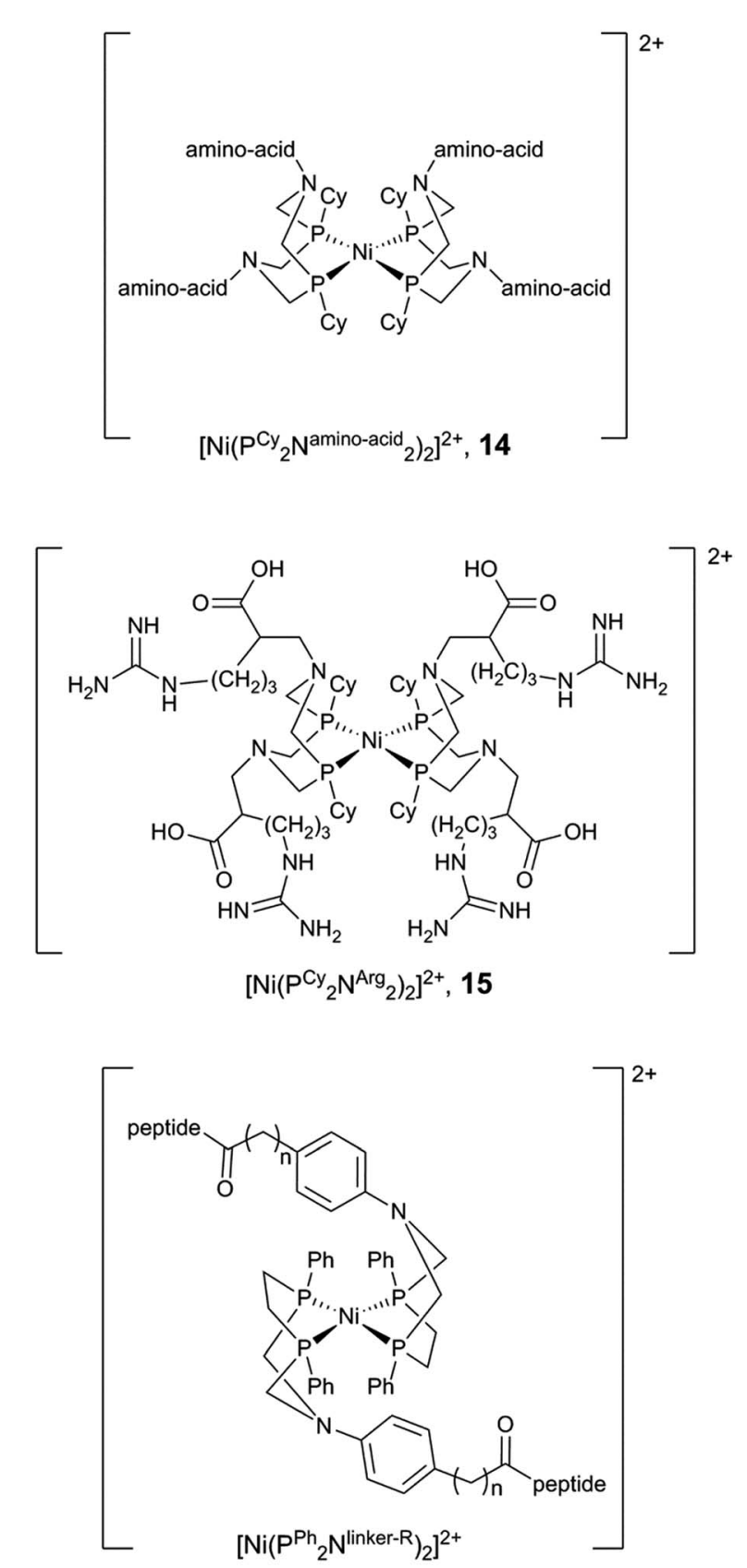

Linker $=4$-amino benzoic acid $(n=0)$, 4-aminophenyl propionic acid (APPA, $n=2$ )

peptide $=$

WIPPRWTGPR-NH $\mathrm{N}_{2}$ (WR10), $\mathrm{n}=2,16$

WIpKKWTG-NH $\mathrm{N}_{2}(\mathrm{~K} 8), \mathrm{n}=2,17$

WIPKKWTGPK-NH $\mathrm{H}_{2}(\mathrm{~K} 10), \mathrm{n}=0,18$

WIPKKWTG-NH $\mathrm{N}_{2}(\mathrm{~K} 8), \mathrm{n}=0,19$

Fig. 13 Schematic representation of mononuclear nickel complexes bearing functionalized $P_{2}^{R} N_{2}^{R \prime}$ ligands. operating at $240 \mathrm{mV}$ overpotential $\left(348 \mathrm{~K}, 100\right.$ atm $\mathrm{H}_{2}$, in acidic aqueous solution $\mathrm{pH}$ 1.0). ${ }^{157}$

Moreover, the influence of peptide mobility was explored by adding larger and more constrained peptide moieties. To that end, a $\beta$-hairpin peptide WIpPRWTGPR-NH H $_{2}$ (WR10, $\mathrm{p}=$ D-proline) was attached via an aminophenyl propionic acid (APPA) linker, producing the $\left[\mathrm{Ni}\left(\mathrm{P}_{2}^{\mathrm{Ph}} \mathrm{N}^{\mathrm{APPA}-\mathrm{WR} 10}\right)_{2}\right]^{2+}$ complex (Fig. 13, 16). ${ }^{159}$ NMR and CD spectroscopy studies suggest that the incorporation of the decapeptide into the parent complex does not affect the peptide structure, and the peptide construct displays a modest increase in electrocatalytic $\mathrm{H}_{2}$ production as compared to the parent compound $\left(\left[\mathrm{Ni}\left(\mathrm{P}_{2}^{\mathrm{Ph}} \mathrm{N}^{\mathrm{APPA}}\right)_{2}\right]^{2+}\right.$, Fig. 13). The structure/activity relationship has been investigated further, and the length of the linker (between the phenyl ring and the peptide) as well as the peptide have been varied. ${ }^{\mathbf{1 6 0}}$ The octapeptide $\left[\mathrm{Ni}\left(\mathrm{P}_{2}^{\mathrm{Ph}} \mathrm{N}^{\text {APPA-K8 }}\right)_{2}\right]^{2+} \quad\left(\mathrm{K} 8=\right.$ WIpKKWTG-NH $\mathrm{N}_{2}$, Fig. 13, 17) shows a 2.5 -fold current increase compared to the parent compound $\left(\left[\mathrm{Ni}\left(\mathrm{P}_{2}^{\mathrm{Ph}} \mathrm{N}^{\mathrm{APPA}}\right)_{2}\right]^{2+}\right)$, operating at the same overpotential as the decapeptide $(\mathbf{1 6}, 540 \mathrm{mV})$. The decrease of the linker length from three to one carbon atom (Fig. 13, 18, 19) led to a reduction in the mobility of the peptide but had a negative impact on the catalytic current for both the octa- and the decapeptide.

Bren and co-workers have prepared and studied the $\mathrm{H}_{2}$ evolution properties in water of a series of cobalt-based artificial hydrogenases by constant potential electrolysis (CPE). A small tripeptide model (CoGly-Gly-His, 20, Fig. 14) based on the copper- and nickel-binding (ATCUN) motif found at the $\mathrm{N}$ terminus of albumins was shown to evolve $\mathrm{H}_{2}$, reaching 275 TON after $2.5 \mathrm{~h}$ of $\mathrm{CPE}$ at near neutral $\mathrm{pH}$ with an $\sim 600 \mathrm{mV}$ overpotential. ${ }^{\mathbf{1 6 1}}$

A Co-porphyrin based system was prepared via metal substitution of the Fe-ion in the heme-undecapeptide MP11 (CoMP11, 21, Fig. 14). MP11, which is derived from horse cytochrome c, features a porphyrin ligand covalently linked to the peptide fragment and provides an additional axial histidine ligand to the metal centre, leaving an open coordination site. CoMP11, 21, showed efficient $\mathrm{H}_{2}$ production with a TON of over 20000 after $4 \mathrm{~h}$ and a surprisingly high tolerance towards $\mathrm{O}_{2}$. However, the maximum current was observed at an overpotential of $852 \mathrm{mV}$, i.e. significantly higher than that of the ATCUN-based system (20). Furthermore, the electrocatalytic activity started to decline after 15 min (active for a few hours in total), suggesting degradation of the catalyst. ${ }^{\mathbf{1 6 2}}$

To overcome the weaknesses encountered with the previous constructs (e.g. peptide flexibility, catalyst exposure to the solvent and fast degradation), a cobalt-substituted cytochrome c-552 system was prepared (Ht-Co, 22, Fig. 14). ${ }^{129}$ Importantly, the active site was improved for $\mathrm{H}^{+}$reduction: methionine involved in the coordination of the native heme-Fe ion was removed in order to open up a site for catalysis (Fig. 14). The resulting artificial enzyme is capable of achieving a very high TON (>270 000), and with an increased longevity, the catalytic activity showed minimal decline over $\sim 6 \mathrm{~h}$ (active for $24 \mathrm{~h}$ in total). Despite this clear improvement, the overpotential stayed nearly unchanged $(830 \mathrm{mV})$. This series of artificial enzyme assemblies nicely exemplify that burying a catalytic site within 
a)<smiles>O=C([O-])C(Cc1c[nH]cn1)N1CCN2C(=O)CNC21</smiles>

CoGly-Gly-His, CoATCUN, 20

b)

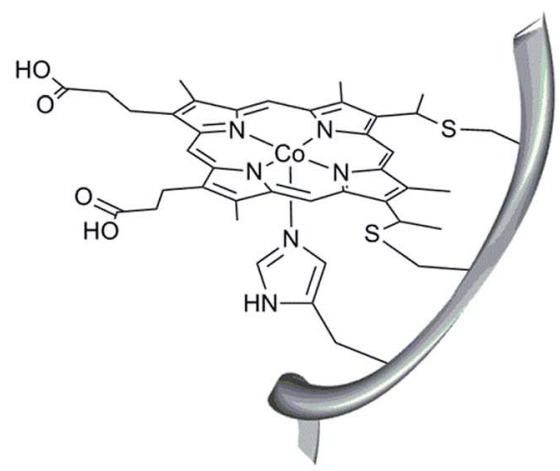

Acetylated cobalt microperoxidase-11, CoMP11-Ac, 21

c)

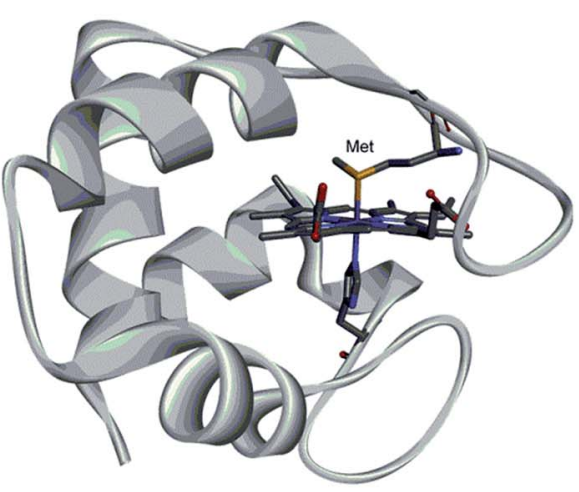

Ht c-552, 22

Fig. 14 Schematic representation of CoGly-Gly-His (COATCUN, 20) and CoMP11-Ac, 21, and the structure of cytochrome c-552 (PDB ID: $1 Y N R)^{163}$ (Ht c-552, 22 also showing the native Met-ligand).

a protein matrix can enhance longevity, but does not necessarily affect the overpotential.

The catalytic properties of miniaturized hydrogenases discussed in this section are summarized in Table 3. A direct comparison is complicated by the different conditions in which the systems are evaluated. Still, both complexes $\mathbf{1 6}$ and $\mathbf{2 1}$ nicely highlight the improvements in both the TOF and the TON that can be achieved via manipulations of the microenvironment of molecular catalysts.

\subsection{Artificial active site pockets}

Incorporation of $[\mathrm{FeFe}]$ hydrogenase active site models into non-biological environments, like polymer matrices, micelles, the hydrophobic cavity of cyclodextrins, or metal-organic frameworks (MOFs), has been developed to realize photocatalytic and electrochemical $\mathrm{H}_{2}$ production in water. These various entities are believed to be capable of mimicking the hydrophobic cavity and the hydrogen bonding sites of the native hydrogenases. In most of the examples reported, incorporation of hydrogenase model complexes into e.g. peptide hydrogels, ${ }^{164}$ micelles ${ }^{165-167}$ or the backbone and side chains of polymers ${ }^{168-171}$ has been shown to keep or enhance the stability and the reactivity of the complex. In the following section we will discuss representative examples.

4.3.1 Polymer matrix/resin. A series of [2Fe] subsite mimics with the general structure $\left[(\mu-\mathrm{SRS}) \mathrm{Fe}_{2}(\mathrm{CO})_{5} \mathrm{X}\right]\left(\mathrm{X}=\mathrm{CO}\right.$ or $\left.\mathrm{PR}_{2}{ }_{2} \mathrm{R}^{\prime \prime}\right)$ have been successfully immobilized on TentaGel resin beads (polyethyleneglycol-rich polystyrene), a material which features cavities and solvent accessible channels. ${ }^{172}$ Unfortunately, rather than enhancing the stability, the resin environment facilitated CO ligand loss and degradation under photochemical or acidic conditions.

Conversely, when a similar complex was coupled with poly (acrylic acid) (PAA) via an isocyanide ligand $\left[(\mu-\mathrm{pdt}) \mathrm{Fe}_{2}(\mathrm{CO})_{5}\right.$ (CNR)] ( $\mathrm{R}=$ diphenylacetylene linker, Fig. 15, 23), the resulting water-soluble polymer catalyst displayed very efficient photocatalytic properties. ${ }^{173}$ Photocatalytic $\mathrm{H}_{2}$ production in water, in the presence of stabilized CdSe quantum dots (QDs) (MPA-CdSe QDs, MPA = 3-mercaptopropionic acid) as a photosensitizer, resulted in an excellent TON of 27135 after $8 \mathrm{~h}$ irradiation. Importantly, this study demonstrated that, aside from solubilizing the diiron mimic, the polymer seems to play a role in protecting CdSe QDs from photo-corrosion and aggregation and ensuring close proximity between the photosensitizer and the catalyst, making the system more efficient. In a similar approach, when polyethylenimine (PEI) is used, the system is photoactive in a broad range of $\mathrm{pH}$, including neutral conditions. ${ }^{174}$

In 2013, a system consisting of an iron-thiolate catalyst [ $(\mu-$ $\left.\left.\mathrm{S}_{2}\right) \mathrm{Fe}_{2}(\mathrm{CO})_{6}\right]$ protected by a dendritic framework achieved a TON of 22000 in $8 \mathrm{~h}$, under photocatalytic conditions in the presence of an Ir-based photosensitiser. ${ }^{175}$ Interestingly, the TOF and total TON values of the system increased with the size of the dendritic structure, highlighting the effect of site isolation.

4.3.2 Oligosaccharides/polysaccharides. Using a supramolecular approach, Darensbourg et al. reported the first inclusion of a diiron model inside discrete supramolecular hosts, cyclodextrins. ${ }^{176}$ Cyclodextrins are cyclic oligosaccharides, consisting of 6-8 glucose units (denoted as $\alpha$-cyclodextrins, $\beta$-cyclodextrins and $\gamma$-cyclodextrins, respectively). The bridgehead nitrogen atom of a $[2 \mathrm{Fe}]$ subsite mimic was modified by an aryl sulfonate group required for the incorporation into $\beta$-cyclodextrins (24, Fig. 16). The resulting assembly has been structurally and electrochemically characterised, showing that the insertion into the cyclodextrin affects the redox and the electrocatalytic properties of the diiron moiety. Follow-up studies have explored the incorporation of substituted $[2 \mathrm{Fe}]$ subsite models featuring phosphine ligands, but unfortunately their electrochemical proton reduction abilities seem to be hindered rather than facilitated, compared to the isolated parent diiron compounds. ${ }^{177}$

Similar systems have also been explored under photocatalytic conditions. Introducing a sulfonate-functionalized 
Table 3 Properties of catalysts based on small peptide sequences for catalytic production of $\mathrm{H}_{2}$ from aqueous solution ${ }^{a}$

\begin{tabular}{|c|c|c|c|c|c|}
\hline Catalyst center & Peptide host & Electron supply/conditions (overpotential) & $\mathrm{TON}^{b}$ & $\operatorname{TOF}^{b}\left(\mathrm{~s}^{-1}\right)$ & Ref. \\
\hline$\left[\left(\mu-\left(\mathrm{S}-\mathrm{CH}_{2} \mathrm{CHRCH}_{2}-\mathrm{S}\right)\right) \mathrm{Fe}_{2}(\mathrm{CO})_{6}\right]$ & 9 & 15 eq. PS, $0.05 \mathrm{M} \mathrm{NaAsc/citrate} \mathrm{buffer,} \mathrm{pH} 4.5$ & $84(2.3 \mathrm{~h})$ & - & 147 \\
\hline 15 & 15 & EC (CV)/GC electrode, $348 \mathrm{~K}, 1 \mathrm{~atm}\left(\mathrm{~N}_{2}\right), \mathrm{H}_{2} \mathrm{O}, \mathrm{pH} 6$ & - & $21 \pm 5 \%$ & 156 \\
\hline$\left[\mathrm{Ni}\left(\mathrm{P}_{2}^{\mathrm{Ph}} \mathrm{N}^{\mathrm{APPA}-\mathrm{WR} 10}\right)_{2}\right]^{2+}$ & WR10 16 & $\begin{array}{l}\mathrm{EC}(\mathrm{CV}) / \mathrm{GC} \text { electrode, } \mathrm{CH}_{3} \mathrm{CN}: \mathrm{H}_{2} \mathrm{O}(90: 10) \\
\text { acidic DMF }(540 \mathrm{mV})\end{array}$ & - & 106000 & 159 \\
\hline 21 & MP11-Ac 21 & EC (CPE)/Hg pool electrode, KPi, pH 7 (852 mV) & $25000(4 \mathrm{~h})$ & $6.7(10 \mathrm{~m})$ & 162 \\
\hline 22 & $\begin{array}{l}\text { Ht c-552 } \\
\text { (Met61Ala) } \\
\text { mutant) } 22\end{array}$ & $\mathrm{EC}(\mathrm{CPE}) / \mathrm{Hg}$ pool electrode, $\mathrm{KPi}, \mathrm{pH} 7(830 \mathrm{mV})$ & $11000(6 \mathrm{~h})$ & - & 129 \\
\hline
\end{tabular}

${ }^{a} \mathrm{EC}=$ electrochemistry, $\mathrm{CV}=$ cyclic voltammetry, $\mathrm{CPE}=$ constant potential electrolysis, $\mathrm{GC}=$ glassy carbon, ini $=$ initial, $\mathrm{Ppa}=N$-Boc-3(diphenylphosphorothioyl)alanine. ${ }^{b}$ In parentheses is the duration of the experiment used to determine the corresponding value. ${ }^{c}$ Directly coordinated by the His10.

diiron-thiolate catalyst and a xanthene dye (eosin $\mathrm{Y}$ or rose Bengal) into the hydrophobic cavity of cyclodextrin resulted in a substantial increase in the lifetime (3-fold) and TON (9-fold, up to 75) of the resulting photocatalytic system in a basic aqueous solution. ${ }^{178}$ A more dramatic improvement is observed with chitosan, a polysaccharide which contains primary amines and hydroxyl groups. When protonated, chitosan is able to interact with the $[2 \mathrm{Fe}]$ subsite model $\left[\mu-\left(\mathrm{SCH}_{2}\right)_{2} \mathrm{NCH}_{2} \mathrm{C}_{6} \mathrm{H}_{5}-\right.$ $\left.\mathrm{Fe}_{2}(\mathrm{CO})_{6}\right]$ (25) and the PS MPA-CdsTe QDs. ${ }^{179}$ Photocatalytic activities were demonstrated in a methanol : water $1: 3(\mathrm{v} / \mathrm{v})$ mixture, in the presence of ascorbic acid $\left(\mathrm{H}_{2} \mathrm{~A}\right)$. Under optimized conditions, the supramolecular assembly can achieve

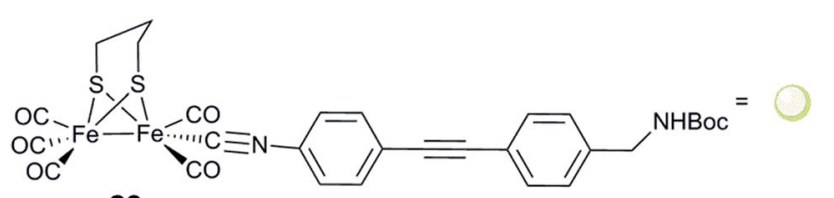

23
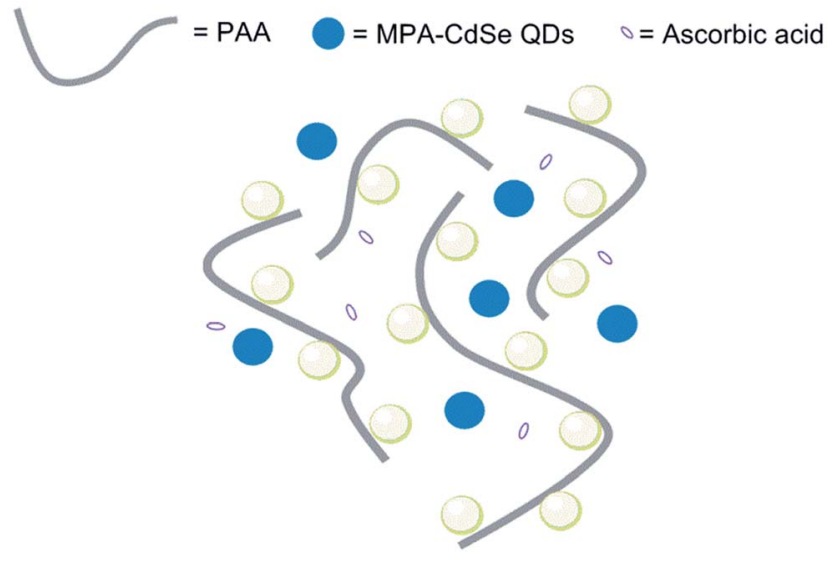

Fig. 15 Schematic representation of an artificial system for photocatalytic $\mathrm{H}_{2}$ production, including $\left[(\mu-\mathrm{pdt}) \mathrm{Fe}_{2}(\mathrm{CO})_{5}(\mathrm{CNR})\right]$ isocyanide complexes. 23, linked to a water soluble PAA polymer and MPA-CdSe QDs. a TON of up to 52800 and a TOF of $1.40 \pm 0.22 \mathrm{~s}^{-1}$, and outperforms the diiron compound without chitosan in terms of both activity and stability.

4.3.3 Micelle systems. In 2010, the water insoluble [2Fe] subsite mimic $\mathbf{1 0}$ and a rhenium photosensitizer were incorporated into sodium dodecyl sulfate (SDS) micelles. ${ }^{\mathbf{1 6 5 , 1 6 6}}$ Under
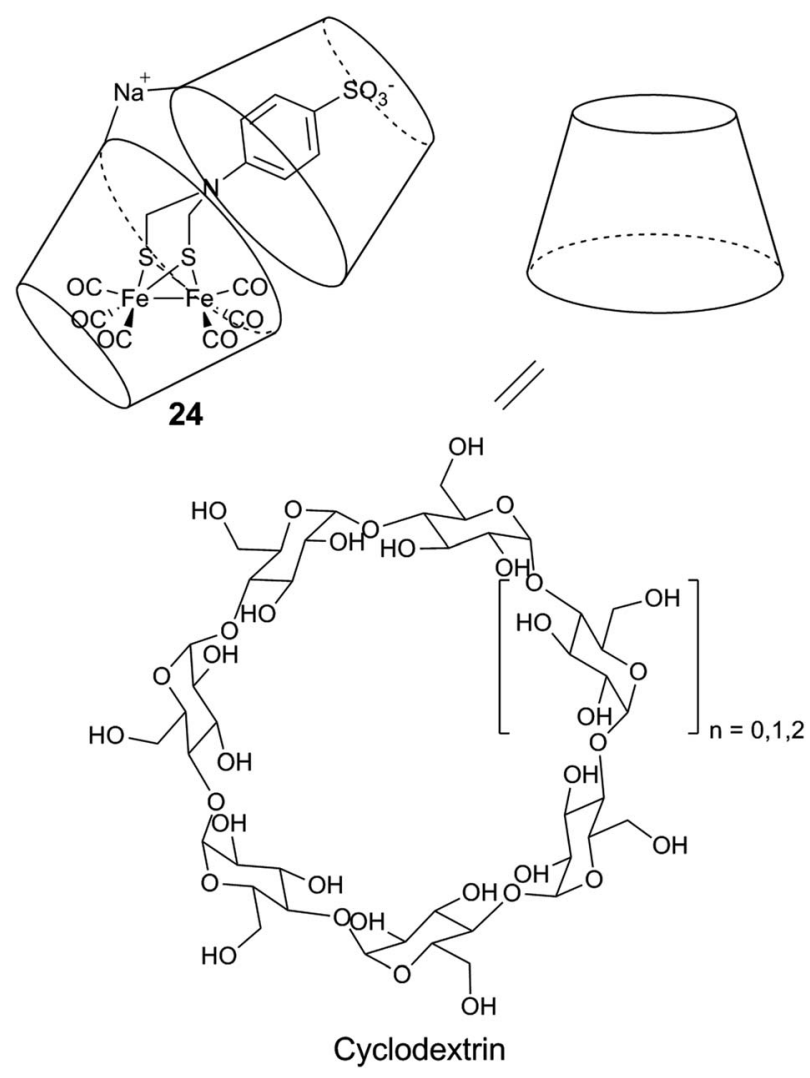

Fig. 16 Schematic representation of a diiron mimic encapsulated in a cyclodextrin unit, and the structure of the $\alpha(n=0), \beta(n=1)$, and $\gamma(n$ $=2$ ) cyclodextrin units. 
photocatalytic conditions, trace amounts of $\mathrm{H}_{2}$ could be detected when all the three components were present. More recently, the same group reported the use of amphiphilic polymeric micelles (P-NB) as microreactors to load 10, as a catalyst for $\mathrm{H}_{2}$ evolution in the presence of a photosensitizer $\left[\mathrm{Ru}(\mathrm{bpy})_{3}\right]^{2+}$ and $\mathrm{H}_{2} \mathrm{~A}$ as an electron and proton source. ${ }^{180}$ The self-assembled system was able to produce $\mathrm{H}_{2}$ in aqueous media (133 TON). The enhanced catalytic properties were attributed to the increase of local concentrations of the photosensitizer and the catalyst in the micelles. The same strategy was used with the water insoluble $\left[(\mu\right.$-bdt $\left.) \mathrm{Fe}_{2}(\mathrm{CO})_{6}\right](\mathbf{2 6}$, bdt $=$ benzenedithiolate). ${ }^{\mathbf{1 8 1}}$ The electrochemical properties of this system were investigated in neutral and acidic water. In particular, $\mathrm{H}_{2}$ production was confirmed by $\mathrm{CPE}$ at $\mathrm{pH} 3$, with a maximum TON of 52 obtained at a relatively low overpotential $(<0.5 \mathrm{~V})$. A similar approach was used with $\left[(\mu\right.$-bdt $\left.) \mathrm{Fe}_{2}(\mathrm{CO})_{4}\left\{\mathrm{P}(\mathrm{OMe})_{3}\right\}_{2}\right]$ (27), leading to an electrocatalytically active catalyst in aqueous micellar solution. ${ }^{167}$ Similar systems, including 26, 27 and $[(\mu-$ bdt $\left.)_{F_{2}}(\mathrm{CO})_{5}\left\{\mathrm{P}(\mathrm{OMe})_{3}\right\}\right]$ (28), were further investigated for visible light-driven $\mathrm{H}_{2}$ production in water with organic dyes (rose Bengal and eosin Y). Complex 26 showed the best photocatalytic abilities for $\mathrm{H}_{2}$ production in aqueous SDS solutions at pH 10.5 (117 TON in $4.5 \mathrm{~h}$ ), in combination with eosin Y. It was shown that $\mathrm{H}_{2}$ production capacities of these systems depend directly on the amplitude of the driving force for electron transfer from the triplet state of the xanthene dye to the ironthiolate catalyst. ${ }^{\mathbf{1 8 2}}$ Recently, Hunt et al. evaluated the effect of encapsulating 10, into dodecyltrimethylammonium bromide (DTAB) micelles, employing IR absorption spectroscopy, an ultrafast IR pump-probe, and 2D-IR spectroscopy. ${ }^{183}$ The data showed that the catalytic subsite can be found in two different environments, located either inside the central core of the micelle in a heptane-like solution or toward the edge of the micelle where water molecules might penetrate the length of the alkyl chain of the surfactant molecule. The authors postulated that this access route from the reactant to the catalyst provided by micelles is likely to contribute to the increase of the catalytic rates observed in such systems.
4.3.4 Metal-organic frameworks, MOFs. MOFs offer surface immobilization and an exceptional loading capacity. Additionally, the pores and overall structure of these systems can be designed to generate e.g. 2nd coordination sphere interactions and efficient electron and substrate transfer pathways. Consequently, these systems have been applied for a wide range of catalysis applications, including hydrogen gas production. Diverse strategies to employ MOF-based materials in photochemical hydrogen production have recently been reviewed by Pullen and Ott. ${ }^{\mathbf{1 8 4}}$ Herein, we focus on strategies concerning the incorporation of molecular diiron catalysts into MOF pores.

The highly stable MOF UiO-66(Zr) was used as the host for the $[2 \mathrm{Fe}]$ subsite mimic $\left[(\mu\right.$-dcbdt $\left.) \mathrm{Fe}_{2}(\mathrm{CO})_{6}\right](29$, dcbdt $=1,4$ dicarboxylbenzene-2,3-dithiolate). ${ }^{\mathbf{1 8 5}}$ The molecular catalyst was incorporated into the MOF pores by post-synthetic exchange. The loaded MOF shows an enhanced photo-induced $\mathrm{H}_{2}$ production in the presence of ascorbate and $\left[\mathrm{Ru}(\mathrm{bpy})_{3}\right]^{2+}$ compared to the catalyst itself in aqueous media, in terms of both the initial rate and the overall amount of produced hydrogen. Recently, two CO ligands of hexacarbonyl species 29 have been successfully exchanged with phosphine ligands inside the MOF UiO-66(Zr). ${ }^{186}$ The use of another framework, MIL-101, exhibiting larger pore diameters (29-34 Å), compared to those of UiO-66 (8-11 $)$ ), has been explored. Interestingly, in MIL-101, a larger proportion of the [FeFe] catalysts within the MOF is engaged in photochemical hydrogen production, and the amount of produced hydrogen is proportional to the catalyst loading. ${ }^{187}$ This result shows the importance of the transport channels through the MOF to generate efficient materials for $\mathrm{H}_{2}$ production.

MOF scaffolds featuring dual functionality have also been reported. Feng et al. described a system in which a [2Fe] subsite mimic was coordinated to the Zn-atom of a porphyrin via the coordination of a pyridine-containing dithiolate bridging ligand in a porphyrin-based MOF (Zr-PF-MOF). ${ }^{188}$ This system, combining both a photosensitizer and a hydrogen-evolving catalyst, has shown photoactive $\mathrm{H}_{2}$ production in a slightly acidic buffer, in the presence of $\mathrm{H}_{2} \mathrm{~A}$.

Table 4 Properties of catalysts based on non-biological assemblies for catalytic production of $\mathrm{H}_{2}$ from aqueous solution ${ }^{a}$

\begin{tabular}{|c|c|c|c|c|c|}
\hline Catalyst center & Encapsulation system & Electron supply/conditions & $\mathrm{TON}^{b}$ & $\operatorname{TOF}^{b}\left(\mathrm{~s}^{-1}\right)$ & Ref. \\
\hline 23 & PAA & $\begin{array}{l}\text { MPA-CdSe QDs, } 0.1 \mathrm{M} \mathrm{H}_{2} \mathrm{~A} / \mathrm{H}_{2} \mathrm{O} \text {, pH } 4 \\
\text { (initial) }\end{array}$ & $27135(8 \mathrm{~h})$ & $3.6(30 \mathrm{~m})$ & 173 \\
\hline$\left[\left(\mu-\mathrm{S}_{2}\right) \mathrm{Fe}_{2}(\mathrm{CO})_{6}\right]$ motif & Fréchet-type dendron & {$\left[\operatorname{Ir}(\text { ppy })_{2}(\text { bpy })\right]^{+}$TEA/acetone $/ \mathrm{H}_{2} \mathrm{O}(9: 1)$} & $22000(8 \mathrm{~h})$ & $2.01(1 \mathrm{~h})$ & 175 \\
\hline 24 & Cyclodextrin & 1 eq. eosin $\mathrm{Y}, 10 \mathrm{vol} \% \mathrm{TEA} / \mathrm{H}_{2} \mathrm{O}, \mathrm{pH} 10$ & $75(24 \mathrm{~h})$ & - & 178 \\
\hline 25 & Chitosan & $\begin{array}{l}\text { MPA-CdTe QDs, } 0.2 \mathrm{M} \mathrm{H}_{2} \mathrm{~A} \mathrm{MeOH} / \mathrm{H}_{2} \mathrm{O} \\
(1: 3), \mathrm{pH} 4.5 \text { (initial) }\end{array}$ & $52800(60 \mathrm{~h})$ & $1.4 \pm 0.22$ & 179 \\
\hline 26 & SDS micelle & $\begin{array}{l}\mathrm{EC}(\mathrm{CPE}) / \mathrm{Hg} \text { pool electrode, } 0.045 \mathrm{M} \mathrm{H}_{2} \mathrm{~A} \\
\mathrm{H}_{2} \mathrm{O} \text {, pH } 3(500 \mathrm{mV})\end{array}$ & $52(1 \mathrm{~h})$ & - & 181 \\
\hline 26 & SDS micelle & 2 eq. eosin $\mathrm{Y}, 10$ vol\% $\mathrm{Et}_{3} \mathrm{~N} / \mathrm{H}_{2} \mathrm{O}, \mathrm{pH} 10.5$ & $117(4.5 \mathrm{~h})$ & & 182 \\
\hline
\end{tabular}

${ }^{a} \mathrm{PAA}=$ poly(acrylic acid), MPA $=3$-mercaptopropionic acid, QDs $=$ quantum dots, $\mathrm{PEI}=$ polyethylenimine, $\mathrm{H}_{2} \mathrm{~A}=$ ascorbic acid, and SDS $=$ sodium dodecyl sulfate. ${ }^{b}$ In parentheses is the duration of the experiment used to determine the corresponding value. 
As summarized in Table 4, the encapsulation of [2Fe] subsite mimics generally results in systems with quite remarkable catalytic efficiencies. Unfortunately, in-depth characterisation to explain the enhanced catalytic performances of these embedded catalysts is generally missing. Thus a rationale between the nature of the encapsulation system and the activity is still unclear. This is certainly a challenge that needs to be tackled for future optimisation of the systems. Nevertheless, the work underscores the strong impact of encapsulation on the activity, and this certainly appears as a promising route towards the development of efficient and stable proton reduction catalysts.

\subsection{Summary and outlook}

The preparation of artificial hydrogenases based on insights from biological systems is a promising route towards the construction of new water-soluble, $\mathrm{O}_{2}$-tolerant, stable and efficient catalytic systems. As outlined above, several imaginative strategies have been explored, and a range of both biological and synthetic scaffolds have been tested. In short, synthetic and artificial systems still struggle in comparison to enzymes with regard to over-potential requirements and stability. Still, work to date nicely illustrates how site isolation can greatly enhance both photo- and electrocatalytic rates, as well as the stability of otherwise fragile catalysts. Moreover, the capacity to modulate the reactivity by modifying the catalyst microenvironment has been elegantly proven via ligand design of purely synthetic catalysts, as well as through protein scaffold optimization in hybrid systems.

In summary this suggests that the incorporation of elaborate molecular catalysts into artificial enzyme pockets should provide a route towards efficient, stable and cheap catalysts for $\mathrm{H}^{+} / \mathrm{H}_{2}$ interconversion. Furthermore, such encapsulation should also facilitate the application of these bio-inspired molecular catalysts in technological devices.

\section{Semi-synthetic hydrogenases}

As discussed above, the H-cluster has long served as an inspiration for synthetic chemists in the development of molecular catalysts for the interconversion of protons and $\mathrm{H}_{2} \cdot{ }^{11,189}$ In parallel, biomimetic model compounds have provided valuable insight into the structural and mechanistic details of the enzyme (see for example ref. 190 and 191). In 2013, it was shown how such synthetic complexes can be introduced into the hydrogenase enzyme itself under in vitro conditions, thus providing a direct link between biomimetic chemistry and biology and allowing the manipulation of the enzyme using synthetic chemistry. ${ }^{53,192}$ In the following section, hydrogenases prepared this way will be referred to as "semi-synthetic hydrogenases", reflecting the fact that they consist of a combination of a synthetic cofactor and the native hydrogenase protein scaffold, while differentiating them from the "artificial hydrogenases" discussed above.

\subsection{Artificial maturation of [FeFe] hydrogenases}

The assembly of the $\mathrm{H}$-cluster inside the [FeFe] hydrogenase occurs in at least two discrete steps. The $[4 \mathrm{Fe}-4 \mathrm{~S}]$ cluster is initially constructed by using house-keeping [FeS] cluster machinery, generating $[4 \mathrm{Fe}-4 \mathrm{~S}]_{\mathrm{H}}-\mathrm{HydA} .^{24,193}$ The enzyme is then activated upon delivery of the $[2 \mathrm{Fe}]$ subsite, in a process involving a minimum of three HydA specific maturases, denoted as HydE, HydG and HydF. ${ }^{194-198}$ A precursor of the [2Fe] subsite is assembled on the HydF protein through the activities of HydE and HydG, via a still incompletely characterised process, from where is then transferred to $\mathrm{HydA}^{\mathbf{1 9 9 - 2 0 2}}$ (for a more in-depth overview of the maturation process see e.g. ref. 16, 17, 203 and 204). The exact structure of the [2Fe] subsite precursor bound to HydF is still unknown. Nevertheless, FTIR spectroscopy indicates that this complex shares structural similarities to the $[2 \mathrm{Fe}]$ subsite observed in $\mathrm{HydA},{ }^{199,202}$ and more recently the preparation of semi-synthetic forms of $\mathrm{HydF}$ has provided a more detailed picture (see Section 5.4). In 2013, it was shown how a set of [2Fe] subsite mimics, differing in the nature of the bridgehead atom, could be introduced into HydF to generate artificially, or synthetically, loaded forms of the maturase (X-HydF).$^{53}$ Critically, these semi-synthetic proteins were able to mimic the reactivity of native HydF and transfer

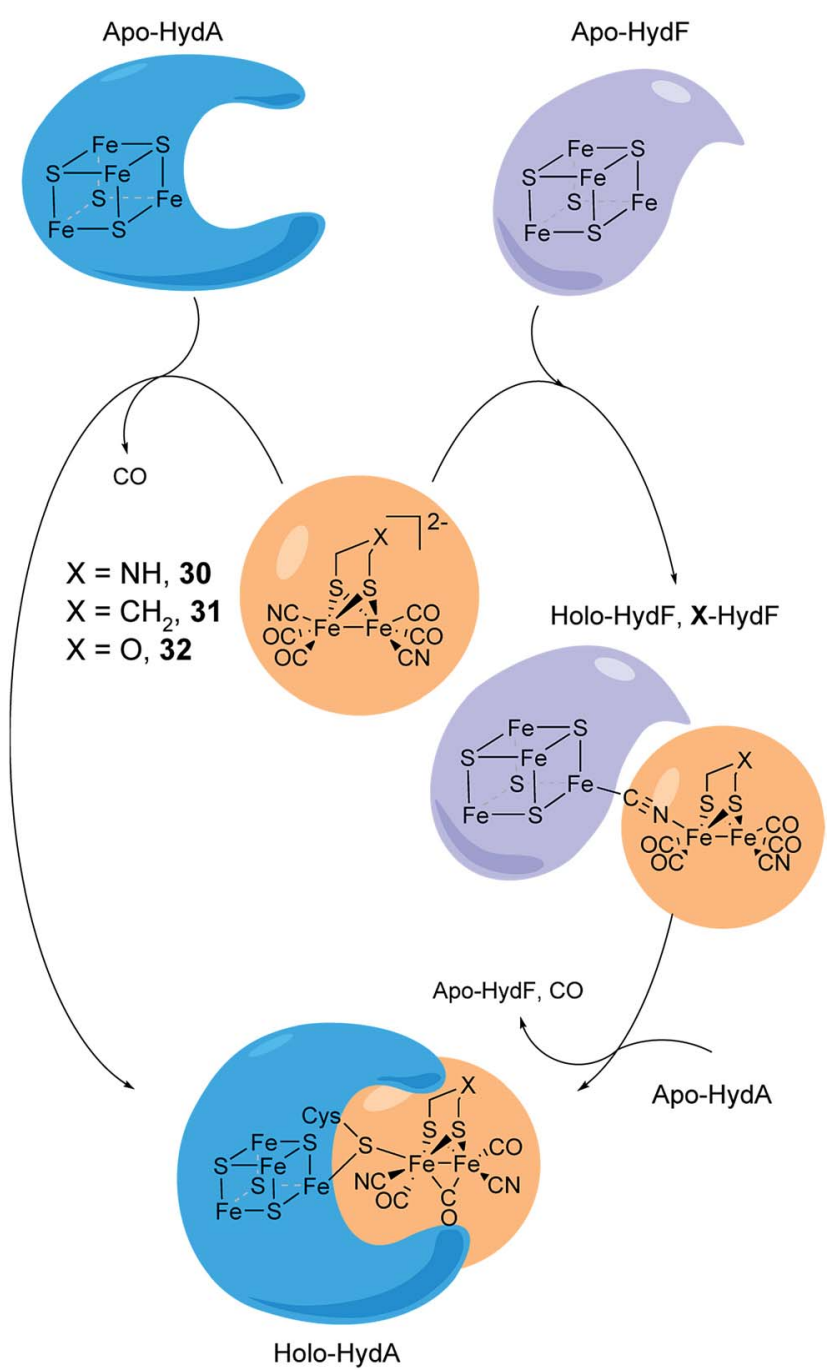

Fig. 17 Schematic representation of artificial maturation of the maturase HydF and the hydrogenase enzyme, HydA. 
their synthetic cargo to [4Fe-4S]-HydA. Shortly thereafter, it was also reported that HydF can be circumvented, and such [2Fe] subsite mimics were directly introduced into HydA (Fig. 17). ${ }^{192}$

An immediate outcome of this finding was that it unequivocally proved the nature of the bridgehead atom as nitrogen, as suggested by earlier spectroscopic studies. ${ }^{\mathbf{5 4 , 1 9 0}}$ The introduction of the $\left[(\mu \text {-adt }) \mathrm{Fe}_{2}(\mathrm{CO})_{4}(\mathrm{CN})_{2}\right]^{2-}$ complex $\left(\right.$ adt $=\left({ }^{-} \mathrm{S}-\mathrm{CH}_{2}-\right.$ $\left.\mathrm{NHCH}_{2}-\mathrm{S}^{-}\right)$) (30, Fig. 17) resulted in a semi-synthetic enzyme practically indistinguishable from the native enzyme with regard to both spectroscopic and catalytic properties (Fig. 18). ${ }^{53}$ In the context of synthetic catalyst design it also served to underscore the effect of the protein surroundings and the $[4 \mathrm{Fe} 4 \mathrm{~S}]_{\mathrm{H}}$ cluster on the catalytic properties of $[2 \mathrm{Fe}]$ subsite mimics. Indeed complex 30 does not appear to be catalytic in solution and is highly unstable towards protonation. ${ }^{171,205}$

The newfound capacity to introduce synthetic cofactors into [FeFe] hydrogenases assists spectroscopic studies via the preparations of isotopologues of the H-cluster, and this is nicely exemplified by two extensive spectroscopic characterizations of such systems. ${ }^{206,207}$ Isotopic labelling of the $\mathrm{C}$ and $\mathrm{N}$ atoms of the cyanide ligands and bridgehead amine, in combination with HYSCORE and ENDOR spectroscopy, allowed the clear identification of ${ }^{15} \mathrm{~N}$-adt ${ }^{2-}$ ligand HYSCORE features. ${ }^{206}$ The iron ions found in both [4Fe-4S] clusters, as well as in the [2Fe] subsite, have also been labelled using ${ }^{57} \mathrm{Fe}^{207}$ In the latter study, the $\mathrm{H}$-cluster was isolated in the $\mathrm{H}_{\mathrm{ox}}$-state and studied by using a number of spectroscopic techniques, including pulsed EPR, Mössbauer and nuclear resonance vibrational spectroscopy (NRVS). It is noteworthy that these initial studies both agree

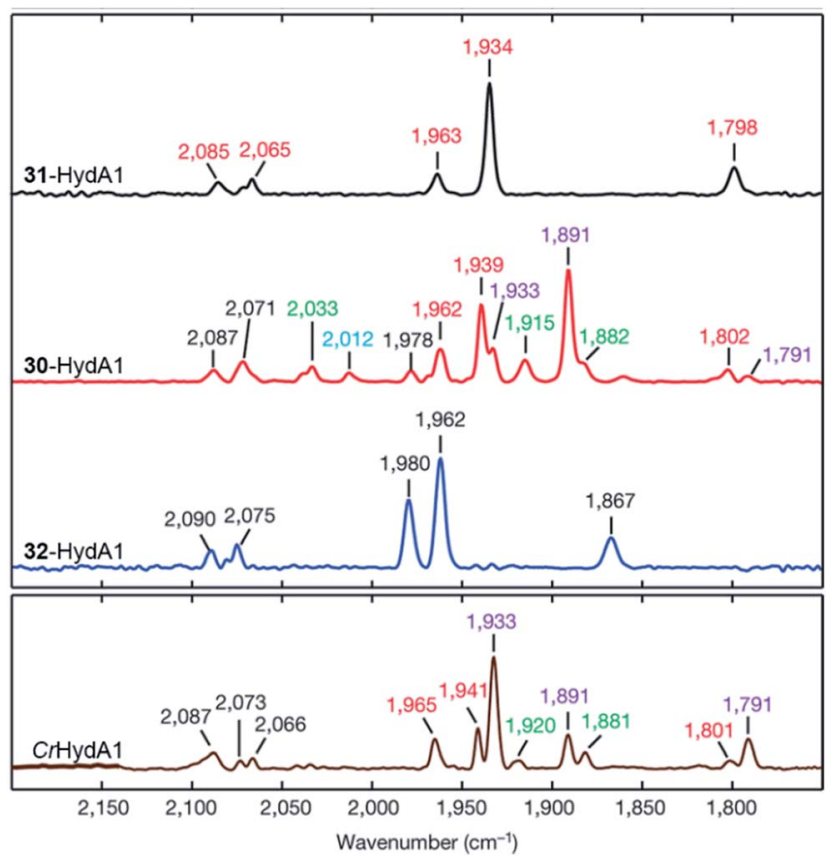

Fig. 18 FTIR spectra with normalized intensities of selected forms of semi-synthetic HydA, loaded with synthetic co-factors 30-32 (3032-HydA1), compared to a form of HydA containing the native cofactor ( $\mathrm{CrHydA} 1)$. The figure was adapted from Berggren et al., Nature, $2013 . .^{53}$ with, and refine findings from, earlier studies using enzymatically maturated forms of the enzyme..$^{5,208,209}$

The concept of artificial maturation has now been applied to [FeFe] hydrogenases from a wide range of different organisms, including Clostridium pasteurianum (CpI), ${ }^{192}$ Chlamydomonas reinhardtii (CrHydA1), ${ }^{53,192,210}$ Megasphaera elsdenii (MeHydA), ${ }^{\mathbf{1 9 2 , 2 1 1}}$ and Desulfovibrio desulfuricans ATCC 7757 (DdHydAB), ${ }^{48}$ underscoring the general applicability of the technique.

A few years after the initial discovery of the artificial maturation technique, its adaptation for in vivo applications was reported, with the successful activation of CrHydA1 inside living E. coli cells using [2Fe] subsite mimics. Treating anaerobic cell cultures expressing apo-HydA1 with complex $\mathbf{3 0}$ resulted in glucose-dependent $\mathrm{H}_{2}$ production. ${ }^{212}$ More recently, this approach has also enabled the detection of the $\mathrm{H}_{\mathrm{ox}}$ and $\mathrm{H}_{\mathrm{ox}}-\mathrm{CO}$ states in vivo, ${ }^{213}$ paving the way for mechanistic studies under physiological conditions. The mechanism of activation under in vivo conditions, including cell entry and enzyme localization, is still unknown, but in vitro assays suggest a high degree of activation of the enzyme. Techniques for the introduction of metal complexes and other small molecules into living cells for the purpose of activating a specific protein are still quite rare. ${ }^{\text {214-219 }}$ However, the activation of HydA1 occurred spontaneously in standard $E$. coli expression strains upon addition of the $[2 \mathrm{Fe}]$ subsite mimic, suggesting a general applicability of the technique to other expression hosts.

\subsection{Reactivity of semi-synthetic hydrogenases}

The artificial maturation technique is not restricted to the preparation of "native" hydrogenases. Already in 2013, it was shown that $\left[(\mu-p d t) \mathrm{Fe}_{2}(\mathrm{CO})_{4}(\mathrm{CN})_{2}\right]^{2-}(31)$ and $\left[(\mu-\mathrm{odt}) \mathrm{Fe}_{2}\right.$ $\left.(\mathrm{CO})_{4}(\mathrm{CN})_{2}\right]^{2-}\left(\right.$ odt $\left.=\left({ }^{-} \mathrm{S}-\mathrm{CH}_{2} \mathrm{OCH}_{2}-\mathrm{S}^{-}\right)\right)(32)$ can be incorporated into an apo-enzyme with good yields. However, both 31-HydA and 32-HydA appeared to be catalytically inactive and instead locked the $\mathrm{H}$-cluster in specific oxidation states. ${ }^{53}$ Since then, a series of studies have been reported involving the incorporation of alternative [2Fe] subsite mimics, and an overview of the complexes assayed for the preparation of semisynthetic hydrogenases at the time of this review is shown in Fig. 19. The main emphasis of these studies has been on the bridging ligand, including changes to the bridgehead atom and the introduction of increased steric bulk. Moreover, the effect of replacing $\mathrm{CN}$ ligands with $\mathrm{CO}$, as well as the possibility to introduce mononuclear $\mathrm{Fe}$ complexes, has been studied.

In particular, 31-HydA attracted initial attention, as it appeared to generate a form of the $\mathrm{H}$-cluster locked in a state highly similar to the $\mathrm{H}_{\mathrm{ox}}$-state observed for the native enzyme. ${ }^{53,192}$ A combined spectroscopy and electrochemistry study of 31-HydA1 later verified that the [2Fe] subsite indeed was isolated in the $\left[\mathrm{Fe}^{\mathrm{I}} \mathrm{Fe}^{\mathrm{II}}\right]$-state, indicating a one-electron oxidation of the complex upon insertion into the protein. ${ }^{220}$ This modified $\mathrm{H}$-cluster only appears to have one readily available redox transition, which involves the $[4 \mathrm{Fe}-4 \mathrm{~S}]_{\mathrm{H}}$ cluster rather than the $[2 \mathrm{Fe}]$ subsite $\left(\mathrm{H}_{\mathrm{ox}} / \mathrm{H}^{\prime}\right.$ red, see Fig. 3). ${ }^{\mathbf{6 2 2 2 0}}$ This observation explains the low catalytic capacity of this semi-synthetic 

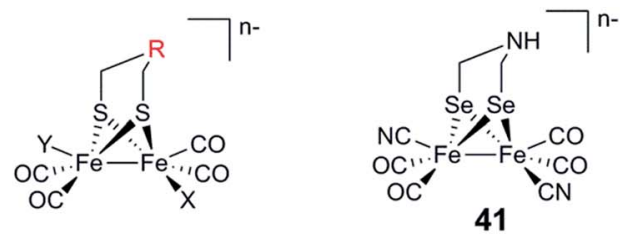

$\mathrm{R}=\mathrm{NH}$ and $\mathrm{Y}=\mathrm{X}=\mathrm{CO}, 33$;

$\mathrm{Y}=\mathrm{X}=\mathrm{CN}, 30 ; \mathrm{Y}=\mathrm{CN}$ and $\mathrm{X}=\mathrm{CO}, 34$

$\mathrm{R}=\mathrm{CH}_{2}$ and $\mathrm{Y}=\mathrm{X}=\mathrm{CN}, 31 ; \mathrm{Y}=\mathrm{CN}$ and $\mathrm{X}=\mathrm{CO}, 35$

$\mathrm{R}=\mathrm{NCH}_{3}$ and $\mathrm{Y}=\mathrm{X}=\mathrm{CN}, 36$; or $\mathrm{Y}=\mathrm{CN}$ and $\mathrm{X}=\mathrm{CO}, 37$

$\mathrm{R}=\mathrm{O}$ and $\mathrm{Y}=\mathrm{X}=\mathrm{CN}, \mathbf{3 2}$

$\mathrm{R}=\mathrm{S}$ and $\mathrm{Y}=\mathrm{X}=\mathrm{CN}, 38$

$\mathrm{R}=\mathrm{CHOH}$ and $\mathrm{Y}=\mathrm{X}=\mathrm{CO}, \mathbf{3 9}$ or $\mathrm{Y}=\mathrm{X}=\mathrm{CN}, \mathbf{4 0}$

$\mathrm{Y}=\mathrm{X}=\mathrm{CO}: \mathrm{n}=0 ; \mathrm{Y}=\mathrm{X}=\mathrm{CN}: \mathrm{n}=-2 ; \mathrm{Y}=\mathrm{CN}$ and $\mathrm{X}=\mathrm{CO}: \mathrm{n}=-1$

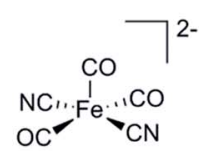

42

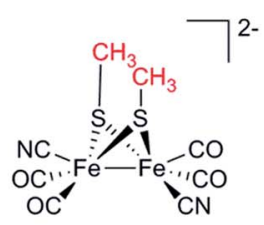

44

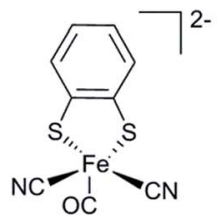

43

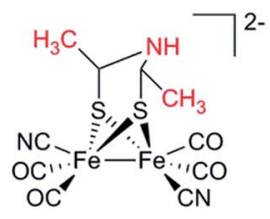

45
Fig. 19 Overview of synthetic complexes screened for insertion into [FeFe] hydrogenases.

hydrogenase and is attributable to the lack of a protonatable bridgehead, which prevents stabilization of the reduced [2Fe] subsite by proton coupled electron transfer and instead favours reduction of the $[4 \mathrm{Fe}-4 \mathrm{~S}]$ cluster. Finally, it is noteworthy that 31-HydA1 appears to be completely unreactive towards CO binding. ${ }^{220}$

More recently, the 32-loaded form of the [FeFe] hydrogenase was explored in depth by Lubitz and co-workers. ${ }^{60}$ As isolated, the FTIR spectrum of 32-HydA1 displays strong similarities to the $\mathrm{H}_{\text {trans }}$ as well as the $\mathrm{H}_{\mathrm{Hyd}^{-}}$-state. As mentioned above ( $c f$. Section 2.2); the latter state was recently reported and shown to accumulate under strongly reducing conditions. ${ }^{57,59}$ Both $\mathrm{H}_{\text {trans }}$ and $\mathrm{H}_{\mathrm{Hyd}}$ have been described as consisting of a reduced $[4 \mathrm{Fe}-$ $4 \mathrm{~S}]_{\mathrm{H}}$ cluster coupled to an oxidised $[2 \mathrm{Fe}]$ subsite, i.e. $[4 \mathrm{Fe}-4 \mathrm{~S}]_{\mathrm{H}}{ }^{+}-$ $\left[\mathrm{Fe}^{\mathrm{II}} \mathrm{Fe}^{\mathrm{II}}\right]$. However, while the $\mathrm{H}_{\text {trans }}$-state is considered to be an inactive oxidised state, the $\mathrm{H}_{\mathrm{Hyd}}$-state is believed to represent an elusive terminal hydride-state in the catalytic cycle. In the native enzyme, the $\mathrm{H}_{\mathrm{Hyd}}$-state has been shown to accumulate in a mutant (Cys169Ser) with a disrupted H-bonding network. Arguably, replacing the amine bridgehead with an ether analogue can result in a similar situation. ${ }^{57} \mathrm{Fe}$ labelling of the 32-cofactor, in combination with NRVS spectroscopy, allowed final confirmation of the presence of the hydride ligand, and DFT calculations were performed to verify that the electronic structure of the 32-HydA-hydride is virtually indistinguishable from that of the native HydA-hydride analogue previously observed by King and co-workers. Not only does the study of 32HydA provide a direct observation of the terminal hydride state, but it also underscores the potential of the artificial maturation technique to provide mechanistic insight via the selective preparation of model systems for catalytically relevant states.

The most comprehensive screening study reported to date was by Siebel $e t$ al. in 2015, using the apo-form of CrHydA1. ${ }^{221}$ The enzyme was incubated with complexes 30-40 and 42-45 (Fig. 19), and their incorporation into the enzyme was determined by a combination of FTIR spectroscopy and Fe quantification. The study underscored the capacity of the active site pocket to harbour a wide range of [2Fe] subsite mimics, as the majority of the complexes assayed, including some of the mononuclear complexes, were successfully incorporated into the enzyme. However, the presence of two cyanide ligands and the avoidance of steric bulk appear to be crucial for the generation of a single well-defined product. Among the other trends observed, the study reinforced the notion that a secondary amine is strictly required in the bridgehead position for efficient catalysis. Still, many of the bridgehead-derivates did in fact show some minor residual enzymatic activity (e.g. 31). Conversely, replacing one cyanide ligand with a $\mathrm{CO}$ ligand resulted in less well-defined semi-synthetic H-clusters, as determined by FTIR spectroscopy. However, this modification had relatively modest influence on the activity of the enzyme, and the mono-cyanide analogue $\left[(\mu \text {-adt }) \mathrm{Fe}_{2}(\mathrm{CO})_{5} \mathrm{CN}\right]^{-}(\mathbf{3 4})$ (Fig. 19) retained almost $50 \%$ of the native activity. The latter complex also appears to generate catalytically competent semisynthetic enzymes in vivo. ${ }^{212}$

The crystal structures of a series of semi-synthetic forms of HydA from C. pasterianum (X-CpI) were reported in 2016.

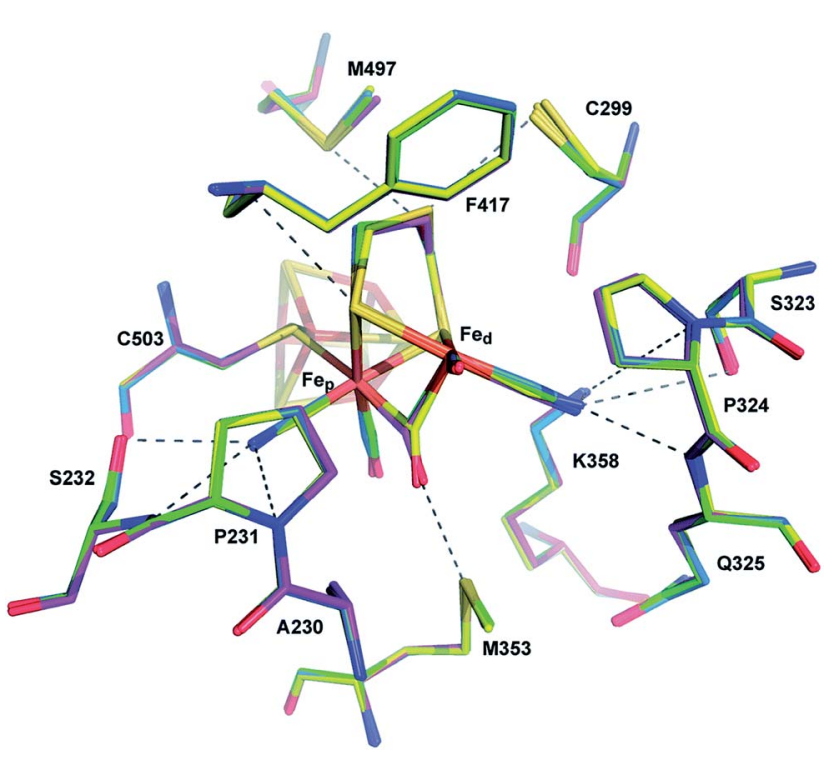

Fig. 20 Comparison of 30-Cpl (carbon atoms in marine) superposed on stick models of 31-Cpl (magenta), 32-Cpl (green) and 38-Cpl (yellow). Dashed lines indicate potential proton transfer pathways or potential interactions of the [2Fe] subsite with the protein. Amino acid numbering as in the structure of native Cpl. Adapted from Esselborn et al. ${ }^{25}$ with permission from the Royal Society of Chemistry. 
Critically, this study showed that regardless of the nature of the bridgehead atom, the structural geometry of the complex remained unchanged, and all of the semi-synthetic hydrogenases studied generated structures similar to the $\mathrm{H}_{\mathrm{ox}}$-state (Fig. 20). ${ }^{25}$ The striking structural similarities between the highly active 30-CpI and the modified cofactors underscore the strong influence of the active site on forming this specific geometry and reinforce the relevance of synthetically modified cofactors as spectroscopic models of the H-cluster. Moreover, these structural similarities appear to exclude the possibility to attribute the lack of activity of 31-, 32-, and 38-CpI to inhibition or steric hindrance and thus further highlight the importance of the bridgehead amine for activity. It is noteworthy that when CpI was assayed after loading with 31, no hydrogenase activity could be detected..$^{25}$ It thus appears to be a variance in how well [FeFe] hydrogenases of different origin can accommodate and utilize modified cofactor mimics. Esselborn et al. raise the possibility that this difference in activity can be attributed to the extent of shielding of the active site from the surface of the protein. ${ }^{25}$ The deeply buried active site in CpI could be more sensitive to a disrupted proton transfer network as compared to the smaller CrHydA1 enzyme.

In parallel to modifications of the [2Fe] subsite, Happe and co-workers also explored the influence of chalcogen exchange of the $[4 \mathrm{Fe}-4 \mathrm{~S}]_{\mathrm{H}}$-cluster. ${ }^{222}$ Chemical reconstitution was employed to generate the Se-derivate $\left([4 \mathrm{Fe}-4 \mathrm{Se}]_{\mathrm{H}^{-}}[2 \mathrm{Fe}]\right)$ of the $\mathrm{H}$-cluster in CrHydA1. Somewhat surprisingly, this Se analogue was shown to be practically indistinguishable from the native cofactor with regard to FTIR spectroscopic properties and enzymatic activities in standard chemical assays. In contrast, Se exchange of the adtderived thiol ligands (Fig. 19, complex 41) was recently shown to result in increased electron density on the [2Fe] subsite. ${ }^{223}$ The initial characterisation suggests that this semi-synthetic hydrogenase displays increased bias towards $\mathrm{H}_{2}$ production as well as a decrease in $\mathrm{O}_{2}$ tolerance.

\subsection{Insights into hydrogenase maturation gained from artificial maturation}

In parallel to the direct application for the preparation of semisynthetic hydrogenases, the artificial maturation technique has also started to provide valuable insights into the biosynthesis of the H-cluster.

5.3.1 Semi-synthetic HydF. The preparation of semisynthetic X-HydF, via the incorporation of [2Fe] subsite models 30-32 into the purified maturation protein HydF, did not only provide the first entry point into the generation of semisynthetic hydrogenases, but also generated a model for the binding of the $[2 \mathrm{Fe}]$ subsite precursor on this chaperone protein. Apart from the [2Fe] subsite precursor, HydF contains a [4Fe-4S] cluster with unknown function. ${ }^{195,199,201,224-226}$ Pulsed EPR spectroscopy of ${ }^{13} \mathrm{CN}^{-}$-labelled 31-HydF in combination with DFT calculations supports a model in which the [2Fe] complex binds to the protein via a cyanide bridge to this $[4 \mathrm{Fe}-$ 4S] cluster (Fig. 17). ${ }^{53}$ Thus, 31-HydF features a hexanuclear Fe complex quite similar to the H-cluster, but with one key difference: the bridging thiol is replaced with a cyanide linker.
Intriguingly, the binding of the [2Fe] complex to HydF induced a linkage isomerization, or flip, of the bridging cyanide, resulting in coordination via the nitrogen instead of the carbon atom to the $[2 \mathrm{Fe}]$ complex. Such cyanide linkage isomerism has been observed in a handful of synthetic systems, but is still quite rare. ${ }^{227-232}$ Whether the binding of the $[2 \mathrm{Fe}]$ subsite to the [4Fe-4S] cluster via a bridging cyanide ligand also represents the situation in the biologically matured HydF remains to be firmly established. However, the peak positions observed in the FTIR spectra recorded on synthetically loaded X-HydF are highly similar to those reported for Clostridium acetobutylicum $\mathrm{HydF}$ expressed in the presence of HydE and HydG, thus containing the native pre-catalyst (Fig. 21). ${ }^{53,199,202,233}$

A recent X-ray crystallography study of HydF from Thermosipho melanesiensis containing its $[4 \mathrm{Fe}-4 \mathrm{~S}]$ cluster provides additional strong support for the involvement of this cluster in binding the synthetic pre-catalyst on HydF. ${ }^{233}$ The structure of holo-HydF containing also the pre-catalyst remains to be solved. However, the latter study revealed the presence of a labile glutamate ligand coordinating the $[4 \mathrm{Fe}-4 \mathrm{~S}]$ cluster, which arguably could become displaced upon binding the [2Fe] subsite precursor. Analogously to Thermotoga maritima HydF, wild-type $T$. melanesiensis $\mathrm{HydF}$ was capable of efficiently binding 30 and $\mathbf{3 1}$ and transferring these complexes to apoHydA. Conversely, replacing the glutamate with potentially stronger ligands, i.e. histidine or cysteine, abolished the capacity of the protein to bind the synthetic cofactor.

5.3.2 Synthesis of the H-cluster. The mechanism by which the pre-catalyst is delivered from HydF to the apo-hydrogenase is still not elucidated, but the insertion mechanism in the absence of HydF has been studied by electrochemical methods, employing complex 30 and the two hydrogenases CPI and CrHydA1. The activation of the enzyme following the addition of complex 30 was monitored as a function of applied potential. The authors argue for a two-step activation process, during which the $[2 \mathrm{Fe}]$

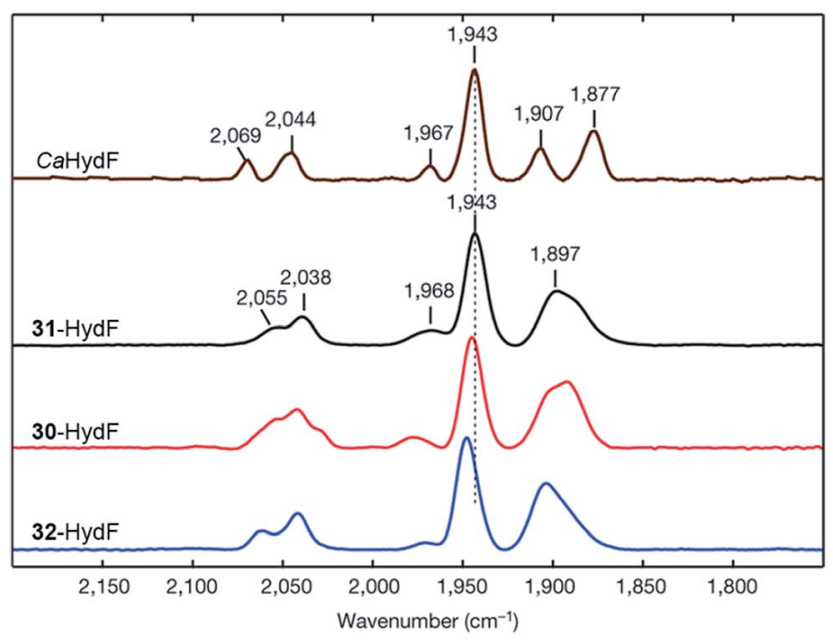

Fig. 21 FTIR spectra with normalized intensities of selected forms of semi-synthetic HydF, loaded with synthetic co-factors 30-32 (30-32HydF), compared to a form of HydF containing the native co-factor (CaHydF). The figure was adapted from Berggren et al., Nature, 2013.53 
subsite precursor first binds to the protein, most likely in the channel leading to the active site. The second step involves the binding of the $[2 \mathrm{Fe}]$ complex to the $[4 \mathrm{Fe}-4 \mathrm{~S}]_{\mathrm{H}}$ cluster, which triggers a series of events including release of a $\mathrm{CO}$ ligand, oxidation of the $[2 \mathrm{Fe}]$ complex by one electron, and a structural rearrangement, resulting in the formation of a complete $\mathrm{H}$ cluster in its $\mathrm{H}_{\mathrm{ox}}$ state. In contrast to the initial binding, the second step is dependent on the electrode potential and will not proceed under conditions where the $[4 \mathrm{Fe}-4 \mathrm{~S}]_{\mathrm{H}}$ cluster is expected to be reduced. This is attributed to an initial electron shunt from the $\left[\mathrm{Fe}^{\mathrm{I}} \mathrm{Fe}^{\mathrm{I}}\right]$ subsite mimic to the $[4 \mathrm{Fe}-4 \mathrm{~S}]_{\mathrm{H}}$ cluster as the $\mathrm{Fe}_{\text {proximal }}-\mathrm{S}_{\text {cys }}$ bond forms. ${ }^{234}$ This hypothesis is further supported by the observed release of the $[2 \mathrm{Fe}]$ subsite from the $[4 \mathrm{Fe}-$ $4 \mathrm{~S}]_{\mathrm{H}}$-cluster under reducing conditions in the presence of excess CO. ${ }^{235}$ The possibility to trap an intermediate 30-[4Fe-4S]-HydA complex under strongly reducing conditions paves the way for detailed spectroscopic analysis of the subsequent formation of the H-cluster. Whether this also reflects the final stages of the natural maturation process is still unknown, but it is likely considering the spectroscopic similarities between enzymatically matured HydF and HydF loaded with complexes 30-32.

\subsection{Artificial maturation of [Fe] hydrogenases}

The concept of artificial enzyme activation has also been applied to two other gas-processing enzymes featuring complex inorganic cofactors, namely [Fe] hydrogenases and nitrogenases. ${ }^{236,237}$ In contrast to [FeFe] hydrogenases, the mono-iron FeGP cofactor found in [Fe] hydrogenases can be extracted from the enzyme and re-introduced when the apo-form of the enzyme is mixed with an ultrafiltrate from the denatured active enzyme. ${ }^{238}$ The successful artificial activation of a Methanocaldococcus jannaschii [Fe] hydrogenase with synthetic analogues of the native FeGP cofactor was reported by $\mathrm{Hu}$ and co-workers in 2015 (Fig. 22). ${ }^{237}$

The synthetic complexes employed (46 and 47) represent truncated versions of the native FeGP cofactor, lacking the two methyl substituents as well as the GMP group on the pyridine ligand. Still, the primary ligand sphere of the Fe centre is highly similar to that of the enzymatic cofactor (Fig. 22). When the acetate ligand is replaced with a thiol ligand, mimicking the coordination environment of the cofactor $\left(46^{\prime}\right.$ and $\left.47^{\prime}\right)$, both complexes are incapable of $\mathrm{H}_{2}$ activation in solution. ${ }^{239,240}$ Conversely, introduction of complex 46 into the apo-enzyme resulted in a semi-synthetic hydrogenase with $1 \%$ activity as compared to the native enzyme, further underscoring the importance of a protein environment for the activity of hydrogenase model complexes. The successful incorporation of 46 into the active site of the enzyme was further supported by FTIR spectroscopy, as the 46-[Fe] hydrogenase displayed two dominant bands at $\sim 2020$ and $1945 \mathrm{~cm}^{-1}$, similar to samples reconstituted with native FeGP (2011 and $\left.1944 \mathrm{~cm}^{-1}\right)$. In the former case, additional minor peaks were also clearly discernible, indicative of non-specific binding. The reconstitution of the apo-enzyme using 46 in the presence of GMP resulted in a decrease in the number of minor peaks and a small shift of the dominant bands to $\sim 2016$ and $1944 \mathrm{~cm}^{-1}$; moreover, the
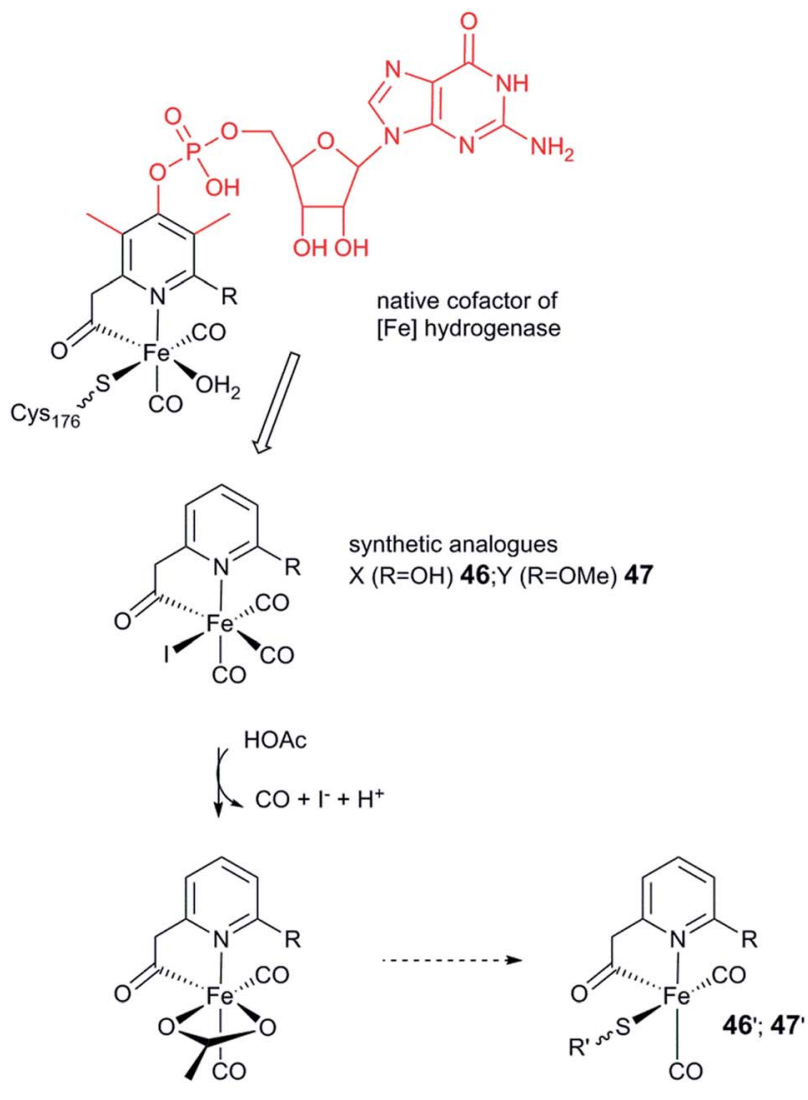

$V_{\text {OAc- }}^{\text {Apo enzyme +/- GMP }}$

Active $[\mathrm{Fe}]$ hydrogenase

Fig. 22 Complexes 46 and 47 are inserted into the apo-[Fe] hydrogenase following the removal of two monodentate ligands ( $\mathrm{CO}$ and $\mathrm{I}^{-}$). Substituents on the pyridine ring lacking in 46 and 47 as compared to the native FeGP cofactor indicated in red.

specific activity increased to $\sim 2 \%$. The introduction of the methylated cofactor analogue, 47 , into the enzyme resulted in FTIR spectra similar to those observed for 46-[Fe] hydrogenase, but no enzymatic activity was observed.

This highlights the importance of the 2-hydroxy group for the activity of the enzyme, in agreement with prior theoretical work. ${ }^{69,70}$ Moreover, the improved incorporation of 46 in the presence of GMP suggests that the synthesis of closer structural FeGP analogues is the key challenge to address artificial maturation of $[\mathrm{Fe}]$ hydrogenases.

\subsection{Summary and outlook}

The concept of "artificial enzyme maturation" is derived from the idea of artificial enzymes developed in the 1970s and made possible by our understanding of the biological maturation processes. Despite its relatively recent inception, the artificial maturation method has proven to be an extremely powerful tool for studying [FeFe] hydrogenases and has accelerated research in this field.

The decoupling of the preparation of active hydrogenases from the biological maturation system, both in vitro and in vivo, 
has facilitated the study of these enzymes in a variety of ways. The technique greatly simplifies heterologous expression enabling the large scale preparation of active enzymes as well as the exploration of different subclasses of [FeFe] hydrogenases, two critical aspects for the implementation of these enzymes in (bio-)technological applications. In combination with the possibility to selectively label the $[2 \mathrm{Fe}]$ subsite, it can certainly also be expected to continue to improve our understanding of these enzymes. The introduction of modified, or non-native, [2Fe] cofactors has primarily proven to be a powerful method for unravelling mechanistic details so far. However, this field is still in its infancy. Looking forward, it provides synthetic chemists with the possibility of designing more robust enzymes as well as a tool for exploring the interplay between synthetic [2Fe] cofactors and the protein cavity.

\section{Concluding remarks}

Tremendous progress has been made in our understanding of hydrogenases and our capacity to mimic their reactivity with synthetic systems over the last few years. In particular, work on [NiFe] hydrogenases has revealed that evolution has developed a number of solutions to influence $\mathrm{O}_{2}$ tolerance and catalytic bias of these enzymes. Our capacity to introduce these properties via enzyme design is still limited. Nevertheless, our attempts to improve on Nature's solution to these issues are providing critical information for the implementation of these enzymes in (bio-)technological applications and guiding us in the preparation of synthetic catalysts.

The development of artificial hydrogenases has proven that encapsulation of catalysts in a variety of different scaffolds results in systems with remarkable catalytic activities. Moreover, as shown by the work on Dubois catalysts in particular, we can greatly enhance the reactivity of synthetic systems by modulating the immediate vicinity of the catalytic site. The impact of the catalyst environment, and by extension the potential of artificial hydrogenases, is underscored by the success of the artificial maturation technique. Indeed, the introduction of [2Fe] subsite mimic 30 into the active site of an $[\mathrm{FeFe}]$ hydrogenase transforms this inactive and fragile complex into an outstanding catalyst. In the context of catalyst design it is noteworthy that we now have the possibility to study [2Fe] subsite models ranging from isolated complexes in organic solvents all the way to their reactivity inside the enzyme under in vivo conditions.

Undoubtedly, the combined efforts of molecular biologists, biophysicists and chemists will continue to improve both our understanding of these different systems and their applicability in an industrial context. Considerable challenges remain, but nevertheless there are strong reasons to believe that we will be able to harness this knowledge in the development of a hydrogen economy over the next few decades.

\section{Conflicts of interest}

There are no conflicts to declare.

\section{Acknowledgements}

Research performed in the authors' laboratories is supported by grants from the Swedish Research Council, VR (G. B. contract no. 621-2014-5670), the Swedish Research Council for Environment, Agricultural Sciences and Spatial Planning, Formas (G. B. contract no. 213-2014-880), Stiftelsen Olle Engkvist Byggmästare (G. B.), the Wenner-Gren Foundations (C. E. and G. B.) and the ERC (G. B. contract no. 714102).

\section{Notes and references}

1 G. Lauermann, P. Häussinger, R. Lohmüller and A. M. Watson, in Ullmann's Encyclopedia of Industrial Chemistry, Wiley-VCH Verlag GmbH \& Co. KGaA, 2013, pp. 1-15, DOI: 10.1002/14356007.a13_297.pub3.

2 J. M. Ogden, Annu. Rev. Energy, 1999, 24, 227-279.

3 S. P. S. Badwal, S. Giddey and C. Munnings, Wiley Interdiscip. Rev.: Energy Environ., 2013, 2, 473-487.

4 D. G. Nocera, Inorg. Chem., 2009, 48, 10001-10017.

5 J. C. Fontecilla-Camps, P. Amara, C. Cavazza, Y. Nicolet and A. Volbeda, Nature, 2009, 460, 814-822.

6 M. Hambourger, M. Gervaldo, D. Svedruzic, P. W. King, D. Gust, M. Ghirardi, A. L. Moore and T. A. Moore, J. Am. Chem. Soc., 2008, 130, 2015-2022.

7 S. Krishnan and F. A. Armstrong, Chem. Sci., 2012, 3, 10151023.

8 N. Plumeré, O. Rüdiger, A. A. Oughli, R. Williams, J. Vivekananthan, S. Pöller, W. Schuhmann and W. Lubitz, Nat. Chem., 2014, 6, 822-827.

9 A. A. Oughli, F. Conzuelo, M. Winkler, T. Happe, W. Lubitz, W. Schuhmann, O. Rüdiger and N. Plumeré, Angew. Chem., Int. Ed. Engl., 2015, 54, 12329-12333.

10 C. Baffert, K. Sybirna, P. Ezanno, T. Lautier, V. Hajj, I. Meynial-Salles, P. Soucaille, H. Bottin and C. Léger, Anal. Chem., 2012, 84, 7999-8005.

11 T. R. Simmons, G. Berggren, M. Bacchi, M. Fontecave and V. Artero, Coord. Chem. Rev., 2014, 270-271, 127-150.

12 F. A. Armstrong, R. M. Evans, S. V. Hexter, B. J. Murphy, M. M. Roessler and P. Wulff, Acc. Chem. Res., 2016, 49, 884-892.

13 C. Wombwell, C. A. Caputo and E. Reisner, Acc. Chem. Res., 2015, 48, 2858-2865.

14 N. Khanna and P. Lindblad, Int. J. Mol. Sci., 2015, 16, 10537. 15 M. Ghirardi, Photosynth. Res., 2015, 125, 383-393.

16 V. Artero, G. Berggren, M. Atta, G. Caserta, S. Roy, L. Pecqueur and M. Fontecave, Acc. Chem. Res., 2015, 48, 2380-2387.

17 W. Lubitz, H. Ogata, O. Rüdiger and E. Reijerse, Chem. Rev., 2014, 114, 4081-4148.

18 S. Kaur-Ghumaan and M. Stein, Dalton Trans., 2014, 43, 9392-9405.

19 B. Ginovska-Pangovska, A. Dutta, M. L. Reback, J. C. Linehan and W. J. Shaw, Acc. Chem. Res., 2014, 47, 2621-2630.

20 J. A. Birrell, O. Rüdiger, E. J. Reijerse and W. Lubitz, Joule, 2017, 1, 61-76. 
21 M. Stephenson and L. H. Stickland, Biochem. J., 1931, 25, 205-214.

22 P. M. Vignais and B. Billoud, Chem. Rev., 2007, 107, 42064272.

23 C. Greening, A. Biswas, C. R. Carere, C. J. Jackson, M. C. Taylor, M. B. Stott, G. M. Cook and S. E. Morales, ISME J., 2015, 10, 761-777.

24 D. W. Mulder, E. S. Boyd, R. Sarma, R. K. Lange, J. A. Endrizzi, J. B. Broderick and J. W. Peters, Nature, 2010, 465, 248-251.

25 J. Esselborn, N. Muraki, K. Klein, V. Engelbrecht, N. Metzler-Nolte, U. P. Apfel, E. Hofmann, G. Kurisu and T. Happe, Chem. Sci., 2016, 7, 959-968.

26 H. Ogata, P. Kellers and W. Lubitz, J. Mol. Biol., 2010, 402, 428-444.

27 S. Shima, O. Pilak, S. Vogt, M. Schick, M. S. Stagni, W. Meyer-Klaucke, E. Warkentin, R. K. Thauer and U. Ermler, Science, 2008, 321, 572-575.

28 M. Teixeira, G. Fauque, I. Moura, P. A. Lespinat, Y. Berlier, B. Prickril, H. D. Peck, A. V. Xavier, J. Le Gall and J. J. G. Moura, Eur. J. Biochem., 1987, 167, 47-58.

29 E. Garcin, X. Vernede, E. C. Hatchikian, A. Volbeda, M. Frey and J. C. Fontecilla-Camps, Structure, 1999, 7, 557-566.

30 P. A. Ash, R. Hidalgo and K. A. Vincent, ACS Catal., 2017, 7, 2471-2485.

31 P. E. M. Siegbahn, J. W. Tye and M. B. Hall, Chem. Rev., 2007, 107, 4414-4435.

32 H. Ogata, K. Nishikawa and W. Lubitz, Nature, 2015, 520, 571-574.

33 A. Abou Hamdan, B. Burlat, O. Gutiérrez-Sanz, P.-P. Liebgott, C. Baffert, A. L. De Lacey, M. Rousset, B. Guigliarelli, C. Léger and S. Dementin, Nat. Chem. Biol., 2012, 9, 15.

34 S. J. George, S. Kurkin, R. N. F. Thorneley and S. P. J. Albracht, Biochemistry, 2004, 43, 6808-6819.

35 C. Fan, M. Teixeira, J. Moura, I. Moura, H. Huynh Boi, J. Le Gall, H. D. Peck and B. M. Hoffman, J. Am. Chem. Soc., 1991, 113, 20-24.

36 J. P. Whitehead, R. J. Gurbiel, C. Bagyinka, B. M. Hoffman and M. J. Maroney, J. Am. Chem. Soc., 1993, 115, 5629-5635.

37 J. W. van der Zwaan, S. P. J. Albracht, R. D. Fontijn and E. C. Slater, FEBS Lett., 1985, 179, 271-277.

38 S. Foerster, M. Stein, M. Brecht, H. Ogata, Y. Higuchi and W. Lubitz, J. Am. Chem. Soc., 2003, 125, 83-93.

39 B. J. Murphy, R. Hidalgo, M. M. Roessler, R. M. Evans, P. A. Ash, W. K. Myers, K. A. Vincent and F. A. Armstrong, J. Am. Chem. Soc., 2015, 137, 8484-8489.

40 R. Hidalgo, P. A. Ash, A. J. Healy and K. A. Vincent, Angew. Chem., Int. Ed. Engl., 2015, 54, 7110-7113.

41 J. W. Peters, W. N. Lanzilotta, B. J. Lemon and L. C. Seefeldt, Science, 1998, 282, 1853-1858.

42 Y. Nicolet, A. L. de Lacey, X. Vernede, V. M. Fernandez, E. C. Hatchikian and J. C. Fontecilla-Camps, J. Am. Chem. Soc., 2001, 123, 1596-1601.

43 Y. Nicolet, C. Piras, P. Legrand, C. E. Hatchikian and J. C. Fontecilla-Camps, Structure, 1999, 7, 13-23.
44 M. Calusinska, T. Happe, B. Joris and A. Wilmotte, Microbiology, 2010, 156, 1575-1588.

45 G. J. Schut and M. W. W. Adams, J. Bacteriol., 2009, 191, 4451-4457.

46 M. F. J. M. Verhagen, T. O'Rourke and M. W. W. Adams, Biochim. Biophys. Acta, Bioenerg., 1999, 1412, 212-229.

47 B. L. Greene, G. J. Schut, M. W. W. Adams and R. B. Dyer, ACS Catal., 2017, 7, 2145-2150.

48 J. A. Birrell, K. Wrede, K. Pawlak, P. Rodriguez-Maciá, O. Rüdiger, E. J. Reijerse and W. Lubitz, Isr. J. Chem., 2016, 56, 852-863.

49 A. Silakov, E. J. Reijerse, S. P. J. Albracht, E. C. Hatchikian and W. Lubitz, J. Am. Chem. Soc., 2007, 129, 11447-11458.

50 W. Roseboom, A. L. De Lacey, V. M. Fernandez, E. C. Hatchikian and S. P. J. Albracht, J. Biol. Inorg Chem., 2006, 11, 102-118.

51 S. P. J. Albracht, W. Roseboom and E. C. Hatchikian, J. Biol. Inorg Chem., 2006, 11, 88-101.

52 C. Sommer, A. Adamska-Venkatesh, K. Pawlak, J. A. Birrell, O. Rüdiger, E. J. Reijerse and W. Lubitz, J. Am. Chem. Soc., 2017, 139, 1440-1443.

53 G. Berggren, A. Adamska, C. Lambertz, T. R. Simmons, J. Esselborn, M. Atta, S. Gambarelli, J. M. Mouesca, E. Reijerse, W. Lubitz, T. Happe, V. Artero and M. Fontecave, Nature, 2013, 499, 66-69.

54 A. Silakov, B. Wenk, E. Reijerse and W. Lubitz, Phys. Chem. Chem. Phys., 2009, 11, 6592-6599.

55 M. Winkler, J. Esselborn and T. Happe, Biochim. Biophys. Acta, Bioenerg., 2013, 1827, 974-985.

56 P. Knörzer, A. Silakov, C. E. Foster, F. A. Armstrong, W. Lubitz and T. Happe, J. Biol. Chem., 2012, 287, 14891499.

57 D. W. Mulder, Y. Guo, M. W. Ratzloff and P. W. King, J. Am. Chem. Soc., 2017, 139, 83-86.

58 S. Morra, S. Maurelli, M. Chiesa, D. W. Mulder, M. W. Ratzloff, E. Giamello, P. W. King, G. Gilardi and F. Valetti, Biochim. Biophys. Acta, Bioenerg., 2016, 1857, 98-106.

59 D. W. Mulder, M. W. Ratzloff, M. Bruschi, C. Greco, E. Koonce, J. W. Peters and P. W. King, J. Am. Chem. Soc., 2014, 136, 15394-15402.

60 E. J. Reijerse, C. C. Pham, V. Pelmenschikov, R. GilbertWilson, A. Adamska-Venkatesh, J. F. Siebel, L. B. Gee, Y. Yoda, K. Tamasaku, W. Lubitz, T. B. Rauchfuss and S. P. Cramer, J. Am. Chem. Soc., 2017, 139, 4306-4309.

61 M. Senger, K. Laun, F. Wittkamp, J. Duan, M. Haumann, T. Happe, M. Winkler, U.-P. Apfel and S. T. Stripp, Angew. Chem., Int. Ed., 2017, 56, 16503-16506.

62 M. Senger, S. Mebs, J. Duan, O. Shulenina, K. Laun, L. Kertess, F. Wittkamp, U.-P. Apfel, T. Happe, M. Winkler, M. Haumann and S. T. Stripp, Phys. Chem. Chem. Phys., 2018, 20, 3128-3140.

63 S. Mebs, M. Senger, J. Duan, F. Wittkamp, U.-P. Apfel, T. Happe, M. Winkler, S. T. Stripp and M. Haumann, J. Am. Chem. Soc., 2017, 139, 12157-12160.

64 R. K. Thauer, A. R. Klein and G. C. Hartmann, Chem. Rev., 1996, 96, 3031-3042. 
65 C. Zirngibl, R. Hedderich and R. K. Thauer, FEBS Lett., 1990, 261, 112-116.

66 S. Shima and R. K. Thauer, Chem. Rec., 2007, 7, 37-46.

67 S. Shima, E. J. Lyon, M. Sordel-Klippert, M. Kauß, J. Kahnt, R. K. Thauer, K. Steinbach, X. Xie, L. Verdier and C. Griesinger, Angew. Chem., Int. Ed. Engl., 2004, 43, 25472551.

68 T. Hiromoto, K. Ataka, O. Pilak, S. Vogt, M. S. Stagni, W. Meyer-Klaucke, E. Warkentin, R. K. Thauer, S. Shima and U. Ermler, FEBS Lett., 2009, 583, 585-590.

69 X. Yang and M. B. Hall, J. Am. Chem. Soc., 2009, 131, 1090110908.

70 A. R. Finkelmann, H. M. Senn and M. Reiher, Chem. Sci., 2014, 5, 4474-4482.

71 T. Hiromoto, E. Warkentin, J. Moll, U. Ermler and S. Shima, Angew. Chem., Int. Ed. Engl., 2009, 48, 6457-6460.

72 A. Abou Hamdan, S. Dementin, P.-P. Liebgott, O. GutierrezSanz, P. Richaud, A. L. De Lacey, M. Rousset, P. Bertrand, L. Cournac and C. Léger, J. Am. Chem. Soc., 2012, 134, 8368-8371.

73 A. S. Ouattara, B. K. C. Patel, J.-L. Cayol, N. Cuzin, A. S. Traore and J.-L. Garcia, Int. J. Syst. Evol. Microbiol., 1999, 49, 639-643.

74 P. Bertrand, F. Dole, M. Asso and B. Guigliarelli, J. Biol. Inorg Chem., 2000, 5, 682-691.

75 D. W. Bak and S. J. Elliott, Curr. Opin. Chem. Biol., 2014, 19, 50-58.

76 J. A. Birrell, C. Laurich, E. J. Reijerse, H. Ogata and W. Lubitz, Biochemistry, 2016, 55, 4344-4355.

77 J. M. Moulis, V. Davasse, M.-P. Golinelli, J. Meyer and I. Quinkal, J. Biol. Inorg Chem., 1996, 1, 2-14.

78 K. Sybirna, P. Ezanno, C. Baffert, C. Léger and H. Bottin, Int. J. Hydrogen Energy, 2013, 38, 2998-3002.

79 T. Maeda, V. Sanchez-Torres and T. K. Wood, Appl. Microbiol. Biotechnol., 2008, 79, 77-86.

80 S. Dementin, V. Belle, P. Bertrand, B. Guigliarelli, G. Adryanczyk-Perrier, A. L. De Lacey, V. M. Fernandez, M. Rousset and C. Léger, J. Am. Chem. Soc., 2006, 128, 5209-5218.

81 A. Petrenko and M. Stein, J. Phys. Chem. B, 2015, 119, 1387013882.

82 P. Raleiras, P. Kellers, P. Lindblad, S. Styring and A. Magnuson, J. Biol. Chem., 2013, 288, 18345-18352.

83 A. Petrenko and M. Stein, Int. J. Mol. Sci., 2017, 18(1), 100.

84 M. Rousset, Y. Montet, B. Guigliarelli, N. Forget, M. Asso, P. Bertrand, J. C. Fontecilla-Camps and E. C. Hatchikian, Proc. Natl. Acad. Sci. U. S. A., 1998, 95, 11625-11630.

85 I. T. Yonemoto, C. W. Matteri, T. A. Nguyen, H. O. Smith and P. D. Weyman, J. Biol. Eng., 2013, 7, 17.

86 I. T. Yonemoto, B. R. Clarkson, H. O. Smith and P. D. Weyman, BMC Biochem., 2014, 15, 10.

87 P. Raleiras, N. Khanna, H. Miranda, L. S. Mészáros, H. Krassen, F. Ho, N. Battchikova, E.-M. Aro, A. Magnuson, P. Lindblad and S. Styring, Energy Environ. Sci., 2016, 9, 581-594.

88 L. A. Flanagan, J. J. Wright, M. M. Roessler, J. W. Moir and A. Parkin, Chem. Commun., 2016, 52, 9133-9136.
89 S. Morra, M. Arizzi, F. Valetti and G. Gilardi, Biochemistry, 2016, 55, 5897-5900.

90 E. C. Hatchikian, N. Forget, V. M. Fernandez, R. Williams and R. Cammack, Eur. J. Biochem., 1992, 209, 357-365.

91 J. Cohen, K. Kim, P. King, M. Seibert and K. Schulten, Structure, 2005, 13, 1321-1329.

92 A. S. Bingham, P. R. Smith and J. R. Swartz, Int. J. Hydrogen Energy, 2012, 37, 2965-2976.

93 V. H. Teixeira, A. M. Baptista and C. M. Soares, Biophys. J., 2006, 91, 2035-2045.

94 Y. Montet, P. Amara, A. Volbeda, X. Vernede, E. C. Hatchikian, M. J. Field, M. Frey and J. C. FontecillaCamps, Nat. Struct. Mol. Biol., 1997, 4, 523-526.

95 P.-P. Liebgott, F. Leroux, B. Burlat, S. Dementin, C. Baffert, T. Lautier, V. Fourmond, P. Ceccaldi, C. Cavazza, I. MeynialSalles, P. Soucaille, J. C. Fontecilla-Camps, B. Guigliarelli, P. Bertrand, M. Rousset and C. Léger, Nat. Chem. Biol., 2010, 6, 63-70.

96 T. Buhrke, O. Lenz, N. Krauss and B. Friedrich, J. Biol. Chem., 2005, 280, 23791-23796.

97 O. Duché, S. Elsen, L. Cournac and A. Colbeau, FEBS J., 2005, 272, 3899-3908.

98 M. Ludwig, J. A. Cracknell, K. A. Vincent, F. A. Armstrong and O. Lenz, J. Biol. Chem., 2009, 284, 465-477.

99 S. Dementin, F. Leroux, L. Cournac, A. L. d. Lacey, A. Volbeda, C. Léger, B. Burlat, N. Martinez, S. Champ, L. Martin, O. Sanganas, M. Haumann, V. M. Fernández, B. Guigliarelli, J. C. Fontecilla-Camps and M. Rousset, J. Am. Chem. Soc., 2009, 131, 10156-10164.

100 P.-P. Liebgott, A. L. de Lacey, B. Burlat, L. Cournac, P. Richaud, M. Brugna, V. M. Fernandez, B. Guigliarelli, M. Rousset, C. Léger and S. Dementin, J. Am. Chem. Soc., 2011, 133, 986-997.

101 A. Volbeda and J. C. Fontecilla-Camps, Coord. Chem. Rev., 2005, 249, 1609-1619.

102 Y. Shomura, K. S. Yoon, H. Nishihara and Y. Higuchi, Nature, 2011, 479, 253-256.

103 J. Fritsch, P. Scheerer, S. Frielingsdorf, S. Kroschinsky, B. Friedrich, O. Lenz and C. M. T. Spahn, Nature, 2011, 479, 249-252.

104 A. Volbeda, P. Amara, C. Darnault, J.-M. Mouesca, A. Parkin, M. M. Roessler, F. A. Armstrong and J. C. Fontecilla-Camps, Proc. Natl. Acad. Sci. U. S. A., 2012, 109, 5305-5310.

105 P. Wulff, C. C. Day, F. Sargent and F. A. Armstrong, Proc. Natl. Acad. Sci. U. S. A., 2014, 111, 6606-6611.

106 M. J. Lukey, M. M. Roessler, A. Parkin, R. M. Evans, R. A. Davies, O. Lenz, B. Friedrich, F. Sargent and F. A. Armstrong, J. Am. Chem. Soc., 2011, 133, 16881-16892.

107 G.-F. Huang, X.-B. Wu, L.-P. Bai, M.-N. Long and Q.-X. Chen, Int. J. Hydrogen Energy, 2014, 39, 18604-18611.

108 A. Volbeda, L. Martin, C. Cavazza, M. Matho, B. W. Faber, W. Roseboom, S. P. J. Albracht, E. Garcin, M. Rousset and J. C. Fontecilla-Camps, J. Biol. Inorg Chem., 2005, 10, 239249. 
109 T. Goris, A. F. Wait, M. Saggu, J. Fritsch, N. Heidary, M. Stein, I. Zebger, F. Lendzian, F. A. Armstrong, B. Friedrich and O. Lenz, Nat. Chem. Biol., 2011, 7, 310-318. 110 M. C. Marques, C. Tapia, O. Gutierrez-Sanz, A. R. Ramos, K. L. Keller, J. D. Wall, A. L. De Lacey, P. M. Matias and I. A. C. Pereira, Nat. Chem. Biol., 2017, 13, 544-550.

111 B. Ginovska-Pangovska, M.-H. Ho, J. C. Linehan, Y. Cheng, M. Dupuis, S. Raugei and W. J. Shaw, Biochim. Biophys. Acta, 2014, 1837, 131-138.

112 A. J. Cornish, K. Gärtner, H. Yang, J. W. Peters and E. L. Hegg, J. Biol. Chem., 2011, 286, 38341-38347.

113 G. Hong, A. J. Cornish, E. L. Hegg and R. Pachter, Biochim. Biophys. Acta, 2011, 1807, 510-517.

114 S. Morra, A. Giraudo, G. Di Nardo, P. W. King, G. Gilardi and F. Valetti, PLoS One, 2012, 7, e48400.

115 A. S. Pandey, T. V. Harris, L. J. Giles, J. W. Peters and R. K. Szilagyi, J. Am. Chem. Soc., 2008, 130, 4533-4540.

116 V. H. Teixeira, C. M. Soares and A. M. Baptista, Proteins: Struct., Funct., Bioinf., 2008, 70, 1010-1022.

117 I. F. Galván, A. Volbeda, J. C. Fontecilla-Camps and M. J. Field, Proteins: Struct., Funct., Bioinf., 2008, 73, 195203.

118 M. E. Wilson and G. M. Whitesides, J. Am. Chem. Soc., 1978, 100, 306-307.

119 F. Yu, V. M. Cangelosi, M. L. Zastrow, M. Tegoni, J. S. Plegaria, A. G. Tebo, C. S. Mocny, L. Ruckthong, H. Qayyum and V. L. Pecoraro, Chem. Rev., 2014, 114, 3495-3578.

120 Y.-W. Lin, Coord. Chem. Rev., 2017, 336, 1-27.

121 T. K. Hyster and T. R. Ward, Angew. Chem., Int. Ed. Engl., 2016, 55, 7344-7357.

122 F. Nastri, M. Chino, O. Maglio, A. Bhagi-Damodaran, Y. Lu and A. Lombardi, Chem. Soc. Rev., 2016, 45, 5020-5054.

123 C. Marchi-Delapierre, L. Rondot, C. Cavazza and S. Ménage, Isr. J. Chem., 2015, 55, 61-75.

124 I. Drienovská and G. Roelfes, Isr. J. Chem., 2015, 55, 21-31. 125 P. Saint-Martin, P. A. Lespinat, G. Fauque, Y. Berlier, J. LeGall, I. Moura, M. Teixeira, A. V. Xavier and J. J. G. Moura, Proc. Natl. Acad. Sci. U. S. A., 1988, 85, 9378-9380.

126 J. W. Slater and H. S. Shafaat, J. Phys. Chem. Lett., 2015, 6, 3731-3736.

127 D. J. Sommer, M. D. Vaughn and G. Ghirlanda, Chem. Commun., 2014, 50, 15852-15855.

128 D. J. Sommer, M. D. Vaughn, B. C. Clark, J. Tomlin, A. Roy and G. Ghirlanda, Biochim. Biophys. Acta, 2016, 1857, 598603.

129 B. Kandemir, S. Chakraborty, Y. Guo and K. L. Bren, Inorg. Chem., 2016, 55, 467-477.

130 M. Bacchi, G. Berggren, J. Niklas, E. Veinberg, M. W. Mara, M. L. Shelby, O. G. Poluektov, L. X. Chen, D. M. Tiede, C. Cavazza, M. J. Field, M. Fontecave and V. Artero, Inorg. Chem., 2014, 53, 8071-8082.

131 K. A. Vincent, G. J. Tilley, N. C. Quammie, I. Streeter, B. K. Burgess, M. R. Cheesman and F. A. Armstrong, Chem. Commun., 2003, 20, 2590-2591.
132 S. Roy, M. Bacchi, G. Berggren and V. Artero, ChemSusChem, 2015, 8, 3632-3638.

133 L. I. Simándi, Z. Szeverényi and É. Budó-Záhonyi, Inorg. Nucl. Chem. Lett., 1975, 11, 773-777.

134 M. Bacchi, E. Veinberg, M. J. Field, J. Niklas, T. Matsui, D. M. Tiede, O. G. Poluektov, M. Ikeda-Saito, M. Fontecave and V. Artero, ChemPlusChem, 2016, 81, 1083-1089.

135 E. A. Brucker, J. S. Olson, G. N. Phillips, Y. Dou and M. Ikeda-Saito, J. Biol. Chem., 1996, 271, 25419-25422.

136 C. M. Bianchetti, G. C. Blouin, E. Bitto, J. S. Olson and G. N. Phillips, Proteins: Struct., Funct., Bioinf., 2010, 78, 917-931.

137 S. R. Soltau, J. Niklas, P. D. Dahlberg, O. G. Poluektov, D. M. Tiede, K. L. Mulfort and L. M. Utschig, Chem. Commun., 2015, 51, 10628-10631.

138 S. R. Soltau, P. D. Dahlberg, J. Niklas, O. G. Poluektov, K. L. Mulfort and L. M. Utschig, Chem. Sci., 2016, 7, 7068-7078.

139 M. Rakowski DuBois and D. L. DuBois, Chem. Soc. Rev., 2009, 38, 62-72.

140 S. R. Soltau, J. Niklas, P. D. Dahlberg, K. L. Mulfort, O. G. Poluektov and L. M. Utschig, ACS Energy Lett., 2017, 2, 230-237.

141 Y. Sano, A. Onoda and T. Hayashi, Chem. Commun., 2011, 47, 8229-8231.

142 A. Onoda, Y. Kihara, K. Fukumoto, Y. Sano and T. Hayashi, ACS Catal., 2014, 4, 2645-2648.

143 A. K. Jones, B. R. Lichtenstein, A. Dutta, G. Gordon and P. L. Dutton, J. Am. Chem. Soc., 2007, 129, 14844-14845.

144 U.-P. Apfel, M. Rudolph, C. Apfel, C. Robl, D. Langenegger, D. Hoyer, B. Jaun, M.-O. Ebert, T. Alpermann, D. Seebach and W. Weigand, Dalton Trans., 2010, 39, 3065-3071.

145 Y. Sano, A. Onoda and T. Hayashi, J. Inorg. Biochem., 2012, 108, 159-162.

146 S. Roy, S. Shinde, G. A. Hamilton, H. E. Hartnett and A. K. Jones, Eur. J. Inorg. Chem., 2011, 2011, 1050-1055.

147 A. Roy, C. Madden and G. Ghirlanda, Chem. Commun., 2012, 48, 9816-9818.

148 C. Tard and C. J. Pickett, Chem. Rev., 2009, 109, 2245-2274.

149 S. Roy, T.-A. D. Nguyen, L. Gan and A. K. Jones, Dalton Trans., 2015, 44, 14865-14876.

150 A. Dutta, G. A. Hamilton, H. E. Hartnett and A. K. Jones, Inorg. Chem., 2012, 51, 9580-9588.

151 A. Jain, S. Lense, J. C. Linehan, S. Raugei, H. Cho, D. L. DuBois and W. J. Shaw, Inorg. Chem., 2011, 50, 4073-4085.

152 M. L. Reback, B. Ginovska-Pangovska, M.-H. Ho, A. Jain and T. C. Squier, Chem.-Eur. J., 2013, 19, 1928-1941.

153 M. L. Reback, B. Ginovska-Pangovska, M.-H. Ho, A. Jain, T. C. Squier, S. Raugei, J. A. S. Roberts and W. J. Shaw, Chem.-Eur. J., 2013, 19, 1928-1941.

154 A. Dutta, S. Lense, J. Hou, M. H. Engelhard, J. A. S. Roberts and W. J. Shaw, J. Am. Chem. Soc., 2013, 135, 18490-18496.

155 A. Dutta, J. A. S. Roberts and W. J. Shaw, Angew. Chem., Int. Ed. Engl., 2014, 53, 6487-6491. 
156 A. Dutta, D. L. DuBois, J. A. S. Roberts and W. J. Shaw, Proc. Natl. Acad. Sci. U. S. A., 2014, 111, 16286-16291.

157 A. Dutta, B. Ginovska, S. Raugei, J. A. S. Roberts and W. J. Shaw, Dalton Trans., 2016, 45, 9786-9793.

158 N. Priyadarshani, A. Dutta, B. Ginovska, G. W. Buchko, M. O'Hagan, S. Raugei and W. J. Shaw, ACS Catal., 2016, 6, 6037-6049.

159 M. L. Reback, G. W. Buchko, B. L. Kier, B. GinovskaPangovska, Y. Xiong, S. Lense, J. Hou, J. A. S. Roberts, C. M. Sorensen, S. Raugei, T. C. Squier and W. J. Shaw, Chem.-Eur. J., 2014, 20, 1510-1514.

160 M. L. Reback, B. Ginovska, G. W. Buchko, A. Dutta, N. Priyadarshani, B. L. Kier, M. L. Helm, S. Raugei and W. J. Shaw, J. Coord. Chem., 2016, 69, 1730-1747.

161 B. Kandemir, L. Kubie, Y. Guo, B. Sheldon and K. L. Bren, Inorg. Chem., 2016, 55, 1355-1357.

162 J. G. Kleingardner, B. Kandemir and K. L. Bren, J. Am. Chem. Soc., 2014, 136, 4-7.

163 C. Travaglini-Allocatelli, S. Gianni, V. K. Dubey, A. Borgia, A. Di Matteo, D. Bonivento, F. Cutruzzolà, K. L. Bren and M. Brunori, J. Biol. Chem., 2005, 280, 25729-25734.

164 P. W. J. M. Frederix, R. Kania, J. A. Wright, D. A. Lamprou, R. V. Ulijn, C. J. Pickett and N. T. Hunt, Dalton Trans., 2012, 41, 13112-13119.

165 H.-Y. Wang, W.-G. Wang, G. Si, F. Wang, C.-H. Tung and L.-Z. Wu, Langmuir, 2010, 26, 9766-9771.

166 F. Wang, W.-G. Wang, H.-Y. Wang, G. Si, C.-H. Tung and L.-Z. Wu, ACS Catal., 2012, 2, 407-416.

167 F. Quentel, G. Passard and F. Gloaguen, Chem.-Eur. J., 2012, 18, 13473-13479.

168 X. Ru, X. Zeng, Z. Li, D. J. Evans, C. Zhan, Y. Tang, L. Wang and X. Liu, J. Polym. Sci., Part A: Polym. Chem., 2010, 48, 2410-2417.

169 C. Zhan, X. Wang, Z. Wei, D. J. Evans, X. Ru, X. Zeng and X. Liu, Dalton Trans., 2010, 39, 11255-11262.

170 S. Ibrahim, P. M. Woi, Y. Alias and C. J. Pickett, Chem. Commun., 2010, 46, 8189-8191.

171 J. A. Wright, L. Webster, A. Jablonskyte, P. M. Woi, S. K. Ibrahim and C. J. Pickett, Faraday Discuss., 2011, 148, 359-371.

172 K. N. Green, J. L. Hess, C. M. Thomas and M. Y. Darensbourg, Dalton Trans., 2009, 4344-4350.

173 F. Wang, W.-J. Liang, J.-X. Jian, C.-B. Li, B. Chen, C.-H. Tung and L.-Z. Wu, Angew. Chem., Int. Ed. Engl., 2013, 52, 81348138.

174 W.-J. Liang, F. Wang, M. Wen, J.-X. Jian, X.-Z. Wang, B. Chen, C.-H. Tung and L.-Z. Wu, Chem.-Eur. J., 2015, 21, 3187-3192.

175 T. Yu, Y. Zeng, J. Chen, Y.-Y. Li and G. Yang, Angew. Chem., Int. Ed. Engl., 2013, 52, 5631-5635.

176 M. L. Singleton, J. H. Reibenspies and M. Y. Darensbourg, J. Am. Chem. Soc., 2010, 132, 8870-8871.

177 M. L. Singleton, D. J. Crouthers, R. P. Duttweiler, J. H. Reibenspies and M. Y. Darensbourg, Inorg. Chem., 2011, 50, 5015-5026.

178 X. Li, M. Wang, D. Zheng, K. Han, J. Dong and L. Sun, Energy Environ. Sci., 2012, 5, 8220-8224.
179 J.-X. Jian, Q. Liu, Z.-J. Li, F. Wang, X.-B. Li, C.-B. Li, B. Liu, Q.-Y. Meng, B. Chen, K. Feng, C.-H. Tung and L.-Z. Wu, Nat. Commun., 2013, 4, 2695.

180 F. Wang, M. Wen, K. Feng, W.-J. Liang, X.-B. Li, B. Chen, C.-H. Tung and L.-Z. Wu, Chem. Commun., 2016, 52, 457460.

181 F. Quentel, G. Passard and F. Gloaguen, Energy Environ. Sci., 2012, 5, 7757-7761.

182 C. Orain, F. Quentel and F. Gloaguen, ChemSusChem, 2014, 7, 638-643.

183 R. Fritzsch, O. Brady, E. Adair, J. A. Wright, C. J. Pickett and N. T. Hunt, J. Phys. Chem. Lett., 2016, 7, 2838-2843.

184 S. Pullen and S. Ott, Top. Catal., 2016, 59, 1712-1721.

185 S. Pullen, H. Fei, A. Orthaber, S. M. Cohen and S. Ott, J. Am. Chem. Soc., 2013, 135, 16997-17003.

186 S. Pullen, S. Roy and S. Ott, Chem. Commun., 2017, 53, 5227-5230.

187 S. Roy, V. Pascanu, S. Pullen, G. Gonzalez Miera, B. MartinMatute and S. Ott, Chem. Commun., 2017, 53, 3257-3260.

188 K. Sasan, Q. Lin, C. Mao and P. Feng, Chem. Commun., 2014, 50, 10390-10393.

189 C. Tard and C. J. Pickett, Chem. Rev., 2009, 109, 2245-2274.

190 Ö. F. Erdem, L. Schwartz, M. Stein, A. Silakov, S. KaurGhumaan, P. Huang, S. Ott, E. J. Reijerse and W. Lubitz, Angew. Chem., Int. Ed. Engl., 2011, 50, 1439-1443.

191 S. Ott, M. Kritikos, B. Åkermark, L. Sun and R. Lomoth, Angew. Chem., Int. Ed. Engl., 2004, 43, 1006-1009.

192 J. Esselborn, C. Lambertz, A. Adamska-Venkatesh, T. Simmons, G. Berggren, J. Noth, J. Siebel, A. Hemschemeier, V. Artero, E. Reijerse, M. Fontecave, W. Lubitz and T. Happe, Nat. Chem. Biol., 2013, 9, 607-609.

193 D. W. Mulder, D. O. Ortillo, D. J. Gardenghi, A. V. Naumov, S. S. Ruebush, R. K. Szilagyi, B. Huynh, J. B. Broderick and J. W. Peters, Biochemistry, 2009, 48, 6240-6248.

194 J. K. Rubach, X. Brazzolotto, J. Gaillard and M. Fontecave, FEBS Lett., 2005, 579, 5055-5060.

195 X. Brazzolotto, J. K. Rubach, J. Gaillard, S. Gambarelli, M. Atta and M. Fontecave, J. Biol. Chem., 2006, 281, 769774.

196 P. W. King, M. C. Posewitz, M. L. Ghirardi and M. Seibert, J. Bacteriol., 2006, 188, 2163-2172.

197 M. C. Posewitz, P. W. King, S. L. Smolinski, L. Zhang, M. Seibert and M. L. Ghirardi, J. Biol. Chem., 2004, 279, 25711-25720.

198 S. E. McGlynn, S. S. Ruebush, A. Naumov, L. E. Nagy, A. Dubini, P. W. King, J. B. Broderick, M. C. Posewitz and J. W. Peters, JBIC, J. Biol. Inorg. Chem., 2007, 12, 443-447.

199 E. M. Shepard, S. E. McGlynn, A. L. Bueling, C. S. GradySmith, S. J. George, M. A. Winslow, S. P. Cramer, J. W. Peters and J. B. Broderick, Proc. Natl. Acad. Sci. U. S. A., 2010, 107, 10448-10453.

200 S. E. McGlynn, E. M. Shepard, M. A. Winslow, A. V. Naumov, K. S. Duschene, M. C. Posewitz, W. E. Broderick, J. B. Broderick and J. W. Peters, FEBS Lett., 2008, 582, 2183-2187.

201 I. Czech, S. Stripp, O. Sanganas, N. Leidel, T. Happe and M. Haumann, FEBS Lett., 2011, 585, 225-230. 
202 I. Czech, A. Silakov, W. Lubitz and T. Happe, FEBS Lett., 2010, 584, 638-642.

203 D. L. M. Suess, J. M. Kuchenreuther, L. De La Paz, J. R. Swartz and R. D. Britt, Inorg. Chem., 2016, 55, 478-487. 204 E. M. Shepard, F. Mus, J. N. Betz, A. S. Byer, B. R. Duffus, J. W. Peters and J. B. Broderick, Biochemistry, 2014, 53, 4090-4104.

205 C. Esmieu and G. Berggren, Dalton Trans., 2016, 45, 1924219248.

206 A. Adamska-Venkatesh, S. Roy, J. F. Siebel, T. R. Simmons, M. Fontecave, V. Artero, E. Reijerse and W. Lubitz, J. Am. Chem. Soc., 2015, 137, 12744-12747.

207 R. Gilbert-Wilson, J. F. Siebel, A. Adamska-Venkatesh, C. C. Pham, E. Reijerse, H. Wang, S. P. Cramer, W. Lubitz and T. B. Rauchfuss, J. Am. Chem. Soc., 2015, 137, 89989005.

208 J. M. Kuchenreuther, Y. Guo, H. Wang, W. K. Myers, S. J. George, C. A. Boyke, Y. Yoda, E. E. Alp, J. Zhao, R. D. Britt, J. R. Swartz and S. P. Cramer, Biochemistry, 2013, 52, 818-826.

209 A. S. Pereira, P. Tavares, I. Moura, J. J. G. Moura and B. H. Huynh, J. Am. Chem. Soc., 2001, 123, 2771-2782.

210 J. Noth, R. Kositzki, K. Klein, M. Winkler, M. Haumann and T. Happe, Sci. Rep., 2015, 5, 13978.

211 G. Caserta, A. Adamska-Venkatesh, L. Pecqueur, M. Atta, V. Artero, S. Roy, E. Reijerse, W. Lubitz and M. Fontecave, Biochim. Biophys. Acta, Bioenerg., 2016, 1857, 1734-1740.

212 N. Khanna, C. Esmieu, L. S. Meszaros, P. Lindblad and G. Berggren, Energy Environ. Sci., 2017, 10, 1563-1567.

213 L. S. Meszaros, B. Nemeth, C. Esmieu, P. Ceccaldi and G. Berggren, Angew. Chem., Int. Ed. Engl., DOI: 10.1002/ anie.201710740.

214 Y. Qiao, H. Molina, A. Pandey, J. Zhang and P. A. Cole, Science, 2006, 311, 1293-1297.

215 J. Li, J. Yu, J. Zhao, J. Wang, S. Zheng, S. Lin, L. Chen, M. Yang, S. Jia, X. Zhang and P. R. Chen, Nat. Chem., 2014, 6, 352-361.

216 J. A. Zorn and J. A. Wells, Nat. Chem. Biol., 2010, 6, 179-188.

217 J. J. Woodward, N. I. Martin and M. A. Marletta, Nat. Methods, 2007, 4, 43-45.

218 T. Mathes, C. Vogl, J. Stolz and P. Hegemann, J. Mol. Biol., 2009, 385, 1511-1518.

219 M. Jeschek, R. Reuter, T. Heinisch, C. Trindler, J. Klehr, S. Panke and T. R. Ward, Nature, 2016, 537, 661-665.

220 A. Adamska-Venkatesh, D. Krawietz, J. Siebel, K. Weber, T. Happe, E. Reijerse and W. Lubitz, J. Am. Chem. Soc., 2014, 136, 11339-11346.

221 J. F. Siebel, A. Adamska-Venkatesh, K. Weber, S. Rumpel, E. Reijerse and W. Lubitz, Biochemistry, 2015, 54, 14741483.
222 J. Noth, J. Esselborn, J. Güldenhaupt, A. Brünje, A. Sawyer, U.-P. Apfel, K. Gerwert, E. Hofmann, M. Winkler and T. Happe, Angew. Chem., Int. Ed. Engl., 2016, 55, 8396-8400.

223 L. Kertess, F. Wittkamp, C. Sommer, J. Esselborn, O. Rudiger, E. J. Reijerse, E. Hofmann, W. Lubitz, M. Winkler, T. Happe and U. P. Apfel, Dalton Trans., 2017, 46, 16947-16958.

224 G. Berggren, R. Garcia-Serres, X. Brazzolotto, M. Clemancey, S. Gambarelli, M. Atta, J.-M. Latour, H. L. Hernandez, S. Subramanian, M. K. Johnson and M. Fontecave, JBIC, J. Biol. Inorg. Chem., 2014, 19, 75-84.

225 M. Albertini, P. Berto, F. Vallese, M. Di Valentin, P. Costantini and D. Carbonera, J. Phys. Chem. B, 2015, 119, 13680-13689.

226 M. Albertini, L. Galazzo, L. Maso, F. Vallese, P. Berto, E. De Rosa, M. Di Valentin, P. Costantini and D. Carbonera, Top. Catal., 2015, 58, 708-718.

227 A. M. Lunsford, C. C. Beto, S. Ding, O. F. Erdem, N. Wang, N. Bhuvanesh, M. B. Hall and M. Y. Darensbourg, Chem. Sci., 2016, 7, 3710-3719.

228 B. S. Lim and R. H. Holm, Inorg. Chem., 1998, 37, 48984908.

229 M. J. Scott and R. H. Holm, J. Am. Chem. Soc., 1994, 116, 11357-11367.

230 M. Shatruk, A. Dragulescu-Andrasi, K. E. Chambers, S. A. Stoian, E. L. Bominaar, C. Achim and K. R. Dunbar, J. Am. Chem. Soc., 2007, 129, 6104-6116.

231 E. Coronado, M. C. Giménez-López, G. Levchenko, F. M. Romero, V. García-Baonza, A. Milner and M. PazPasternak, J. Am. Chem. Soc., 2005, 127, 4580-4581.

232 A. Geiss and H. Vahrenkamp, Inorg. Chem., 2000, 39, 40294036.

233 G. Caserta, L. Pecqueur, A. Adamska-Venkatesh, C. Papini, S. Roy, V. Artero, M. Atta, E. Reijerse, W. Lubitz and M. Fontecave, Nat. Chem. Biol., 2017, 13, 779-784.

234 C. F. Megarity, J. Esselborn, S. V. Hexter, F. Wittkamp, U.-P. Apfel, T. Happe and F. A. Armstrong, J. Am. Chem. Soc., 2016, 138, 15227-15233.

235 P. Rodríguez-Maciá, E. Reijerse, W. Lubitz, J. A. Birrell and O. Rüdiger, J. Phys. Chem. Lett., 2017, 8(16), 3834-3839.

236 K. Tanifuji, C. C. Lee, Y. Ohki, K. Tatsumi, Y. Hu and M. W. Ribbe, Angew. Chem., Int. Ed. Engl., 2015, 54, 14022-14025.

237 S. Shima, D. Chen, T. Xu, M. D. Wodrich, T. Fujishiro, K. M. Schultz, J. Kahnt, K. Ataka and X. Hu, Nat. Chem., 2015, 7, 995-1002.

238 G. Buurman, S. Shima and R. K. Thauer, FEBS Lett., 2000, 485, 200-204.

239 B. Hu, D. Chen and X. Hu, Chem.-Eur. J., 2014, 20, 16771682.

240 D. Chen, R. Scopelliti and X. Hu, Angew. Chem., Int. Ed. Engl., 2011, 50, 5671-5673. 